Marcelo Fernando Selli

\title{
IDENTIFICAÇÃO DE PADRÕES DE ESCOAMENTO HORIZONTAL BIFÁSICO GÁS-LÍQUIDO ATRAVÉS DE DISTRIBUIÇÃO TEMPO-FREQÜÊNCIA E REDES NEURAIS
}

Tese apresentada à Escola de Engenharia de São Carlos da Universidade de São Paulo, como parte dos requisitos para obtenção do Título de Doutor em Engenharia Mecânica.

Orientador: Prof. Assoc. Paulo Seleghim Jr.

São Carlos 


\section{DEDICATÓRIA}

A minha filhinha Marcela, que tantas vezes interrompeu-me a escrita desta tese, e trazia ainda mais de seus motivos e alegrias. 


\section{AGRADECIMENTOS}

Agradeço ao Prof. Assoc. Paulo Seleghim Jr., meu orientador e amigo, por esta oportunidade, pela paciência que teve comigo e pela sabedoria e destacada competência com as quais orientou meus trabalhos e redirecionou meus esforços nos momentos em que eu perdera o caminho.

À Universidade de São Paulo por colocar a sua estrutura à minha disposição.

Sou grato também aos meus professores, pela formação, e aos funcionários do NETeF - USP, pelos esforços na construção e manutenção das tubulações, bombas, válvulas, instrumentação e programas computacionais para controle da seção de testes e aquisição de dados. Sem eles, e seus resultados, a conclusão deste trabalho não teria sido possível. 


\section{RESUMO}

SELLI, M. F. (2007). Identificação de padrões de escoamento horizontal bifáisco gás-líquido através de distribuição tempo-freqüência e redes neurais. Tese de Doutorado em Engenharia Mecância, Escola de Engenharia de São Carlos - Universidade de São Paulo.

O presente trabalho tem como objetivo fundamental a construção de um sistema de identificação capaz de diagnosticar em tempo real as diferentes configurações de escoamentos bifásicos horizontais. É importante ressaltar que o desenvolvimento deste "know-how" é capital para a operação eficaz de instalações de manipulação e ou transporte de fluidos multifásicos, e representa, hoje, um dos grandes desafios nas indústrias do petróleo e termonuclear.

O princípio de funcionamento do sistema proposto baseia-se nos sinais captados por um sensor de pressão flutuante de resposta rápida, e no seu pósprocessamento com auxílio da transformada de Gabor e de uma rede neural convenientemente treinada. A implementação é tal que a operação de diagnóstico pode ser feita "on-line", desde a aquisição dos sinais até o pósprocessamento. Resultados experimentais foram obtidos no circuito experimental do NETeF - Núcleo de Engenharia Térmica e Fluidos da USP Universidade de São Paulo, para uma secção de testes horizontal com $12 \mathrm{~m}$ de comprimento e diâmetro interno de $30 \mathrm{~mm}$. Em específico foram ensaiados os seguintes padrões de escoamento ar-água: estratificado liso, ondulado, intermitente, anular e a bolhas. Os resultados mostram que, dependendo dos limites de detecção pré-estabelecidos, todos o principais padrões de escoamento bifásico horizontal são identificados corretamente .

Palavras-chave: Escoamento multifásico. Padrões de escoamento.

Transformada de Gabor. Redes neurais. 


\section{ABSTRACT}

SELLI, M. F. (2007). Identification of horizontal gas-liquid two-phase flow patterns through time-frequence distribution and neural networks. Ph.D. Thesis in Mechanical Engineering, Escola de Engenharia de São Carlos Universidade de São Paulo.

The fundamental objective of this work is the construction of an identification system capable of diagnosing in real time different configurations of horizontal two-phase flow patterns. It is important to emphasize that the development of this know-how is capital to the efficient operation of facilities for manipulation and transportation of multiphase fluids, and represents, today, one of the most important challenges in the oil and thermonuclear industries.

The working principle of the proposed system is based on the signals acquired by a rapid response fluctuating pressure sensor, and on its post processing through Gabor Transform and on a conveniently trained artificial neural network. The implementation is accomplished in way that the diagnosis operation is performed on-line, from signal acquisition to post-processing. Experimental results were obtained on the experimental circuit at NETeF - Núcleo de Engenharia Térmica e Fluidos of USP - Universidade de São Paulo, at São Carlos, using a horizontal test section, with 12 m length and $30 \mathrm{~mm}$ internal diameter. Experiments were done with the following air-water flow patterns: stratified smooth, wavy, intermittent, annular, and bubbly. Results show that depending on the preset detection limits, all the main horizontal two phase flow patterns were correctly identified.

Keywords: Multiphase flow. Flow patterns. Gabor transform. Neural networks. 


\section{LISTA DE FIGURAS}

Figura 1: Padrões típicos de escoamento gás-líquido.

Figura 2: Seção do duto de transporte bifásico gás-líquido em escoamento

estratificado liso 20

Figura 3: Diagrama de blocos de solução da transição entre padrões estratificado e intermitente ou anular

Figura 4: Diagrama de blocos de solução da transição entre padrões intermitente e anular

Figura 5: Diagrama de blocos de solução da transição entre os padrões estratificado liso e estratificado ondulado

Figura 6: Diagrama de blocos de solução da transição entre padrões intermitente e a bolhas.

Figura 7: Mapa de padrões de escoamento bifásico de Taitel \& Dukler para tubulação horizontal e diâmetro interno de $30 \mathrm{~mm}$ - NETeF

Figura 8: Mapa de padrões de escoamento bifásico de Taitel \& Dukler para tubulação horizontal e diâmetro interno de $22 \mathrm{~mm}$ - NETeF 34

Figura 9: Mapa de padrões de escoamento bifásico de Taitel \& Dukler para tubulação horizontal e diâmetro interno de $21 \mathrm{~mm}$ - NETeF

Figura 10: Representação esquemática de uma rede neural tipo "feed-forward" mapeando um vetor de entrada de 5 coordenadas de para um vetor de saída de 3 coordenadas. 39

Figura 11: Seção de testes no NETeF - USP 44

Figura 12: Diagrama esquemático da seção de testes do NETeF - USP. 45

Figura 13: Instrumentação de operação da planta 46

Figura 14: Montagem do transmissor de pressão na seção de testes. 48

Figura 15: Diagrama de blocos da solução. 51

Figura 16: Diagrama esquemático da solução 51

Figura 17: Janela LabView para a operação da planta e aquisição e condicionamento de sinais. 52

Figura 18: Arquitetura geral do sistema 54

Figura 19: Diagrama de Fluxo de Dados do Sistema. .55

Figura 20: Diagrama Hierárquico de Funções do Sistema 55 
Figura 21: Janela de parâmetros do módulo de execução e controle da transformada de Gabor. Pode-se nela arbitrar todos os parâmetros de aquisição e processamento da transformada. As áreas gráficas permitem a visualização interativa da modulação entre a janela analisadora gaussiana e a freqüência de teste arbitrada 58

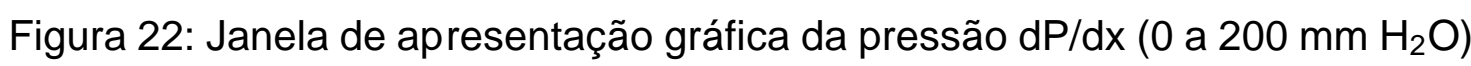
e seus respectivos coeficientes tempo-freqüência, para uma janela de tempo de 30 segundos, $T=0.5 \mathrm{~s}$, range de 0 a $18 \mathrm{~Hz}$ e $\Omega=0.5$ $\mathrm{Hz}$. 60

Figura 23: Arquitetura de alimentação da rede neural artificial 61

Figura 24: Janela de ajuste dos parâmetros da rede neural 62

Figura 25: Ambiente operacional do SNNS, com as janelas de controle, treinamento, gráfico de convergência, arquitetura e níveis de disparo de cada neurônio

Figura 26: Janela de identificação do padrão de escoamento. De cima para baixo: pressão $\mathrm{dP} / \mathrm{dx}$, coeficientes tempo-freqüência e as saídas da rede neural (em verde, e em zero quando inativas e em vermelho, e em 1 , quando ativadas) 65

Figura 27 : Mapa de Taitel \& Dukler calculado para a seção de testes do NETeF. A região tracejada delimita o espaço de amostragem e operação efetiva da planta, com seus limites definidos pela potência do compressor e pela região de operação estável das bombas 67

Figura 28 : Gráfico SNNS de convergência de erro no treinamento da rede neural. $\mathrm{O}$ eixo $\mathrm{x}$ mostra o número de épocas do algoritmo de treinamento e o y mostra o erro relativo 68

Figura 29: Sinais de pressão, seus respectivos coeficientes tempo-freqüência e as saídas da rede neural durante transição entre os padrões anular e a bolhas. A janela total de tempo apresentada é de 30 segundos.

Figura 30: Sinais de pressão, seus respectivos coeficientes tempo-freqüência e as saídas da rede neural durante transição entre os padrões a bolhas e intermitente. A janela total de tempo apresentada é de 30 segundos. 
Figura 31: Sinais de pressão, seus respectivos coeficientes tempo-freqüência e as saídas da rede neural em diagnóstico de padrão anular. A janela total de tempo apresentada é de 30 segundos.

Figura 32: Visualização gráfica da função de erro simplificada para $\Re^{3}$ .74

Figura 33: Visualização gráfica da distribuição das saídas da rede neural combinadas para os diagnósticos de padrão estratificado, estratificado ondulado e intermitente.

Figura 34: Visualização gráfica da distribuição das saídas da rede neural combinadas para os diagnósticos de padrão a bolhas, anular e intermitente.

Figura 35: Função sigmóide de ativação neural. Utilizada uniformemente em todos os neurônios da rede. 


\section{LISTA DE SÍMBOLOS}

Em decorrência da superposição de alguns símbolos utilizados em diferentes seções, a lista de símbolos deste trabalho é aqui dividida em três diferentes sub listas:

\section{Lista de Símbolos utilizados na modelagem de escoamentos bifásicos na} seção 2.1:

D Diâmetro

$D_{L} \quad$ Diâmetro hidráulico equivalente para fase líquida

$D_{G} \quad$ Diâmetro hidráulico equivalente para fase gasosa

h Altura de coluna da fase líquida no duto

$A_{L} \quad$ Área de seção transversal ocupada pela fase líquida

$A_{G} \quad$ Área de seção transversal ocupada pela fase gasosa

$S_{L} \quad$ Superfície de contato entre fase líquida e parede do duto

$S_{G} \quad$ Superfície de contato entre fase gasosa e parede do duto

$\mathrm{S}_{\mathrm{i}} \quad$ Superfície de interface entre as fases líquida e gasosa

$U_{G S}$ Velocidade superficial da fase gasosa

$U_{L S} \quad$ Velocidade superficial da fase líquida

$\beta \quad$ Ângulo de inclinação do duto

$\tau_{L} \quad$ Tensão de cisalhamento da fase líquida na parede do duto

$\tau_{G} \quad$ Tensão de cisalhamento da fase gasosa na parede do duto

$\tau_{i} \quad$ Tensão de cisalhamento na interface entre as fases líquida e gasosa

$\rho_{\llcorner} \quad$ Massa específica da fase líquida

$\rho_{G} \quad$ Massa específica da fase gasosa

g Aceleração da gravidade

$\mathrm{f}_{\mathrm{L}} \quad$ Fator de atrito da fase líquida

$\mathrm{f}_{\mathrm{G}} \quad$ Fator de atrito da fase gasosa

$\tilde{h} \quad \mathrm{~h}$ adimensional

$\tilde{A}_{L} \quad$ Área da fase líquida adimensional

$\tilde{A}_{G} \quad$ Área da fase gasosa adimensional 
$\tilde{S}_{L} \quad$ Superfície adimensional de contato entre fase líquida e parede do duto

$\tilde{S}_{G} \quad$ Superfície adimensional de contato entre fase gasosa e parede do duto

$\tilde{S}_{i} \quad$ Superfície adimensional de contato entre fases líquida e gasosa

$\tilde{U}_{L} \quad$ Razão entre áreas adimensionais do duto da fase líquida

$\tilde{U}_{G} \quad$ Razão entre áreas adimensionais do duto da fase gasosa

$v_{L} \quad$ Viscosidade cinemática da fase líquida

$v_{G} \quad$ Viscosidade cinemática da fase gasosa

$F_{B} \quad$ Forcas de empuxo atuante na fase gasosa

$F_{T} \quad$ Forcas de flutuação turbulenta atuantes na fase líquida

$\alpha \quad$ Fração de vazio

\section{Lista de Símbolos utilizados na modelagem dos diagramas tempo-} freqüência na seção 2.2:

$\tau \quad$ Vizinhança do tempo de análise t.

T Resolução temporal dos coeficientes de tempo freqüência

$\Omega \quad$ Resolução em freqüência dos coeficientes de tempo freqüência

$\omega \quad$ Freqüência em rad/s

$\mathrm{S}_{\mathrm{t}}(\tau) \quad$ Sinal genérico $\mathrm{s}()$ no tempo $\tau$

$h_{t}(\tau) \quad$ Função analisadora

$P(t, \omega)$ Distribuição de densidade de potência

$\alpha(\tau)$ Função de decaimento da janela gaussiana

$a_{m k} \quad$ Coeficientes de decomposição ou átomos de Gabor 
Lista de Símbolos utilizados na modelagem de redes neurais artificiais na seção 2.3:

$\mathrm{F}_{\mathrm{i}, \mathrm{j}}(\bullet)$ Função de ativação do neurônio i na camada j da rede

$\mathrm{s}_{\mathrm{ij}} \quad$ Saída do neurônio i na camada j da rede

$b_{i, j} \quad$ "Bias" neurônio i na camada j da rede

$w_{i, j} \quad$ Peso neurônio i na camada j da rede

$\xi_{i} \quad$ Valores de entrada da rede

$\eta_{i} \quad$ Valores de saída da rede

$\xi_{i}{ }^{p} \quad$ Conjunto de valores de entrada com dimensão $p$

$\delta_{i}{ }^{p} \quad$ Conjunto de valores de saída com dimensão $p$

e Função de erro da rede 


\title{
SUMÁRIO
}

\author{
RESUMO
}

ABSTRACT

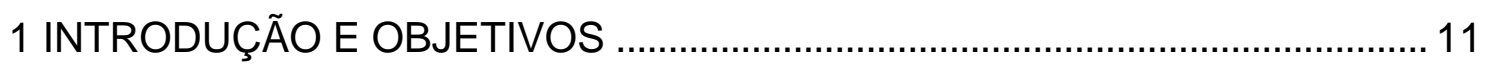

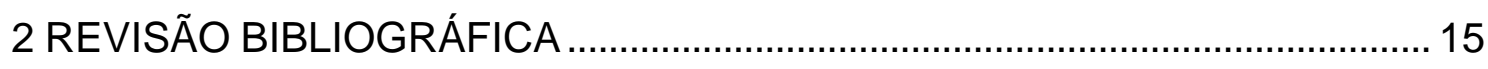

2.1 ESCOAMENTOS GÁS-LÍQUIDO................................................................ 19

2.1.1.1 Escoamento estratificado em regime permanente .................................. 21

2.1.1.2 Transição entre escoamentos estratificado e intermitente ...................... 25

2.1.1.3 Transição entre escoamentos intermitente e anular ................................ 26

2.1.1.4 Transição entre escoamentos estratificado liso e estratificado ondulado 26

2.1.1.5 Transição entre escoamentos intermitente e a bolhas 28

2.1.2 Cálculo do mapa de Taitel \& Dukler para o circuito de testes do NETeF 30

2.2 DIAGRAMAS TEMPO FREQÜÊNCIA E A TRANSFORMADA DE GABOR 35

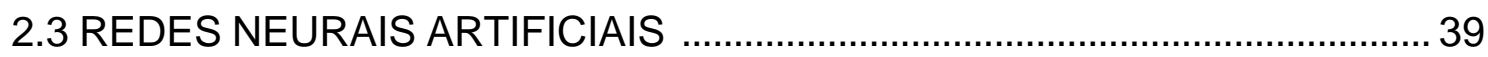

3 CIRCUITO EXPERIMENTAL E INSTRUMENTAÇÃO...................................... 43

3.1 Instrumentação de Operação da Planta da Seção de Testes......................... 43

3.2 Instrumentação Experimental ....................................................................... 48

4 DESENVOLVIMENTO EXPERIMENTAL ……….............................................. 50

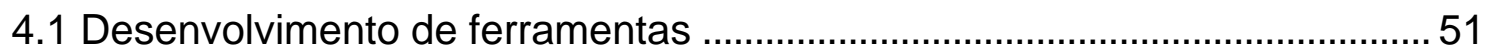

4.1.1 Desenvolvimento do módulo de cálculo dos coeficientes tempo-freqüência

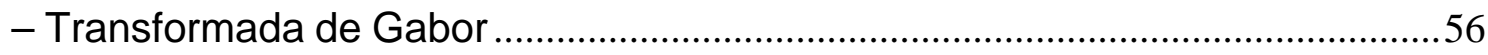

4.1.2 Desenvolvimento do módulo de simulação de redes neurais .......................61

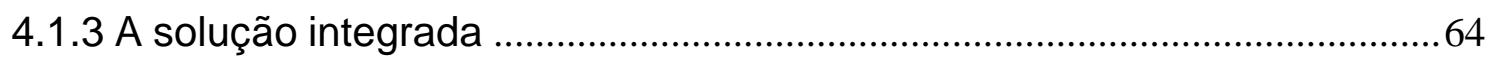

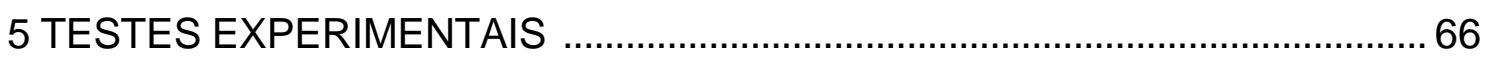

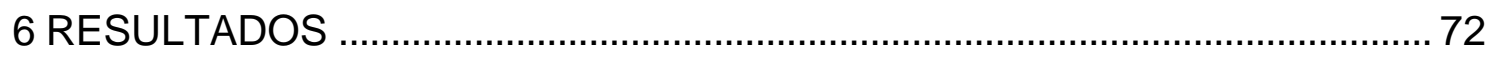

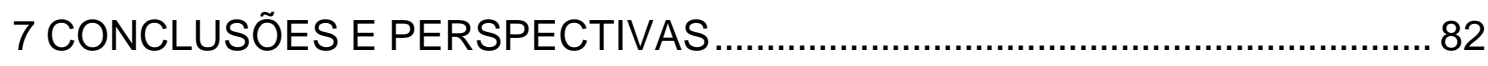

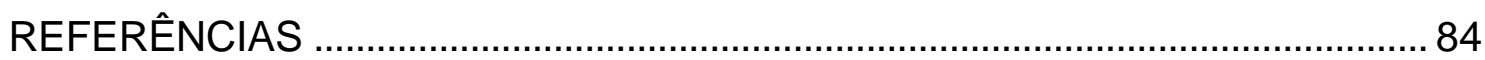

APÊNDICE A - Programas $C$ para cálculos das transições Taitel \& Dukler..... 91 
APÊNDICE B - Transições entre padrões de escoamento por Taitel \& Dukler 


\section{INTRODUÇÃO E OBJETIVOS}

Escoamentos multifásicos são comuns em tubulações na indústria de processamento e transporte de fluidos. Na indústria do petróleo, como exemplo, a monitoração de escoamentos óleo-gás se faz cada vez mais necessária para operação segura nos campos de exploração e produção. Sistemas de controle de separadores trifásicos água-óleo-gás embarcados em plataformas de produção "off-shore" são freqüentemente submetidos a importantes transientes de operação. Estes transientes podem diminuir de forma drástica a eficiência e a vida útil destes equipamentos. Um exemplo típico de transiente nestes separadores é a chegada não monitorada de uma golfada de óleo, que causa grandes distúrbios nas estratégias de controle de nível de interface entre fases, percentual de injeção de desemulsificantes, entre outros fatores. Oscilações desta natureza contribuem para a diminuição da eficiência do equipamento, o que produz o aumento do BSW ("based sediment \& water" - ou percentual de água no óleo) do óleo e o TOG (teor de óleo e graxa) da água nas saídas do separador. A aplicação de mecanismos de inferência capazes de diagnosticar mudanças nos padrões de escoamento podem ampliar o espectro de informações disponíveis aos operadores destas industrias, tornando a operação mais eficiente e segura. Outra abordagem também interessante é a que se relaciona à monitoração de escoamentos em dutos de transporte de óleo e gás.

Aplicações industriais de monitoração de escoamentos multifásicos em dutos podemos citar com segurança as aplicações de detecção de vazamentos na indústria do petróleo - ainda hoje podem ser consideradas incipientes. A indisponibilidade de ferramentas que disponibilizem informações acerca da configuração do escoamento no interior do duto impossibilita a aplicação de uma mesma solução tecnológica em diferentes condições de operação. Como exemplo, temos a aplicação de sistemas de detecção de vazamentos baseados em modelos matemáticos para escoamento bifásico a óleo e gás. Estas aplicações, desenvolvidas à partir de modelos matemáticos estabelecidos para uma determinada configuração de escoamento multifásico não produzem 
resultados satisfatórios em outras. Isso implica em que as condições de operação de um determinado duto devem ser conhecidas previamente, na fase de análise do projeto. A disponibilidade de ferramentas de tempo real para o diagnóstico do padrão de escoamento multifásico em dutos contribuiria para o aumento da aplicabilidade destas tecnologias através da generalização das suas soluções. A conseqüência direta disto seria a diminuição de custos operacionais e 0 aumento na confiabilidade e disponibilidade destas aplicações.

De forma geral, sistemas baseados em modelagem matemática têm sido aplicados em escoamentos monofásicos e bifásicos estratificados. Em escoamentos monofásicos de hidrocarbonetos na fase líquida, estimativas de volume vazado podem ser calculadas a partir da aplicação de modelos físicomatemáticos para balanço de volumes compensados, de acordo com o que é estabelecido pela norma APr1130 (1995). Após o anúncio de um alarme de vazamento, a localização deste ao longo de um duto pode ser estimada à partir do método dos gradientes de pressão. Em outro conjunto de tecnologias estão as aplicações orientadas aos escoamentos bifásicos a óleo e gás. Nesta classe de solução a indústria tem aplicado tecnologias baseadas em análise de formas de onda de pressão (SILVA et al.,1996). Podemos também citar os sistemas disponíveis comercialmente e conhecidos como acústicos - termo este que se baseia no fato de todo o processamento ser feito à partir das ondas de pressão dinâmica, adquiridas a montante e a jusante do trecho monitorado, e de modelos baseados na velocidade de propagação destas ondas no meio multifásico. Vale observar que esta velocidade depende fortemente da fração de fase e das configurações de velocidades e interfaces entre as fases do escoamento. Modelagens elaboradas são descritas por Lamb (1932) acerca do comportamento hidrodinâmico destes escoamentos.

O funcionamento desta tecnologia passa pela aplicação de filtros e processamentos matemáticos aos sinais de pressão - adquiridos por sensores de resposta rápida instalados à montante e à jusante do trecho monitorado. $\mathrm{O}$ objetivo é inferir se uma forma de onda peculiar à um vazamento é encontrada nos dois sinais. Se sim, a localização do vazamento é então calculada com 
base nos tempos de propagação destas ondas a montante e a jusante do vazamento. Atualmente, esta tecnologia não permite que se estime quantitativamente o volume vazado (pode-se estimar de forma qualitativa, pela energia do sinal captado, sua distância ao sensor, fatores de atenuação, etc.) e é muito sensível às mudanças na velocidade de propagação destes transientes hidrodinâmicos. Esta velocidade é, por sua vez, função também do padrão do escoamento multifásico estabelecido e das características físicas dos fluidos em transporte. Outro fato a destacar é que a estimativa da localização do suposto vazamento tem sua maior componente de incerteza na variação da velocidade de propagação destas ondas.

Aplicações baseadas em autras tecnologias estão também disponíveis para uso industrial em monitoração e transporte de fluidos monofásicos, em fase líquida ou gasosa. Zhang (1993, 1997, 1999), Tindel (2004) e Moura et al. (2004) descrevem aplicações industriais de sistemas de monitoração de escoamento baseados em computação de balanço de volume compensado combinado com técnicas estatísticas de tratamento de sinais. Silva et al. (2003) apresenta um modelo de deteç̧ão de vazamentos para um duto de GLP à partir de balanço de volume compensado com mecanismo de decisão de alarme efetuado por algoritmo baseado em lógica "fuzzy". Especificações e métodos de aferição de performance esperada para estes sistemas de detecção de vazamentos em dutos para transporte de hidrocarbonetos podem ser encontradas nas normas API 1130 (1995) e API 1155 (1995).

Cada uma das diferentes abordagens possuem suas próprias peculiaridades, que se figuram como vantagens ou desvantagens em referência às demais. Pode-se conceber, no objetivo de se fazer uso das características favoráveis de cada uma das tecnologias em um sistema para aplicação industrial, um sistema híbrido que use modelos matemáticos e/ou técnicas de processamento de sinais adequados ao padrão de escoamento detectado na tubulação. $O$ diagnóstico dos padrões de escoamento multifásico - o monofásico de gás ou líquido é um subconjunto deste - portanto faz-se de capital importância na habilitação do desenvolvimento e aplicação da próxima geração destes sistemas híbridos para monitoração de escoamentos. 
Foi determinado então o objetivo principal deste trabalho, que é a implementação de um método capaz de inferir em tempo real o padrão de escoamento bifásico gás-líquido no interior de uma tubulação. A inferência é feita com auxílio de diagramas tempo-freqüência, calculados à partir da transformada de Gabor, aplicada a sinais de pressão diferencial flutuante adquiridos em tomadas na tubulação, e de modelos de redes neurais artificiais. O texto é organizado progressivamente em tópicos; são descritos conceitos básicos da análise dos coeficientes tempo-freqüência e da Transformada de Gabor; conceitos básicos de redes neurais artificiais; instalações experimentais e instrumentação utilizada; alguns detalhes acerca dos experimentos, análise de resultados e conclusões e perspectivas para trabalhos futuros. A nomenclatura e simbologia utilizadas são específicas para cada capítulo. 


\section{REVISÃO BIBLIOGRÁFICA}

Novas tecnologias de escoamento interno confinado vêm sendo desenvolvidas, como a de transporte de óleos pesados através do escoamento bifásico óleoágua em padrão anular ou "core flow" (BANNWART, 2001, BANNWART et al., 2004), que traz resultados expressivos em ganhos de produtividade, decorrente da drástica redução da perda de carga ao longo da tubulação. Contudo, a aplicação segura destas tecnologias na indústria, de modo geral, demanda a disponibilidade de sistemas de monitoração e controle dos diferentes padrões de escoamento multifásico.

O desenvolvimento de critérios objetivos de identificação de padrões de escoamento tem sido objetivo central de muitas pesquisas nos últimos anos (SELEGHIM, 1996). O uso de sinais de pressão e suas respectivas analises espectrais foi provavelmente uma das primeiras pesquisas neste assunto, desenvolvida por Hubbard e Dukler (1966), através da qual alguns padrões de escoamento puderam ser inferidos. Na mesma linha de pesquisa, podemos citar outros trabalhos como Weisman et al. (1979), Vince e Lahey (1982), Matsui (1984), Tutu (1984), Mishima e Ishii (1984), Sekoguchi et al. (1987) entre outros.

Uma revisão detalhada dos trabalhos realizados nesta linha de pesquisa até os anos 80 foi feita por Drahos e Cermak (1989). Este trabalho descreve os métodos de diagnósticos de padrões de escoamentos e visualiza que os diagnósticos baseados em processamento dos parâmetros estruturais ("voidage") e energéticos (pressão) seriam promissores. Com a disponibilidade de hardware e software adequados, começa-se então a publicar alguns trabalhos onde diferentes técnicas de extração de informação e mecanismos de inferências são utilizados para processar estes parâmetros e diagnosticar com menor incerteza estes padrões de escoamento.

Entre estas técnicas, temos as de análise de sinais, como a filtragem adaptativa, "wavelets" e os métodos fractais, que marcaram a tendência nos 
anos 90. Métodos interessantes foram propostos para caracterização dos padrões de escoamento à partir de aspectos fractais ou caóticos por Saether et al. (1990), França et al. (1991) e Lewin (1992). Para escoamentos bifásicos, Hervieu e Leducq (1991) demonstraram o potencial da transformada "wavelet" na caracterização de padrões em escoamentos verticais. Depois, Seleghim e Hervieu (1994) apresentaram um indicador de transição de padrão a bolhas para o intermitente baseado na quantificação de perda de estacionariedade pelo desvio padrão da freqüência instantânea de Ville. Finalmente, Hervieu e Seleghim (1998) otimizaram o critério proposto, fazendo-o universal, independente de transição e sinais analisados, propondo o uso da covariância tempo-freqüência, calculada pela transformada de Gabor.

Em 1998, Angeli e Hewitt publicaram um trabalho mostrando a relação entre a fração de fase - apurada a partir de sonda de impedância de alta freqüência com a velocidade da mistura e o padrão de escoamento.

Paralelamente, outra abordagem interessante e promissora que de certa medida segue as idéias descritas acima é a aplicação de técnicas de reconhecimento de padrões, através de modelo conexionistas ou redes neurais artificiais. Alguns destes modelos, dentre outras propriedades matemáticas interessantes, possuem a chamada memória associativa, o que thes confere capacidade de generalização. Esta característica em teoria habilita a obtenção de melhores resultados em interpolações e extrapolações de resultados.

Provavelmente, o primeiro trabalho que aplicou redes neurais artificiais para identificar padrões de escoamento foi o de Mi et al. (1998), que usou como entrada da rede os momentos estatísticos calculados à partir de sinais de impedância. Estes sinais foram simulados através de um modelo teórico de escoamento gás-líquido vertical, baseado no mapa de Mishima e Ishi (1984). Neste trabalho, os autores simularam redes neurais tipo "back-propagation" e auto organizáveis.

Crivelaro $(1999,2002)$ treinou varias redes individuais com saída única, cada uma acionada na presença de um determinado padrão de escoamento, a partir 
de sinais de impedância adquiridos de escoamento horizontal água-ar. Neste trabalho foram obtidos índices de detecção correta entre $80 \%$ e $60 \%$, respectivamente para os padrões intermitente e anular, com atrasos variando entre 5 e 120 segundos. Estes resultados, associados à necessidade de se instalar uma sonda de impedância elétrica para a aquisição dos sinais, tornaram inadequada a utilização da técnica proposta em aplicações industriais.

$\mathrm{Na}$ tendência do uso de técnicas de processamento digital de sinais em conjunto com mecanismos inteligentes de inferência, Wu et al. (2001) descreve um método de diagnóstico à partir de sinais de pressão diferencial adquiridos com sensores piezo resistivos de resposta rápida. Neste trabalho os sinais são filtrados através de séries de "wavelets", e um vetor de características dos vários padrões de escoamento é calculado através da teoria dos fractais. Estes vetores são então utilizados como entrada no treinamento de uma rede neural artificial para reconhecimento dos padrões estratificado, intermitente e anular.

Em outra arquitetura, Yan (2003) treinou uma rede neural classificadora com várias saídas, uma para cada padrão, utilizando dados simulados baseados em sensor capacitivo de tomografia. Xie et al. (2004) obtém resultados satisfatórios em estudos de transportabilidade de aplicações de diagnóstico de escoamento vertical gás-líquido-fibra utilizando a mesma rede neural para processar sinais provenientes de diferentes sensores de pressão.

O presente trabalho é sobre o desenvolvimento de uma aplicação para uso "online" e em tempo real para o diagnóstico dos padrões de escoamento bifásico horizontal gás-líquido. A expressão "on-line" é usada no sentido de que os sensores estão conectados diretamente na tubulação, fazendo medidas de forma contínua para processamento em tempo real. O diagnóstico será dado por redes neurais artificiais, que terão como entrada as distribuições de coeficientes tempo-freqüência, calculados pela aplicação da transformada de Gabor a sinais de gradientes de pressão convenientemente adquiridos da tubulação. Um dos primeiros trabalhos a utilizar redes neurais artificiais 
conjuntamente com distribuições tempo-freqüência é relatado por Kandel (1992).

A principal idéia a corroborar o desenvolvimento e aplicação conjunta destas técnicas é o fato de que, se as componentes espectrais - obtidas a partir da distribuição tempo-freqüência de Gabor - são distintas para cada padrão de escoamento, e se é dado que uma rede neural pode classificar e generalizar estes diagramas, pode-se então construir uma ferramenta de inferência capaz de produzir resultados mais precisos e confiáveis que a aplicação isolada de cada uma destas tecnologias. A não aplicação de filtragem no processamento dos sinais é também parte do objetivo, porque pode-se considerar que importantes porções de informação contidas nestes sinais são perdidas durante a extração daquilo que acredita-se serem os ruídos. 


\subsection{ESCOAMENTOS GÁS-LÍQUIDO}

As duas subseções seguintes descrevem os modelos aplicados ao escoamento bifásico de Taitel e Dukler (1976) e os cálculos dos mapas de escoamento específicos a cada uma das seções de testes do NETeF.

\subsubsection{Modelagem dos Mapas de Escoamento}

Temos nesta seção uma breve explanação sobre escoamento horizontal bifásico confinado. São descritas as equações (TAITEL e DUKLER, 1976) que delimitam as regiões de fronteira entre os diferentes padrões de escoamento bifásico gás-líquido e o resultante mapa de escoamento bifásico de Taitel \& Dukler. A resolução das equações é feita através de métodos computacionais e os seus resultados são utilizados como referência para condução dos experimentos e avaliação dos resultados obtidos.

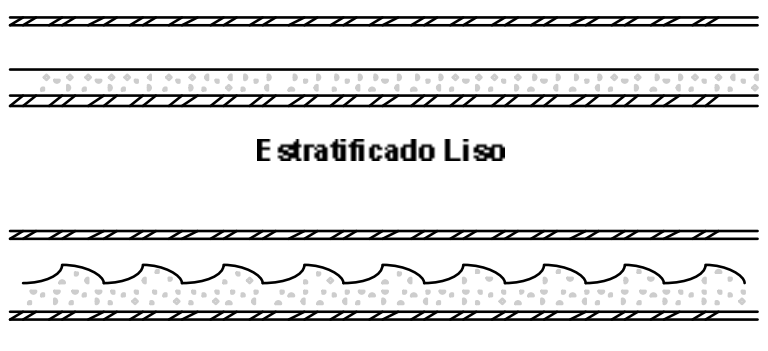

Estratificado ondulado

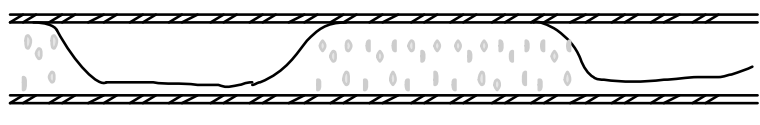

Intermitente

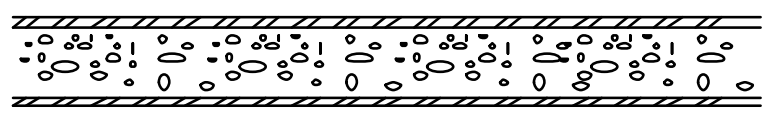

Bolhas

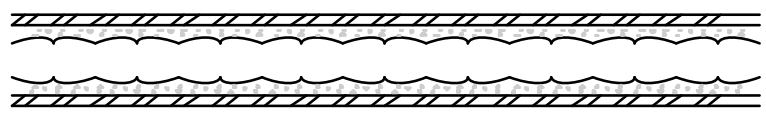

Anular

Figura 1: Padrões típicos de escoamento gás-líquido. 
A figura 1 acima descreve os padrões de escoamento bifásico referenciados e produzidos nos desenvolvimentos e experimentações deste trabalho. Nos detalhes temos os padrões estratificado liso (fase líquida estratificada e escoamento laminar na interface entre as fases), estratificado ondulado (fase líquida estratificada e escoamento com estrutura ondulada na interface gáslíquido), intermitente (fases líquida e gasosa ocorrendo alternadamente), a bolhas dispersas (fase gasosa em bolhas dispersas na fase líquida) e o anular (a fase gasosa escoa completamente envolvida pela fase líquida, que escoa em contato com a parede do duto).

As ocorrências destas fases foi pioneiramente modelada por Taitel e Dukler em 1976. Deste trabalho resultou o bem conhecido mapa de escoamento que leva o nome dos autores. O mapa é definido graficamente pela velocidade superficial do gás $U_{G S}(\mathrm{~m} / \mathrm{s})$ no eixo das abscissas e pela velocidade superficial do líquido $U_{L S}(\mathrm{~m} / \mathrm{s})$ no eixo das ordenadas. A relação entre os pares $\left(U_{G S}, U_{L S}\right)$ que definem a fronteira entre os diferentes padrões de escoamento é deduzida das equações diferenciais para conservação de momento, energia ou massa para um duto onde existem as fases líquida e gasosa. A figura 2 descreve a seção do duto e os parâmetros à partir dos quais os cálculos são efetuados.
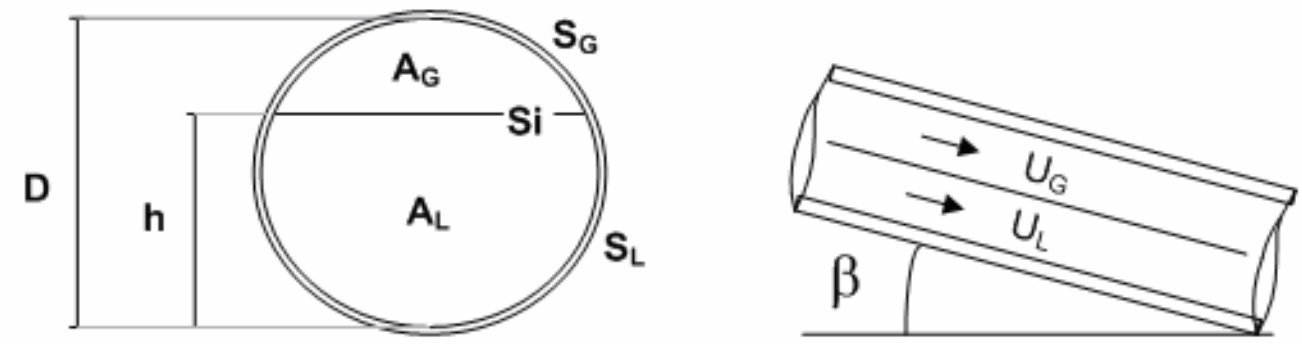

Figura 2: Seção do duto de transporte bifásico gás-líquido em escoamento estratificado liso.

Nesta figura são determinadas as dimensões $D=$ diâmetro interno, $h=$ altura de coluna da fase líquida, $A_{G}$ e $A_{L}$,que são as áreas ocupadas pelas fases gasosa e líquida, respectivamente, $S_{G}, S_{L}$ e $S_{i}$, que são os componentes perimetrais definidos pelas fases gasosa, líquida e de interface entre elas, 
respectivamente. Os temos $U_{G}$ e $U_{L}$ são as velocidades médias locais das fases gasosa e líquida, respectivamente, e $\beta$, o ângulo de inclinação da seção.

Uma revisão detalhada dos modelos e equacionamentos utilizados aqui pode ser encontrada no trabalho de Taitel e Dukler (1976). No escopo deste trabalho apenas apresentaremos as equações regentes de cada uma das transições estudadas com alguns comentários acerca de seus desenvolvimentos e utilização.

\subsubsection{Escoamento estratificado em regime permanente}

Como esta configuração de escoamento é de central importância, o nosso passo inicial é o estabelecimento das relações gerais que a governam O balanço de momento para cada uma das fases nos leva a:

$$
\begin{aligned}
& -A_{\llcorner}\left(\frac{d P}{d x}\right)-\tau_{\llcorner} S_{L}+\tau_{i} S_{i}+\rho_{\llcorner} A_{\llcorner} g \sin \beta=0 \\
& -A_{G}\left(\frac{d P}{d x}\right)-\tau_{G} S_{G}-\tau_{i} S_{i}+\rho_{G} A_{G} g \sin \beta=0
\end{aligned}
$$

Igualando $\mathrm{oP} / \mathrm{dx}$ nas equações e assumindo que o gradiente hidráulico nas condições de transição é desprezível temos:

$$
\tau_{G} \frac{S_{G}}{A_{G}}-\tau_{L} \frac{S_{L}}{A_{L}}+\tau_{i} S_{i}\left(\frac{1}{A_{L}}+\frac{1}{A_{G}}\right)+\left(\rho_{L}-\rho_{G}\right) g \sin \beta=0
$$

A tensão cisalhante é avaliada com U sendo a velocidade média da fase:

$$
\tau_{L}=f_{L} \frac{\rho_{L} U_{L}^{2}}{2} \quad \tau_{G}=f_{G} \frac{\rho_{G} U_{G}^{2}}{2} \quad \tau_{i}=f_{i} \frac{\rho_{G}\left(U_{G}-U_{i}\right)^{2}}{2}
$$

onde os fatores de atrito das fases avaliados a partir de: 


$$
f_{L}=C_{L}\left(\frac{D_{L} U_{L}}{v_{L}}\right)^{-n} \quad f_{G}=C_{G}\left(\frac{D_{G} U_{G}}{v_{G}}\right)^{-m}
$$

onde $D_{L}$ e $D_{G}$ são os diâmetros hidráulicos calculados como sugerido por Agrawal et al. (1973) :

$$
D_{L}=\frac{4 A_{L}}{S_{L}} \quad D_{G}=\frac{4 A_{G}}{S_{G}+S_{i}}
$$

Isso implica que a resistência do líquido na parede do duto é similar ao caso do escoamento em canal aberto e para o gás é similar ao caso de escoamento confinado em duto.

Transições começam a ser observadas quando $U_{G} \gg U_{i}$. $A$ tensão de cisalhamento interfacial no gás é avaliada com a mesma equação da tensão de cisalhamento do gás na parede do duto. Taitel e Duckler utilizaram os seguintes coeficientes: $C_{G}=C_{L}=0.045, n=m=0.2$ para escoamento turbulento e $C_{G}=C_{L}=16, n=m=1.0$ para escoamento laminar.

As equações são então adimensionalizadas, utilizando a variável de referência $D$ para os comprimentos, $D^{2}$ para as áreas e as velocidades superficiais $U_{L S} e$ $\mathrm{U}_{\mathrm{GS}}$ para as velocidades do líquido e gás, respectivamente. Substituindo as equações (4) e (5) na (3) temos:

$\mathrm{X}^{2}\left[\left(\tilde{U}_{\mathrm{L}} \tilde{D}_{\llcorner}\right)^{-\mathrm{n}} \tilde{U}_{\llcorner}^{2} \frac{\tilde{S}_{L}}{\tilde{A}_{L}}\right]-\left[\left(\tilde{U}_{G} \tilde{D}_{G}\right)^{-m} \tilde{U}_{G}^{2}\left(\frac{\tilde{S}_{G}}{\tilde{A}_{G}}+\frac{\tilde{S}_{i}}{\tilde{A}_{L}}+\frac{\tilde{S}_{\mathrm{i}}}{\tilde{A}_{G}}\right)\right]-4 Y=0$

onde:

$$
X^{2}=\frac{\frac{4 C_{L}}{D}\left(\frac{U_{L S} D}{v_{L}}\right)^{-n} \frac{\rho_{L} U_{L S}^{2}}{2}}{\frac{4 C_{G}}{D}\left(\frac{U_{G S} D}{v_{G}}\right)^{-m} \frac{\rho_{G} U_{G S}^{2}}{2}}=\frac{\left|\left(\frac{d P}{d x}\right)_{L S}\right|}{\left.\mid \frac{d P}{d x}\right)_{G S} \mid}
$$




$$
Y=\frac{\left(\rho_{L}-\rho_{G}\right) g \sin \beta}{\frac{4 C_{G}}{D}\left(\frac{U_{G S} D}{v_{G}}\right)^{-m} \frac{\rho_{G} U_{G S}^{2}}{2}}=\frac{\left(\rho_{L}-\rho_{G}\right) g \sin \beta}{\left|\left(\frac{d P}{d x}\right)_{G S}\right|}
$$

$(\mathrm{dP} / \mathrm{dx})_{\mathrm{s}}$ designa a queda de pressão de uma fase apenas escoando pelo duto. X é o parâmetro introduzido por Lockhart e Martinelli (1949) e pode ser calculado com o conhecimento das vazões, propriedades dos fluidos e o diâmetro do tubo. $Y$ é zero para tubos horizontais e representa as forças relativas, atuando no líquido na direção do escoamento, devidas à gravidade e às perdas de pressão. Todas as variáveis adimensionais com superscript dependem apenas de $\tilde{h}=\mathrm{h} / \mathrm{D}$. São elas:

$$
\begin{aligned}
& \tilde{A}_{L}=0.25\left[\pi-\cos ^{-1}\left(2 \tilde{h}_{-1}\right)+\left(2 \tilde{h}_{-1}\right) \sqrt{1-\left(2 \tilde{h}_{-1}\right)^{2}}\right] \\
& \tilde{A}_{G}=0.25\left[\cos ^{-1}(2 \tilde{h}-1)-\left(2 \tilde{h}_{-1}\right) \sqrt{1-\left(2 \tilde{h}_{-1}\right)^{2}}\right] \\
& \tilde{S}_{L}=\pi-\cos ^{-1}(2 \tilde{h}-1) \\
& \tilde{S}_{G}=\cos ^{-1}\left(2 \tilde{h}_{-1}\right) \\
& \tilde{S}_{i}=\sqrt{1-\left(2 \tilde{h}_{-1}\right)^{2}} \\
& \tilde{U}_{L}=\frac{\tilde{A}}{\tilde{A}_{L}} \\
& \tilde{U}_{G}=\frac{\tilde{A}}{\tilde{A}}
\end{aligned}
$$


Fica estabelecido então que as quantidades incluídas nos colchetes da Equação (7) dependem apenas do valor de h/D, e que para cada valor de h/D (existem casos em que temos 2 valores $Y$ para um mesmo valor de $X$ ), sempre existirá um par $X-Y$ que resolva a Equação (7). A decisão sobre se o escoamento é laminar ou turbulento em cada fase deve ser baseada no cálculo do número de Reynolds, calculado à partir da velocidade e do diâmetro hidráulico equivalente preenchido por aquela fase, em vez da velocidade superficial e do diâmetro da seção. 


\subsubsection{Transição entre escoamentos estratificado e intermitente}

Com o aumento da vazão da fase líquida, o nível (h) desta aumenta e uma onda é formada rapidamente e tende a bloquear o escoamento de gás. Isto se processa em decorrência da diminuição do diâmetro hidráulico do gás, que, em função disto, vê sua velocidade aumentada. De acordo com o efeito de Bernoulli, a pressão é então diminuída neste ponto, o que tende a fazer a onda da fase líquida crescer ainda mais. O equilíbrio entre esta tendência e os efeitos da força da gravidade e das tensões superficiais, que atuam em sentido contrario, é o principio do utilizado no critério de instabilidade de Kelvin Helmholtz (Milne-Tomsom, 1960). Este princípio, após adimensionalizado estabelece que :

$$
F^{2}\left[\frac{1}{C_{2}^{2}} \frac{\tilde{U_{G}^{2}}}{\tilde{A}_{G}} \frac{d \tilde{A}_{L}}{d \tilde{h}}\right] \geq 1 \quad C_{2}=1-\frac{h}{D}
$$

onde F é o número de Froude modificado pela razão de densidades:

$$
F=\sqrt{\frac{\rho_{G}}{\left(\rho_{L}-\rho_{G}\right)}} \frac{U_{G S}}{\sqrt{D g \cos \beta}}
$$

A solução das equações de balanço de momento e de instabilidade de Kelvin Helmholtz produz os pares $U_{G S} U_{L S}$ formadores da curva de transição entre os escoamentos estratificado e intermitente. 


\subsubsection{Transição entre escoamentos intermitente e anular}

A Equação (17) - instabilidade de Kelvin-Helmholtz, apresenta o critério segundo o qual uma onda finita na superfície da interface entre as fases tende a crescer. Nos casos em que o nível da fase líquida é inadequado à formação e manutenção das golfadas, a onda é quebrada e é então estabelecido o escoamento anular, no qual a fase gasosa escoa no interior de um filme adjacente à parede do duto formado pela fase líquida. Isto sugere que o escoamento se desenvolverá intermitente ou anular dependendo apenas da relação $h / D=0.5 \phi$, onde $\phi$ é a fração de fase do líquido nos pistões formados.

\subsubsection{Transição entre escoamentos estratificado liso e estratificado ondulado}

A formação de ondas estáveis à partir de uma interface estratificada lisa acorrerá apenas se existir uma fonte de energia para a fase líquida. Em escoamentos horizontais, esta fonte de energia é unicamente o gás. Esta transição ocorrerá se a velocidade do gás for suficiente para causar estas ondas mas menor que o suficiente para provocar o crescimento rápido das ondas e a conseqüente transição para o padrão anular ou intermitente. A inclinação negativa do duto, no sentido do escoamento, faz com que a componente gravitacional seja presente nesta fonte de energia.

Em termos fenomenológicos, a formação destas ondas se iniciará quando a pressão e o trabalho das tensões de cisalhamento na interface líquida for maior que a dissipação viscosa no fluido. Uma boa descrição deste mecanismo de transferência de energia foi feita por Stewart (1967). Jeffreys $(1925,1926)$ apresentou o seguinte critério para a formação das ondas:

$$
\left(U_{G}-C\right)^{2} C=\frac{4 v_{L} g\left(\rho_{L}-\rho_{G}\right)}{s \rho_{G}}
$$


onde s é um coeficiente para o qual Benjamin (1959) indicou valores entre 0.01 e 0.03. Este equacionamento utiliza $s=0.1$ e $C$ é a velocidade de propagação das ondas. As transições ocorrem em sua maioria quando $U_{G} \gg C$. Teorias sobre estas ondas sugerem que a razão entre a velocidade das ondas e a média da velocidade do filme $\mathrm{C} / \mathrm{U}_{\mathrm{L}}$ decresce com o acréscimo do número de Reynolds do líquido (BROCK, 1970) (CHU, 1973). Em escoamentos turbulentos esta razão fica entre 1.0 e 1.25. Para simplificação, o autor utiliza $U_{L}=C$ o que leva a:

$$
U_{G} \geq \sqrt{\left[\frac{4 v_{L}\left(\rho_{L}-\rho_{G}\right) g \cos \beta}{s \rho_{G} U_{L}}\right]}
$$

Que na forma adimensional fica:

$$
K \geq \frac{2}{\tilde{U}_{G} \sqrt{\tilde{U}_{L S}}}
$$

onde $\mathrm{K}$ é o produto do número de Froude modificado pela raiz quadrada do número de Reynolds superficial do líquido:

$$
K^{2}=F^{2} \operatorname{Re}_{L S}=\left[\frac{\rho_{G}\left(U_{G S}\right)^{2}}{\left(\rho_{L}-\rho_{G}\right) D g \cos \beta}\right]\left(\frac{D U_{L S}}{v_{L}}\right)
$$

Todas as quantidades dependem apenas de h/D. 


\subsubsection{Transição entre escoamentos intermitente e a bolhas}

Em configurações onde se têm elevadas velocidades da fase líquida e baixas velocidades da fase gasosa, o nível de equilíbrio da fase líquida se aproxima do topo da tubulação, o que marca a tendência do gás se misturar ao líquido. Nestas condições a transição para o escoamento a bolhas dispersas ocorre quando as flutuações turbulentas são fortes o suficiente para vencer as forcas de empuxo que tendem a manter o gás no topo da tubulação.

A força de empuxo por unidade de comprimento pode ser expressa por :

$$
F_{B}=g \cos \beta\left(\rho_{L}-\rho_{G}\right) A_{G}
$$

Como usado por Levich (1962) a força devida à turbulência pode ser estimada como:

$$
F_{T}=\frac{1}{2} \rho_{L} \overline{V^{\prime 2}} S_{i}
$$

onde V'é a flutuação da velocidade radial para a qual a raiz média quadrática é estimada aproximadamente igual à velocidade de fricção :

$$
\sqrt{\overline{\mathrm{V}^{\prime 2}}}=\mathrm{U}^{*}=\mathrm{U}_{\mathrm{L}} \sqrt{\frac{\mathrm{f}_{\mathrm{L}}}{2}}
$$

A dispersão do gás é visua lizada quando $F_{T} \geq F_{B}$, ou

$$
U_{L} \geq \sqrt{\frac{4 A_{G}}{S_{i}} \frac{g \cos \beta}{f_{L}}\left(1-\frac{\rho_{G}}{\rho_{L}}\right)}
$$

Que na sua forma adimensional fica : 


$$
T^{2} \geq \frac{8 \tilde{A}_{G}}{\tilde{S}_{i} U_{L}^{2}\left(\tilde{U}_{L} \tilde{D}_{L}\right)^{-n}}
$$

onde:

$$
T=\sqrt{\frac{\frac{4 C_{L}}{D}\left(\frac{U_{L S} D}{v_{L}}\right)^{-n} \frac{\rho_{L} U_{L S}^{2}}{2}}{\left(\rho_{L}-\rho_{g}\right) g \cos \beta}}=\sqrt{\frac{\left|\left(\frac{d P}{d x}\right)_{L S}\right|}{\left.\rho_{L}-\rho_{g}\right) g \cos \beta}}
$$

e T pode ser considerado como a razão entre as forças de turbulência e gravidade atuando no gás.

Quando as bolhas estão dispersas pela ação da turbulência, o escorregamento entre as fases é desprezível, ou seja $U_{L}=U_{G}$. Se $U_{G S}=U_{G} \alpha$ e $U_{L S}=(1-\alpha) U_{L}$ onde $\alpha$ é a fração de vazio média podemos formular que

$$
\mathrm{U}_{\mathrm{LS}}=\mathrm{U}_{\mathrm{GS}} \frac{1-\alpha}{\alpha}
$$

ou

$$
\alpha=\frac{\frac{U_{G S}}{U_{L S}}}{1+\frac{U_{G S}}{U_{L S}}}
$$

A fração de vazio portanto aumenta com o acréscimo de UGs para um dado $U_{\text {LS. }}$ Todavia com $\alpha=0.52$ tem-se a mistura com a máxima densidade possível de bolhas. Para valores maiores de $U_{G}$ as bolhas tendem a coalescer, o que em dado momento causa a transição para o escoamento intermitente. 


\subsubsection{Cálculo do mapa de Taitel \& Dukler para o circuito de testes do NETeF}

A experimentação neste trabalho consiste na geração de padrões de escoamentos em número e diversidade suficientes para os treinamentos das redes neurais e testes do software de diagnóstico. A geração destes escoamentos é possível através do estabelecimento de vazões convenientemente determinadas para as fases líquida e gasosa presentes no escoamento. A arbitragem das trajetórias - excursões dos pares (Ugs, Uls), da mesma forma, é mais eficiente se feita seguindo critérios prévios de seleção. É no objetivo de estabelecer estes critérios, utilizados tanto na condução dos experimentos quanto na ava liação dos resultados, que calcularemos o mapa de escoamentos de Taitel \& Dukler específico para circuito de testes do NETeF. Apresentamos nesta seção os métodos e cálculos necessários para o levantamento destes mapas.

Para a obtenção destes mapas foram implementados métodos computacionais baseados no algoritmo de ZBrent para solução de raízes de equações matemáticas. Os códigos foram escritos em ANSI C, compilados e executados em ambiente UNIX. Os códigos estão disponíveis no Apêndice 1 e os resultados obtidos para a tubulação de $30 \mathrm{~mm}$ de diâmetro interno - utilizada no escopo deste trabalho - no Apêndice 2.

Os seguintes parâmetros foram utilizados :

$\begin{array}{rlll}\rho_{\mathrm{G}} & = & 1.179 & \mathrm{~kg} / \mathrm{m}^{3} \\ \rho_{\mathrm{L}} & = & 995.3 & \mathrm{~kg} / \mathrm{m}^{3} \\ v_{\mathrm{G}} & = & 1.57 \mathrm{e}-5 & \mathrm{~m}^{2} / \mathrm{s} \\ v_{\mathrm{L}} & = & 7.32 \mathrm{e}-7 & \mathrm{~m}^{2} / \mathrm{s} \\ \mathrm{g} & = & 9.8 & \mathrm{~m} / \mathrm{s}^{2} \\ \mathrm{D} & =0.03 / 0.022 / 0.021 \mathrm{~m} ; \\ B & =0 & \end{array}$

A solução das equações de balanço de momento (7), aqui referida por $\phi_{1}\left(U_{G S}\right.$, $\left.U_{L S}, h\right)=0$ e da instabilidade de Kelvin-Helmholtz (17), aqui por $\phi_{2}\left(U_{G S}, h\right)=0$ conforme descrito na figura 3 resulta nos pares $\left(U_{G S}, U_{L S}\right)$ que determinam a região de fronteira entre os escoamentos estratificado e intermitente ou anular. 


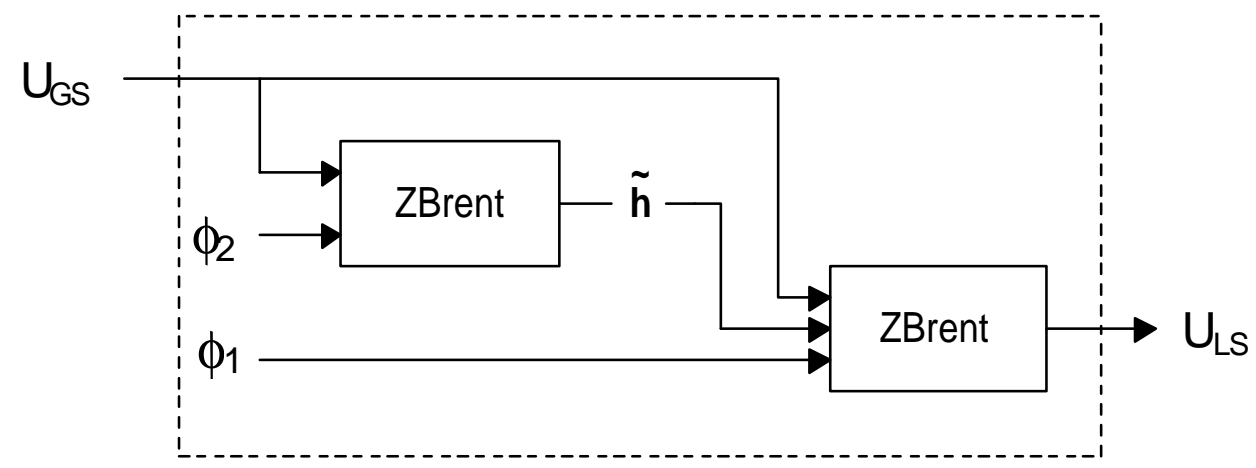

Figura 3: Diagrama de blocos de solução da transição entre padrões estratificado e intermitente ou anular

A transição entre os padrões intermitente e anular é determinada pelas raízes das mesmas equações $\phi_{1}\left(U_{G S}, U_{L S}, h\right)=0 \quad \phi_{2}\left(U_{G S}, h\right)=0$, em rearranjo conforme apresentado pela figura 4. Foi descrito na seção 2.1.1.3 que para valores de $\tilde{h}$ maiores que 0.5 tem-se a configuração do padrão intermitente, e abaixo deste valor, o padrão de escoamento anular. A resolução de $\phi_{2}$ com $\tilde{h}=0.5$ através do método ZBrent resulta num valor mínimo de UGs, chamado aqui U'Gs, à partir do qual se pode calcular a raiz de $\phi_{1}$ com $\tilde{h}=0.5$ para se obter os pares $\left(\bigcup_{G S}, U_{L S}\right)$ que definem esta transição.

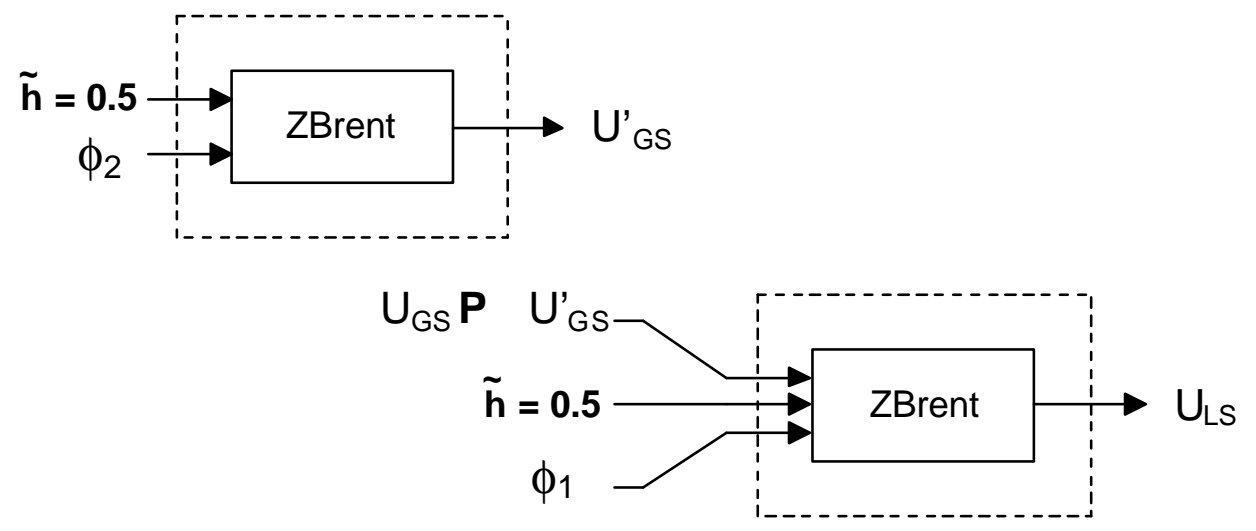

Figura 4: Diagrama de blocos de solução da transição entre padrões intermitente e anular 
A transição entre os padrões estratificado liso e estratificado ondulado é de outra forma calculado através da solução das raízes das equações que modelam a relação entre os trabalhos das forças de cisalhamento devidas à pressão e as dissipações viscosas na interface líquido-gás. A figura 5 descreve este esquema, onde a Equação (22) é re-arranjada em $\phi_{c}\left(U_{G S}, U_{L S}, h\right)=0$ e a Equação $(7)$ em $\phi^{*}{ }_{1}\left(U_{G S}, h\right)$ - reescrita para cálculo de $U_{L S}$ à partir de $h$ e $U_{G S}$ determinados.

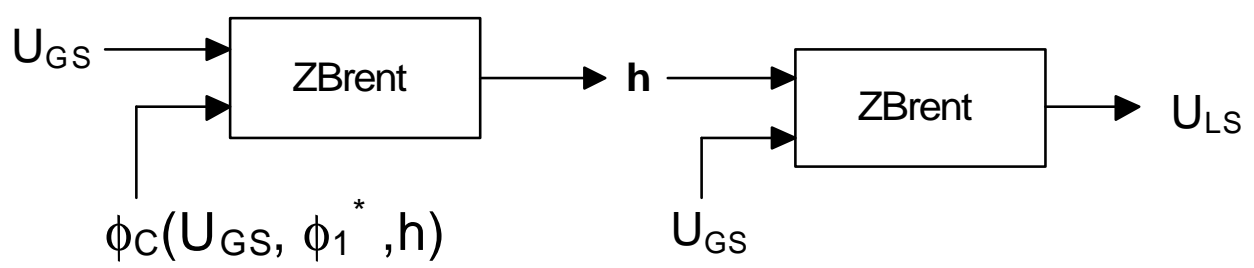

Figura 5: Diagrama de blocos de solução da transição entre os padrões estratificado liso e estratificado ondulado

Outra transição calculada é a que determina a fronteira entre os padrões intermitente e a bolhas. Nesta, é assumido que o padrão a bolhas se estabelece quando as forças de flutuações turbulentas são maiores que as forças de empuxo aplicadas nas bolhas em formação - esta condição impede as bolhas de se fundirem em um slug de gás. A solução computacional desta transição é então feita conforme descrito pela figura 6, onde a Equação (28) é reescrita em $\phi_{D}\left(\phi^{*}{ }_{1} h\right)=0$ e a Equação $(7)$ em $\phi^{*}{ }_{1}\left(U_{G S}, h\right)$.

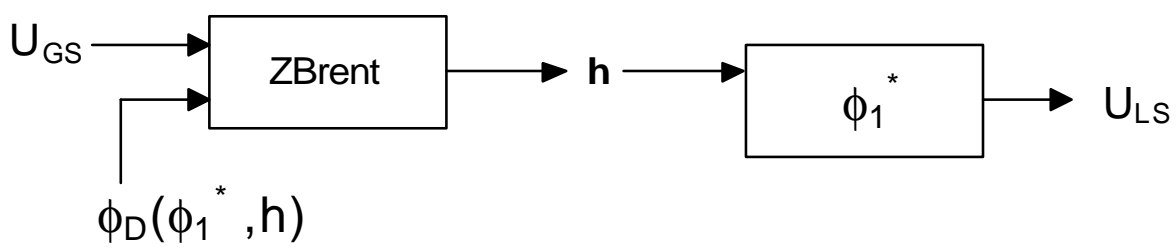

Figura 6: Diagrama de blocos de solução da transição entre padrões intermitente e a bolhas. 
As figuras 7, 8 e 9 seguintes apresentam os gráficos de transições entre os padrões de escoamento de objeto de nosso estudo, calculados especificamente para as tubulações das secções de testes do NETeF, considerados escoamento horizontal e diâmetros internos de 30, 22 e 21 milímetros, respectivamente.

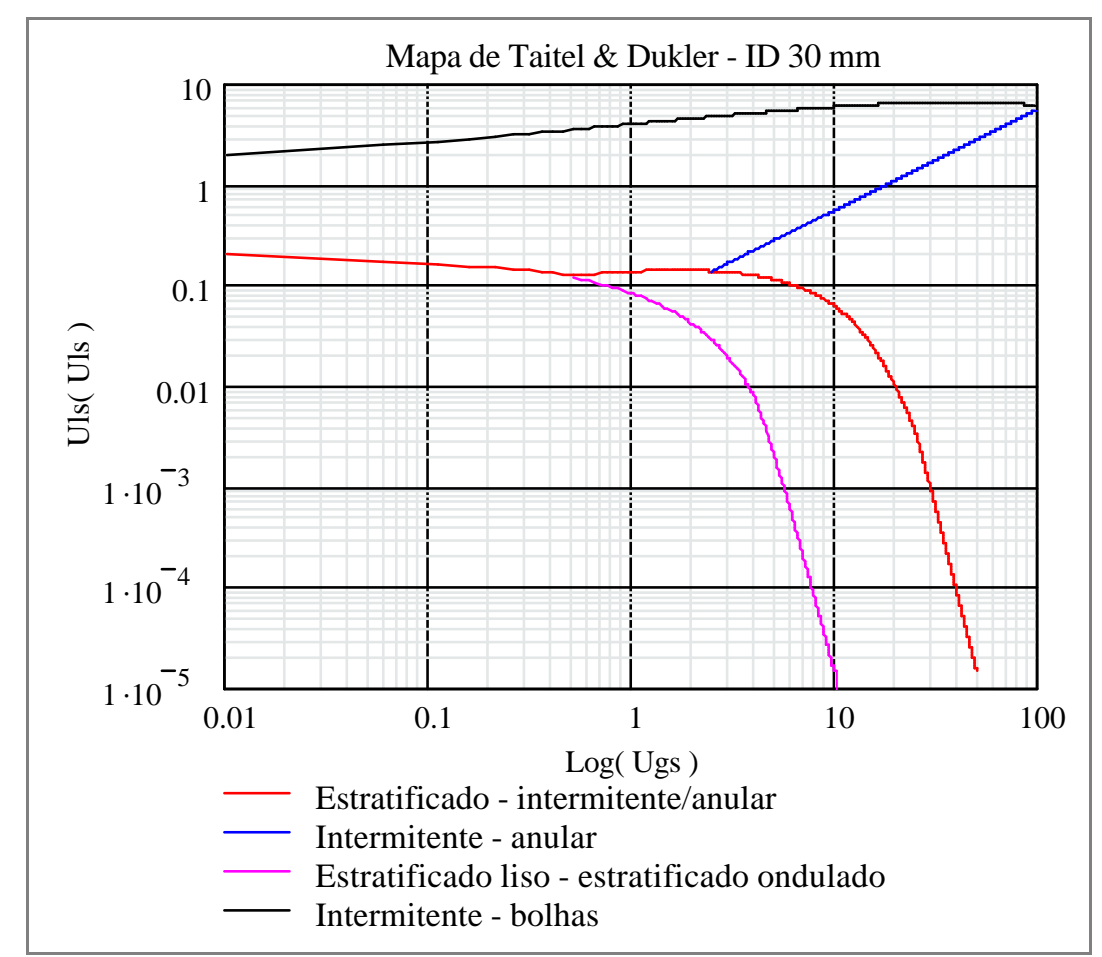

Figura 7: Mapa de padrões de escoamento bifásico de Taitel \& Dukler para tubulação horizontal e diâmetro interno de $30 \mathrm{~mm}$ - NETeF 


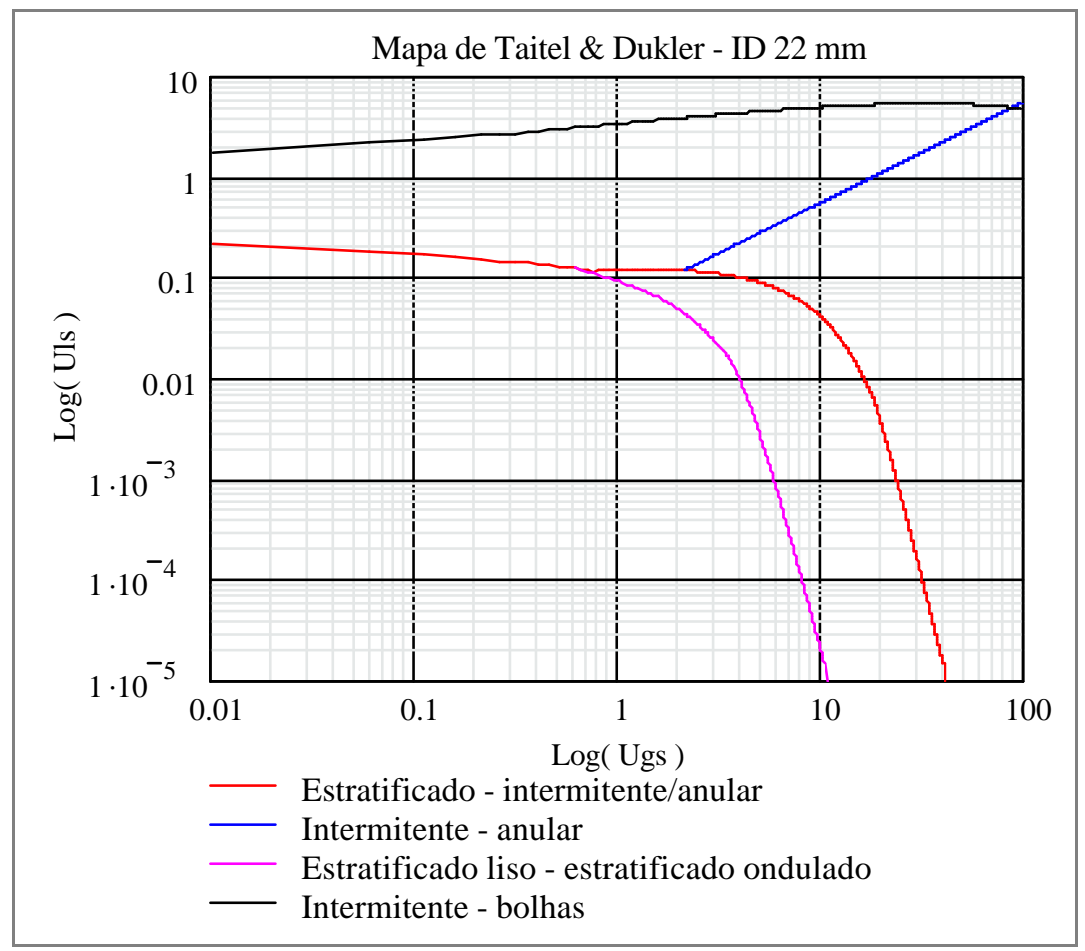

Figura 8: Mapa de padrões de escoamento bifásico de Taitel \& Dukler para tubulação horizontal e diâmetro interno de $22 \mathrm{~mm}$ - NETeF

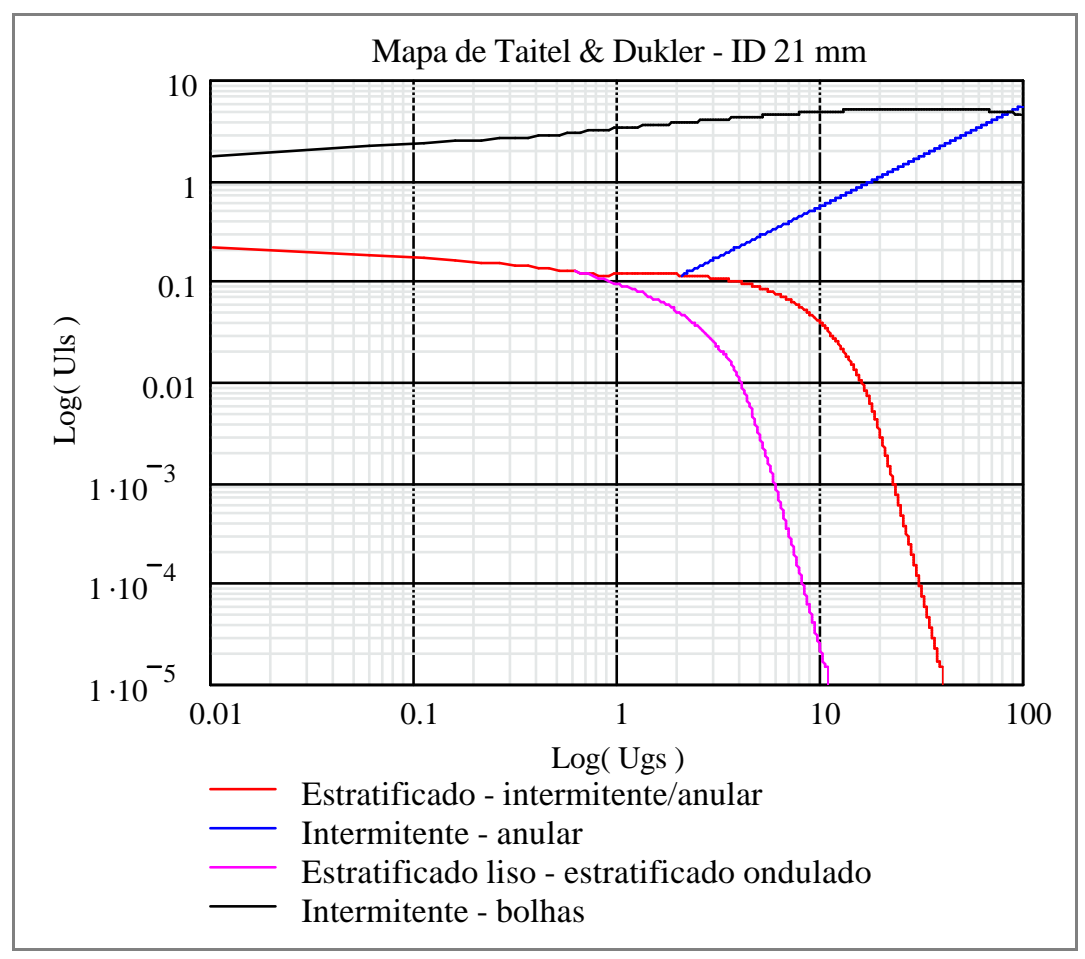

Figura 9: Mapa de padrões de escoamento bifásico de Taitel \& Dukler para tubulação horizontal e diâmetro interno de $21 \mathrm{~mm}$ - NETeF 


\subsection{Diagramas tempo-freqüência e a transformada de Gabor}

A análise do conteúdo espectral de um sinal baseada apenas na sua transformada de Fourier pode não ser suficiente para descrever um processo ou fenômeno físico à partir do qual este sinal foi extraído. A informação temporal é perdida devido à integração no tempo, isto é, a transformada de Fourier enfatiza toda a informação em termos das freqüências presentes no sinal, em total detrimento dos aspectos temporais. Pode-se dizer que ela omite informações acerca do tempo t em que estas freqüências ocorrem.

Em muitos processos de interesse, as freqüências presentes em seus respectivos sinais variam ao longo do tempo, e esta informação, isto é, as leis de modulação do conteúdo espectral, são da maior importância para a interpretação inequívoca do sinal. Bons exemplos são as linguagens tonais, como o Mandarin Chinês e o Cantonês, nos quais a mudança no timbre de um som leva a palavras completamente diferentes. Assim, o objetivo da análise tempo-freqüência é construir, à partir de um sinal original unidimensional, uma distribuição bidimensional associada a este sinal, capaz de identificar os conteúdos espectrais instantâneos - ou conteúdos locais na vizinhança do tempo de análise. Um bom exemplo disto é o que se pode observar em uma escala musical.

Uma representação do tipo tempo-freqüência pode ser visualizada como uma distribuição de densidade de potência, calculada a partir de um sinal, capaz de identificar suas freqüências e os períodos correspondentes nos quais estas freqüências estiveram presentes. Existem varias alternativas possíveis para se construir este tipo de distribuição. Pode-se definir uma à partir da medida da similaridade - definida pelo produto escalar - entre um sinal genérico $s(\bullet)$ e uma função analisadora $h_{t, w}(\cdot)$ bem localizada ao redor do tempo t e da freqüência $\omega$ :

$$
P(t, \omega)=\left\langle s, h_{t, \omega}\right\rangle=\int_{-\infty}^{+\infty} s(\tau) h_{t, \omega}^{*}(\tau) d \tau
$$


Diferentes famílias de funções analisadoras levam a diferentes classes de distribuições. Por exemplo, se $\mathrm{h}_{\mathrm{t}, \omega}(\bullet)$ é gerada à partir transformações afins aplicadas a uma função mãe admissível $h(\bullet)$ qual seja :

$$
h_{t, \omega}(\tau)=h\left(\frac{\tau-t}{\omega_{0} / \omega}\right)
$$

então $\mathrm{P}(\mathrm{t}, \mathrm{w})$ se torna a conhecida Transformada Wavelet. um exemplo de classe afim são as "wavelets" de Y. Meyer (1993) e de I. Daubechies (1992).

A transformada STFT - "Short Time Fourier Transform" - pertence à classe de Cohen e é obtida pela translação no tempo e na freqüência da função mãe admissível :

$$
h_{t, \omega}(\tau)=h(\tau-t) e^{j \omega \tau}
$$

onde $j=\sqrt{-1}$. A transformada de Gabor corresponde a um caso especial de uma STFT na qual a função mãe é a janela Gaussiana, ou seja:

$$
h(\tau)=e^{-a t^{2}}
$$

onde $\alpha$ é o parâmetro que controla a velocidade de decaimento da janela Gaussiana. Pela aplicação da definição expressa pela Equação (30) obtemos :

$$
P(t, \omega)=\int_{-\infty}^{+\infty} s(\tau) e^{-\alpha(\tau-t)^{2}-i \omega \tau} d \tau
$$

A Transformada de Gabor é uma escolha interessante porque sua função analisadora, a gaussiana, possui o mínimo espalhamento possível. Mais precisamente, pela definição de uma medida do suporte de $h(\bullet)$ e de sua transformada de Fourier $h(\bullet)$ de acordo com : 


$$
\begin{aligned}
& \Delta_{\mathrm{h}}=\frac{1}{\mathrm{E}} \int_{-\infty}^{+\infty}\left(\tau-\mathrm{t}_{0}\right)^{2}|\mathrm{~h}(\tau)|^{2} \mathrm{~d} \tau \\
& \Delta_{\hat{\mathrm{h}}}=\frac{1}{\mathrm{E}} \int_{-\infty}^{+\infty}\left(\tau-\omega_{0}\right)^{2}|\hat{\mathrm{h}}(\tau)|^{2} \mathrm{~d} \tau
\end{aligned}
$$

onde $E$ é a energia do sinal e $\hbar$ e $w_{0}$ respectivamente são seus tempo e freqüências centrais. É então possível demonstrar (COHEN,1995) que

$$
\Delta_{\mathrm{h}} \Delta_{\hat{\mathrm{h}}}=2 \pi
$$

onde, para qualquer sinal $s(\bullet)$ diferente da janela Gaussiana, esta relação se torna (GABOR, 1946) :

$$
\Delta_{s} \Delta_{\hat{s}} \geq 2 \pi
$$

Uma conseqüência importante disto é que a transformada de Gabor produz uma partição ótima do espaço tempo-freqüência através da translação de $h(\bullet$ ) em passos $T$ no tempo e $\Omega$ na freqüência, ou seja :

$$
h_{m, k}(\tau)=h(\tau-m T) e^{j k \Omega \tau}
$$

onde $k= \pm 1, \pm 2 \ldots$ e $m= \pm 1, \pm 2 \ldots$ Definindo $\mathrm{T}$ e $\Omega$ de acordo com :

$$
\mathrm{T} \Omega=\frac{2 \pi}{\beta}
$$

se obtém uma partição do plano tempo-freqüência que pode ser redundante se $\beta>1$, exata se $\beta=1$ ou deficiente $s \quad \beta<1$. A essa partição pode-se associar os coeficientes de decomposição - chamados de átomos por Gabor : 


$$
a_{m, k}=\int_{-\infty}^{+\infty} s(\tau) e^{-\alpha(\tau-m T)^{2}-j k \Omega \tau} d \tau
$$

que na forma discreta fica :

$$
a_{m, k}=\sum_{n} s(n) e^{-\alpha(n \Delta t-m T)^{2}-j k \Omega n \Delta t}
$$

onde $s(n)$ é o sinal discreto equivalente do sinal $s(\tau)$.

Neste trabalho, os coeficientes são calculados à partir de sinais de pressão e utilizados para identificar o padrão de escoamento através de uma rede neural previamente treinada. Descrições abrangentes sobre análises no espaço tempo-freqüência podem ser revisadas em Cohen (1995). 


\subsection{Redes neurais artificiais}

As redes neurais podem ser definidas como um mapeamento não linear de um vetor de espaço de entrada para um vetor de espaço de saída. Isto pode ser feito através de camadas de funções de ativação ou neurônios, nos quais coordenadas de entrada são somadas de acordo com o valor de seus respectivos pesos e "bias" para produzir uma saída simples, ativada ou não, de acordo com o seu respectivo nível de disparo. Esta estrutura é conhecida como perceptron e foi proposta originalmente por F. Rosenblatt (1958).

A rede neural artificial utilizada neste trabalho é a do tipo multi-camadas ou "MLP - multi-layer perceptrons" não recursiva, na qual o vetor de entrada de uma camada especifica de neurônios é formado apenas pelos valores de disparo da camada precedente. A fgura 10 seguinte descreve este tipo de arquitetura.

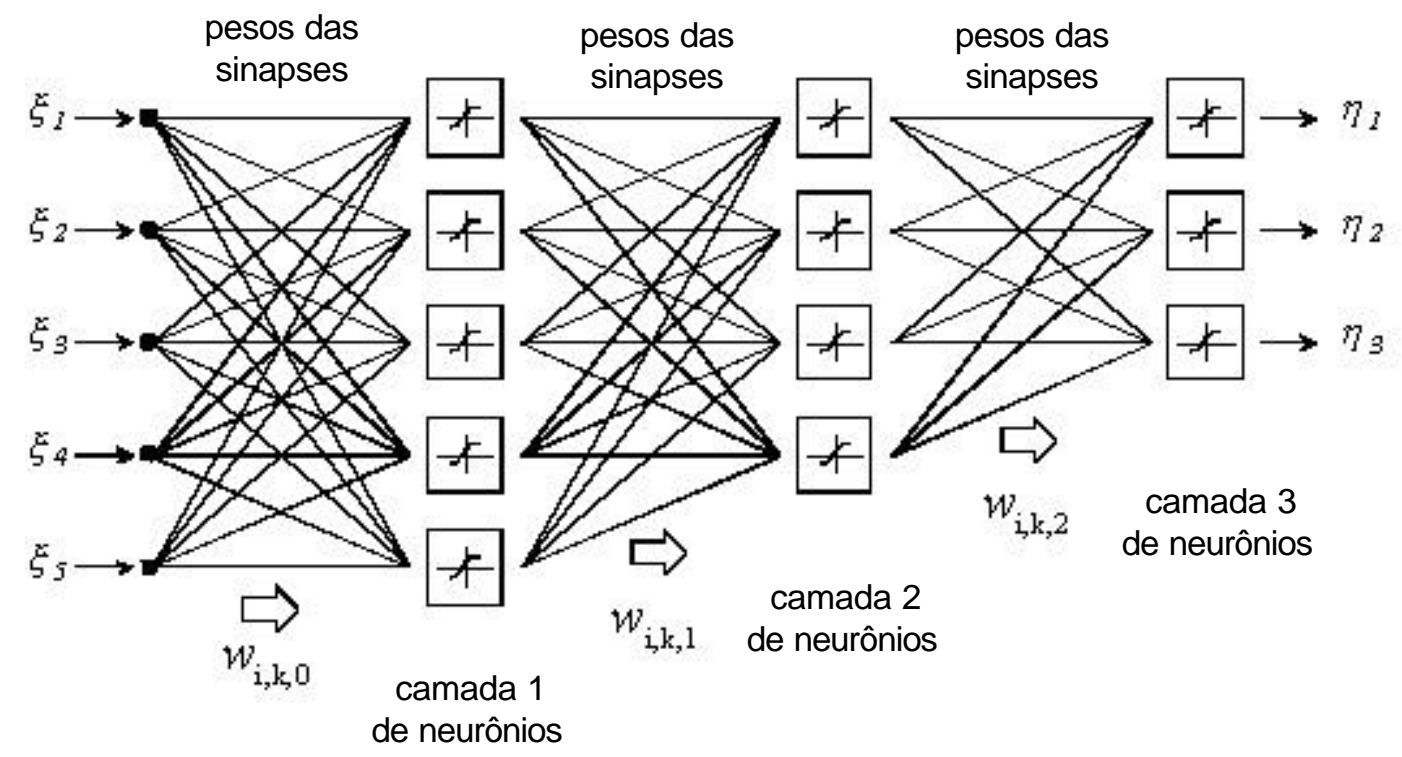

Figura 10: Representação esquemática de uma rede neural tipo "feed-forward" mapeando um vetor de entrada de 5 coordenadas para um vetor de saída de 3 coordenadas. 
Formalmente, se a função de ativação do iésimo neurônio na jésima camada é indicada por $\mathrm{F}_{\mathrm{i}, \mathrm{j}}(\bullet)$, sua saída $\mathrm{s}_{\mathrm{ij}}$ é calculada a partir das saídas da camada precedente $s_{i, j-1}$, do "bias" $b_{i, j}$ correspondente e dos valores dos pesos $w_{i, k, j-1}$ (o índice $k$ indica o neurônio na camada j-1), de acordo com a expressão

$$
s_{i, j}=F_{i, j}\left(b_{i, j}+\sum_{k} w_{i, k, j-1} s_{k, j-1}\right)
$$

onde os valores de entrada e saída da rede neural são denotados respectivamente por $\xi_{i}$ e $\eta_{i}$, e a relação de mapeamento de um neurônio para outro é calculado sucessivamente pela aplicação da Equação (43). Para a arquitetura da figura 10 resulta que :

$$
\begin{array}{r}
\eta_{i}=F_{i, 3}\left(b_{i, 3}+\sum_{k=1}^{4} w_{i, k, 2} F_{k, 2}\left(b_{k, 2}+\sum_{m=1}^{5} w_{k, m, 1} F_{m, 1}\left(b_{m, 1}+\sum_{n=1}^{5} w_{m, n, 0} \xi_{n}\right)\right)\right) \\
i=1,2,3
\end{array}
$$

Fica portanto claro pela expressão (44) que a relação entre $\xi_{i}$ e $\eta_{i}$ é definida inequivocamente pela escolha das funções de ativação e pela atribuição dos valores dos pesos e "bias". Entre outras propriedades, a rede neural possui uma muito importante que é a capacidade de aprendizado, i.e. a possibilidade de ajuste dos valores de "bias" e pesos através de regras de treinamento convenientes, a fim de reproduzir com relativa precisão valores de pares de entrada/saída pré-estabelecidos (HAYKIN, 1999). O "backpropagation" é provavelmente a heurística de treinamento mais empregada e é particularmente bem aceita para arquiteturas "feed-forward", desenvolvido independentemente por diversos autores (HAGAN et. al., 1996). Esta heurística é baseada na aplicação iterativa de um algoritmo de otimização segundo a direção dos gradientes máximos, computados à partir da primeira derivada de uma função de erro convenientemente definida com respeito aos parâmetros da rede. Em linhas gerais, os passos básicos do procedimento "back-propagation" são os seguintes: 
1. Inicialização dos parâmetros da rede $b_{i, j}$ e $w_{i, k, j}$

2. De um conjunto de dados de treinamento pré-estabelecidos de entrada-saída $\left(\xi_{i}{ }^{p}, \delta_{i}{ }^{p}\right)$ o algoritmo usa um em específico e forma o $\operatorname{par}\left(\xi_{i}, \delta_{i}\right)$

3. Cálculo da função de erro de acordo com a norma Euclideana:

$$
e=\sqrt{\sum_{i}\left(\delta_{i}^{p}-\eta_{i}^{p}\right)^{2}}
$$

4. Cálculo das derivadas do erro e em relação a $b_{i, j}$ and $w_{i, k, j}$

5. Modificação dos parâmetros da rede de acordo com a estratégia "steepest descent" e uma taxa de aprendizado $\alpha$

$$
b_{i, j} \leftarrow b_{i, j}-\alpha \frac{\partial e}{\partial b_{i, j}} \quad \text { and } \quad w_{i, k, j} \leftarrow w_{i, k, j}-\alpha \frac{\partial e}{\partial w_{i, k, j}}
$$

6. Iteração do passo 2 até o 5 , sucessivamente, modificando $b_{i, j}$ and $w_{i, k, j}$, até um número definido de épocas - ciclos de treinamento - ou até que um critério conveniente de parada - por exemplo, um erro aceitável - seja atingido.

A performance de uma rede neural é profundamente afetada pela sua arquitetura interna - o número de camadas intermediárias e o número de neurônios por dada camada - e o tipo de interconexão utilizado, que pode ser o "feed-foward", a recursiva, o "winner-take-all" entre outros. A despeito da existência destas gamas de possibilidades, não existe uma teoria matemática geral para predizer quando construir um modelo específico. Existem todavia alguns métodos empíricos para ajudar nestas avaliações.

A arquitetura utilizada neste trabalho (Figura 10), é baseada no modelo "feed-forward" independente, com $m \times k$ neurônios de entrada, $m_{j} \times k_{j}$ neurônios nas camadas intermediárias, $n$ camadas intermediárias e 5 neurônios de saída. Os neurônios da camada de entrada são dispostos em grade, de forma a 
acomodar os valores dos pixeis da imagem produzida pela distribuição tempofreqüência de Gabor. A camada de saída foi disposta com 5 neurônios, cada um deles ativado quando seu padrão de escoamento bi-fasico ar-água é diagnosticado. Os cinco padrões associados aos neurônios da camada de saída são os estratificado liso, estratificado ondulado, intermitente, anular e a bolhas dispersas.

A implementação numérica foi feita com auxílio da plataforma SNNS (Stutgard Neural Network Simulator), descrita em mais detalhes adiante. 


\section{CIRCUITO EXPERIMENTAL E INSTRUMENTAÇÃO}

Os diferentes padrões de escoamento de interesse deste trabalho foram gerados nas dependências do laboratório do NETeF - Núcleo de Engenharia Térmica e Fluidos da USP - Universidade de São Paulo em São Carlos, Brasil. Nesta seção descreveremos a instrumentação em duas subseções: a da instrumentação de operação da planta e a da instrumentação utilizada para aquisição dos sinais de análise.

\subsection{Instrumentação de Operação da Planta da Seção de Testes}

O laboratório conta com um aparato construído sobre suporte inclinável (Figura 11) para operar em regime de circuito fechado, com 3 tanques que possibilitam a produção de escoamentos compostos de até 3 fases, a óleo, água e ar. Estes tanques são ligados por bombas a um misturador instalado a montante das tubulações de acrílico transparente. O misturador, por sua vez, pode ser acoplado a 1 de 3 três tubos disponíveis - cada um dos tubos com 12 metros de comprimento e 21, 22 e $30 \mathrm{~mm}$ de diâmetro interno respectivamente. Com esta configuração 0 aparato oferece as condições necessárias para a reprodução de ampla gama de configurações de escoamento. 


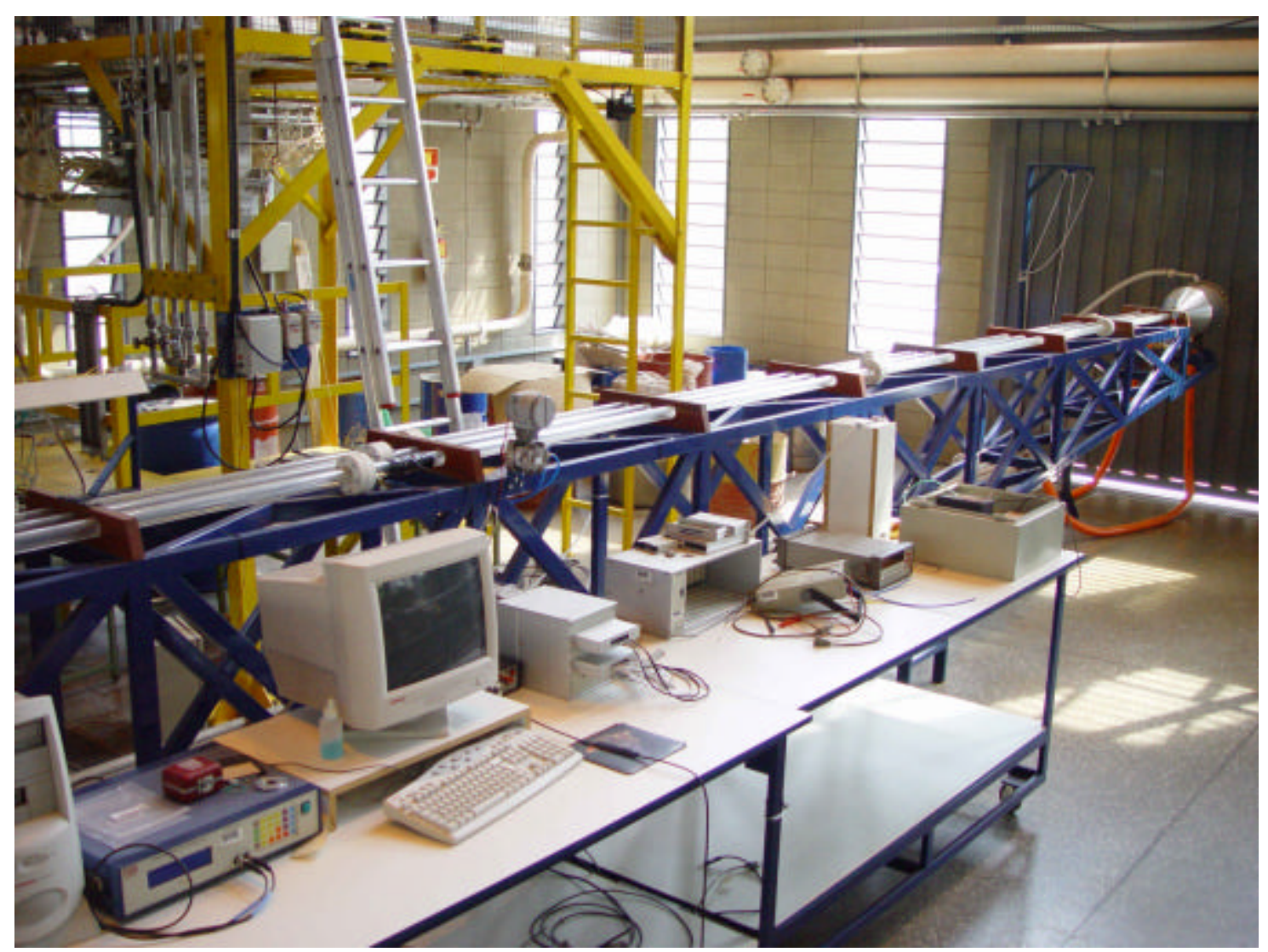

Figura 11: Seção de testes no NETeF - USP

A figura 12 apresenta o diagrama esquemático do dispositivo e descreve a montagem dos tanques, bombas, compressor, misturador, tubulações e elementos primários de controle. 


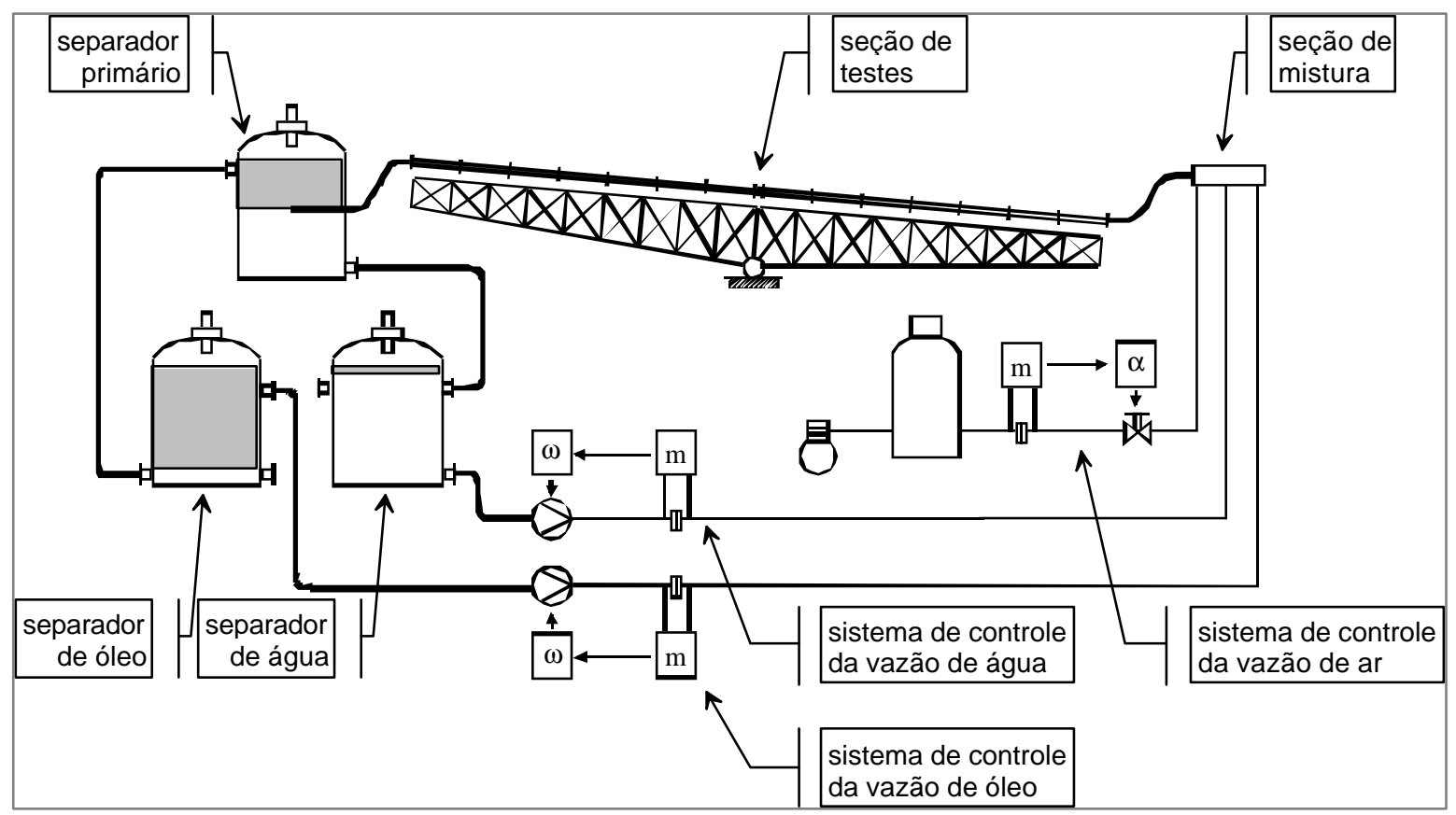

Figura 12: Diagrama esquemático da seção de testes do NETeF - USP

No diagrama esquemático pode-se ver que a jusante dos tanques estão montadas duas bombas centrífugas, cujos acionamentos são feitos através de inversores de freqüência. Seguindo o circuito temos, a jusante das bombas, o misturador, que além da alimentação de óleo e água, recebe também em conexão à montante a alimentação de ar. Este esquema de alimentação paralela de ar se faz através de 3 posicionadores pneumáticos de válvulas (SMAR FY301) acoplados à válvulas de controle (Valtek-P15). Esta arquitetura foi adotada para permitir maiores variações de escala nas estratégias de controle de vazão. O primeiro tramo atua na faixa de 0 a $10 \mathrm{~m} 3 / \mathrm{h}$, o segundo, de 7 a $40 \mathrm{~m} 3 / \mathrm{h}$, e o terceiro, de 30 a $100 \mathrm{m3} / \mathrm{h}$ (Figura 13). Os elementos primários de atuação são acionados à partir de estações de transferência automático manual (SMAR AM01P). Estas estações permitem acionamento em modo manual através de seu painel frontal ou em modo automático, no qual o equipamento retransmite proporcionalmente em escala de 4 a $20 \mathrm{~mA}$ o sinal de entrada, recebido em escala de 0 a $5 \mathrm{~V}$ ou 4 a $20 \mathrm{~mA}$, proveniente do módulo I/O National PXI 1000B. Este útimo é acoplado a um computador compatível IBM PC, rodando o software LabView, também da National. A planta é então operada à partir de programas escritos na linguagem Labview, que fazem as 
operações de entrada e saída, condicionamento dos sinais e interface homem máquina.

As vazões individuais de água, óleo e gás são medidas à partir das pressões diferenciais adquiridas dos elementos deprimogênitos tipo placa de orifício dimensionadas e instaladas nas linhas de acordo com a norma ASME MFC-3M (1989). Estas medições de pressão são transmitidas pelos sensores de pressão diferencial SMAR LD 301 ao módulo National PXI 6025E que os envia ao LabView. Malhas individuais de controle PID foram configuradas no LabView para cada um dos acionamentos (Figura 13).

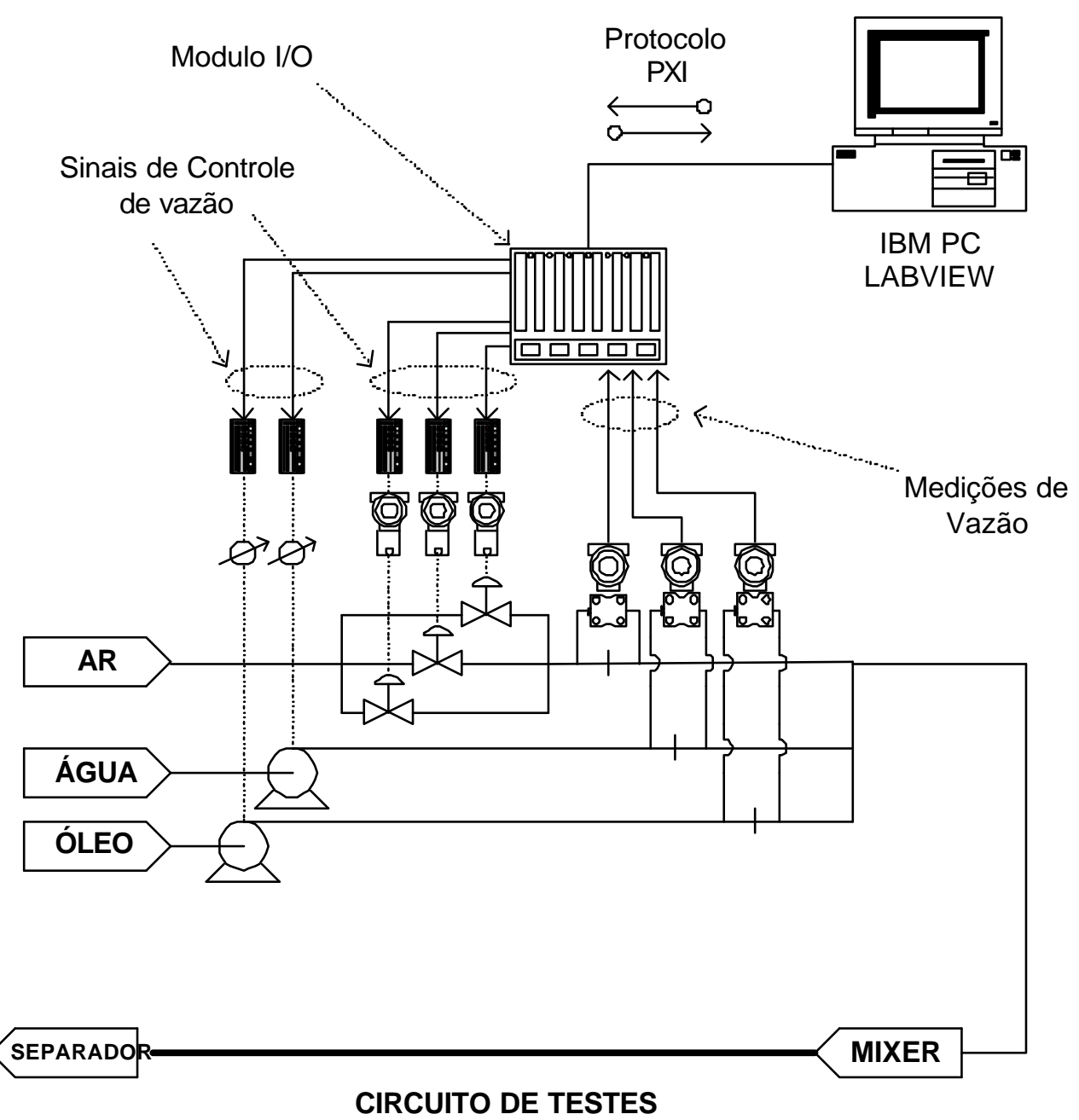

Figura 13: Instrumentação de operação da planta 
$\mathrm{Na}$ próxima seção trataremos da instrumentação desenvolvida para o procedimento experimental. 


\subsection{Instrumentação Experimental}

A seção de testes é instrumentada para fornecer sinais de pressão manométrica, pressão diferencial flutuante, sinais provenientes de sensores baseados em tecnologias de ultra-som, anéis capacitivos e indutivos entre outros.

O objetivo de construir um método de diagnóstico à partir de instrumentação disponível no mercado e de baixo custo - para tornar viável adequações à eventuais futuras instalações industriais - nos levou à escolha da aplicação do sinal de pressão flutuante. Para a aquisição e transmissão deste sinal utilizamos o modelo de sensor e transmissor de pressão diferencial Smar LD 400, um modelo de transmissor de resposta rápida.

O transmissor foi acoplado ao duto de acrílico, 6 metros a jusante do misturador. As tomadas de pressão foram posicionadas na parte mais baixa do duto, guardados $20 \mathrm{~cm}$ de distância de uma a outra, com a tomada de alta pressão à montante da de baixa (Figura 14). A conexão entre o duto e as tomadas do transmissor é feita através de flexíveis de 0.25 " de diâmetro e 25 $\mathrm{cm}$ de comprimento cada. Este tipo de montagem possibilita a medição de pequenas diferenças mesmo em dutos de alta pressão. A freqüência de corte do sistema transmissor + acoplamento foi medida e é de aproximadamente 15 $\mathrm{Hz}$.

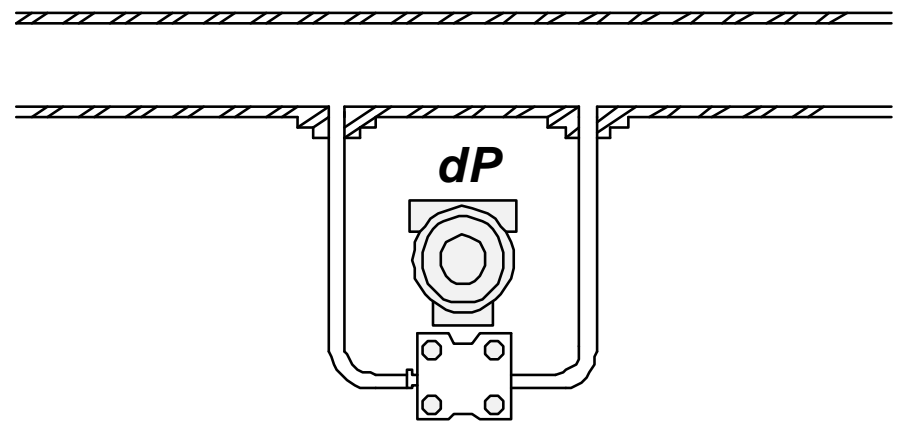

Figura 14: Montagem do transmissor de pressão na seção de testes. 
Da mesma maneira que os demais sinais, e utilizando a mesma interface de entrada / saída, este sinal tem sua aquisição e condicionamentos feitos no IBMPC pelo programa LabView. No próximo capítulo descreveremos os hardwares e softwares utilizados no processamento deste sinais. 


\section{DESENVOLVIMENTO EXPERIMENTAL}

É neste capítulo que trazemos de volta ao foco o objetivo principal do trabalho: o de se desenvolver uma solução para uso em tempo real. Esta diretiva nos levou à implementação de códigos proprietários, em detrimento da possibilidade de uso restrito de ferramentas de simulação matemática disponíveis no mercado. A performance de processamento exigida pelos cálculos efetuados em tempo real, em conjunto com as extensivas manipulações de grandes blocos de memória e a portabilidade dos códigos escritos também foram consideradas nesta decisão.

Os trabalhos foram feitos primeiramente na direção dos cálculos computacionais para o levantamento do mapa de escoamentos de Taitel \& Dukler, especificamente para o circuito do NETeF. Esta fase é descrita em detalhes na seção 2.2. Isto feito, seguimos com a implementação e testes das ferramentas de processamento dos sinais, experimentação e obtenção dos resultados. As seções seguintes descrevem estas fases em detalhes. 


\subsection{Desenvolvimento de ferramentas}

O software para diagnóstico de padrões de escoamento é descrito pelo diagrama de blocos e esquema apresentados nas Figuras 15 e 16 a seguir. $O$ sinal é adquirido, condicionado e discretizado, após o que, alimenta o módulo de cálculo dos coeficientes da distribuição tempo-freqüência de Gabor. Esta distribuição é então enviada como entrada do módulo de simulação da rede neural. Esta última, após convenientemente treinada é capaz de produzir o resultado final, que é o diagnóstico de um entre vários possíveis padrões de escoamento.

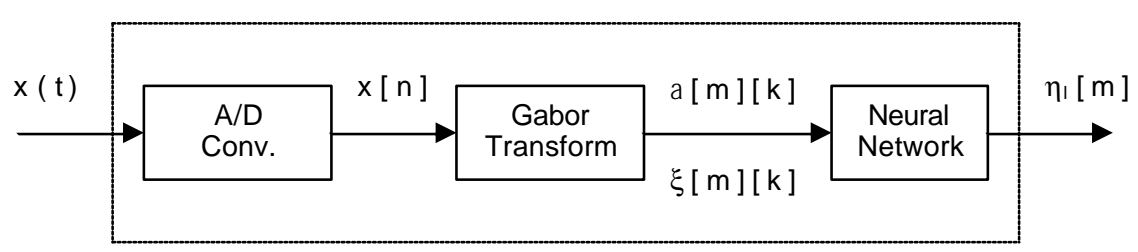

Figura 15: Diagrama de blocos da solução

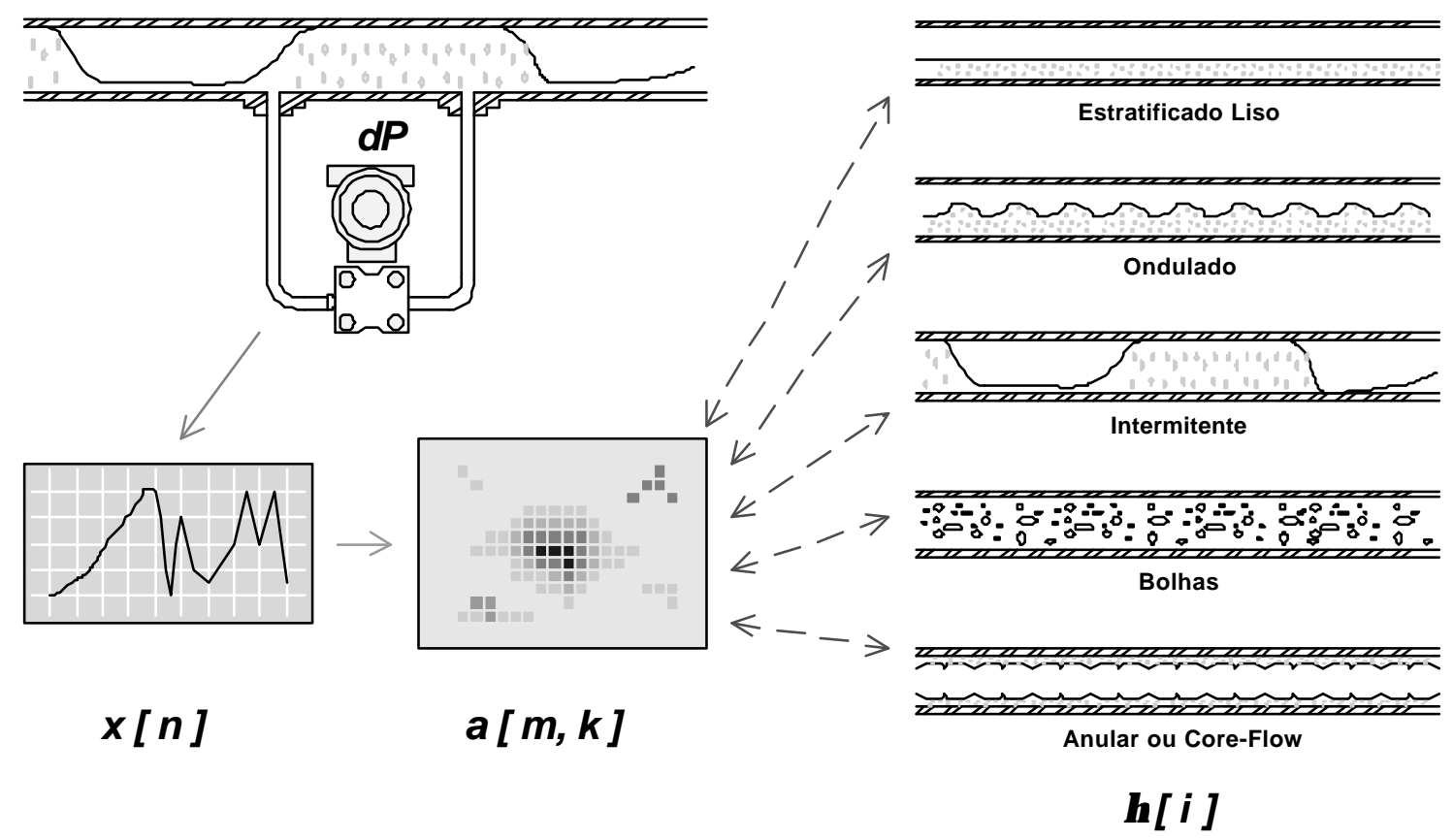

Figura 16: Diagrama esquemático da solução 
Estes processamentos demandam uma considerável performance computacional, o que nos fe z optar por distribuí-los em dois computadores.

O primeiro deles hospeda os programas escritos em LabView. Estes programas executam os módulos de operação e de aquisição e condicionamento de sinais. A figura 13 na seção 3.1 apresenta a arquitetura de aplicação deste módulo. A figura 17 a seguir apresenta a sua janela gráfica de operação.

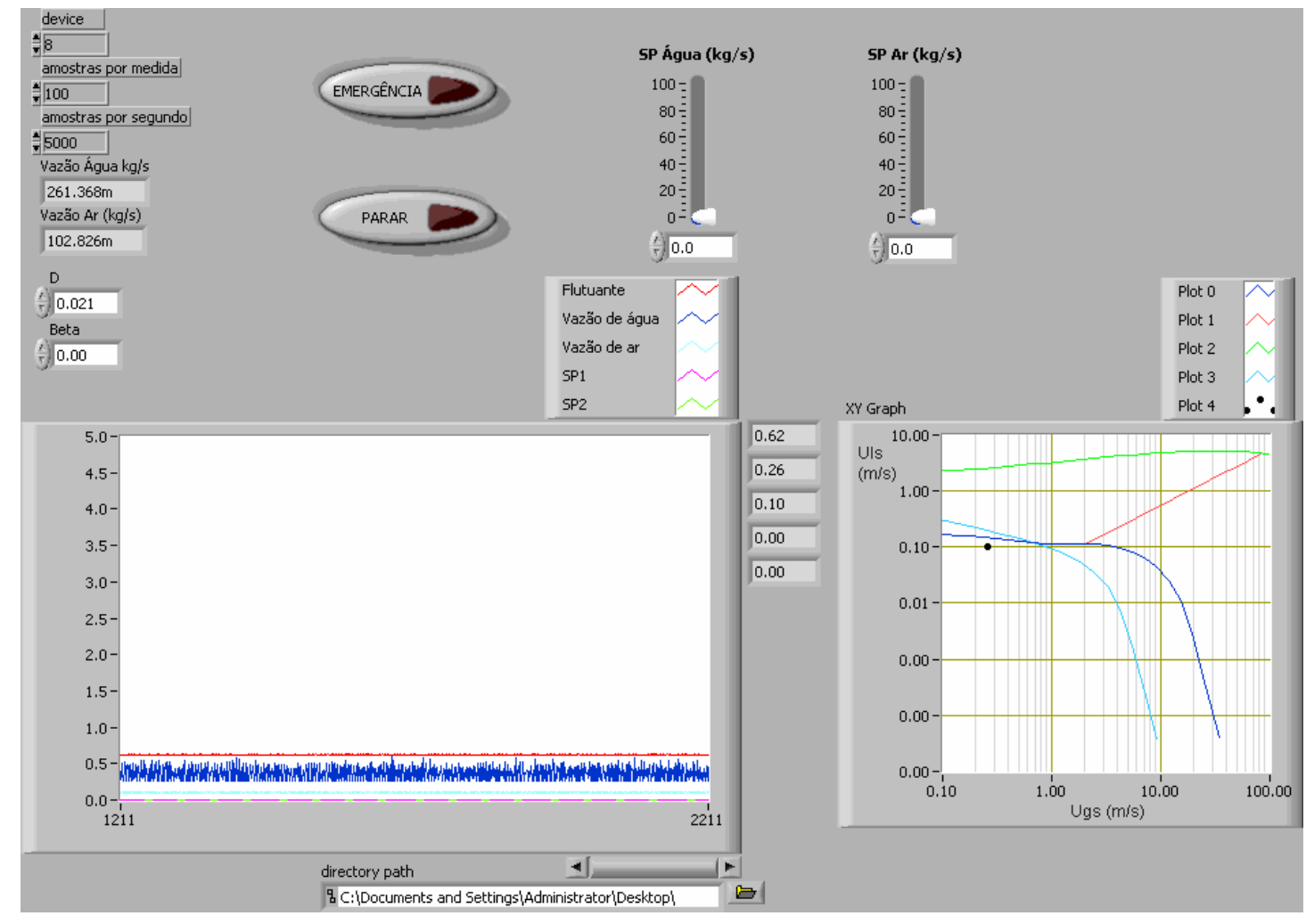

Figura 17: Janela LabView para a operação da planta e aquisição e condicionamento de sinais.

Através desta janela gráfica podemos arbitrar, interativamente através de botões e caixas de edição, os valores de referência, ou "set points", de vazão das fases gasosa e líquida, e também os parâmetros utilizados na aquisição e condicionamento dos sinais experimentais. Os gráficos de tendências, localizados na porção esquerda e inferior da janela, registram em tempo real as variáveis monitoradas e atuadas, e permitem avaliar a qualidade destas medições. Na porção direita e inferior da janela temos o mapa de escoamentos 
de Taitel \& Dukler, calculado para a seção de $30 \mathrm{~mm}$, à partir dos códigos apresentados na seção 2.2.3. Neste mapa, pode-se observar em tempo de execução, de forma qualitativa, a posição de um par de velocidades $U_{G}$ e $U_{L}$, no eixo $x$ e y respectivamente, relativamente às fronteiras de transição entre os diferentes padrões de escoamento. Também desenhado em tempo real, este mapa auxilia na operação do aparato de testes, habilitando-nos a estabelecer as trajetórias dos pontos $\left(U_{G}, U_{L}\right)$ de forma conveniente e segundo os objetivos da experimentação. No mapa de escoamentos, o ponto correspondente às vazões instantâneas de ar e de água é marcado dentro de uma das regiões correspondentes aos padrões de escoamento. Esta característica mostrourse de fundamental importância durante a fase de treinamento da rede neural, porque oferece informação importante, de forma visual e intuitiva, para a geração dos conjuntos de valores de entrada e saída da rede, utilizados nestes treinamentos. Baseado na visualização gráfica da localização dos pares $U_{G S} \mathrm{e}$ $U_{L S}$, pode-se gerar conjuntos voltados para um aprendizado tão generalizado ou especializado quanto se queira.

Os módulos seguintes, destinados à geração dos coeficientes da distribuição tempo-freqüência de Gabor e à execução das redes neurais, foram implementados numa segunda Workstation padrão IBM-PC, rodando uma versão de sistema operacional padrão UNIX. A linguagem de programação escolhida é a ANSI C padrão. As escolhas da linguagem e do sistema operacional, foram feitas desta forma em atendimento às necessidade de performance para processamento em tempo real, disponibilidade de ferramentas e características de portabilidade. Esta última, de vital importância, garante que sejam menores os esforços de migração dos códigos para outras plataformas, como por exemplo Controladores Lógicos Programáveis, Unidades Remotas de Processamento, ou até mesmo outro tipo de CPU e sistema operacional. Migrações deste tipo podem se tornar necessárias em aplicações futuras ou mesmo em uma eventual fase de industrialização do projeto.

As comunicações entre as duas estações foram implementadas utilizando protocolo TCP/IP sobre arquitetura de rede Ethernet É importante destacar 
que este meio de conexão entre as CPUs permite que o processamento seja distribuído local ou remotamente. A única necessidade é que os computadores estejam endereçados e conectados à uma rede TCP/IP válida. Adicionalmente, e para formarmos uma idéia da banda de comunicação necessária, consideremos o caso em que trafeguem dados x[n] à taxa de aquisição de 50 $\mathrm{Hz}$ através desta conexão. Temos portanto que fazer chegar à estação de processamento algo da ordem de 50 vezes 4 (número de bytes contidos numa variável de ponto flutuante) vezes 8 (oito bits por byte), ou 1600 bits por segundo. A utilização de outros meios de comunicação pode também ser considerada, como por exemplo, rádio ou par trançado via padrões de comunicação serial RS-232 ou o bem conhecido na indústria RS-485. A figura a seguir descreve a arquitetura geral do sistema.

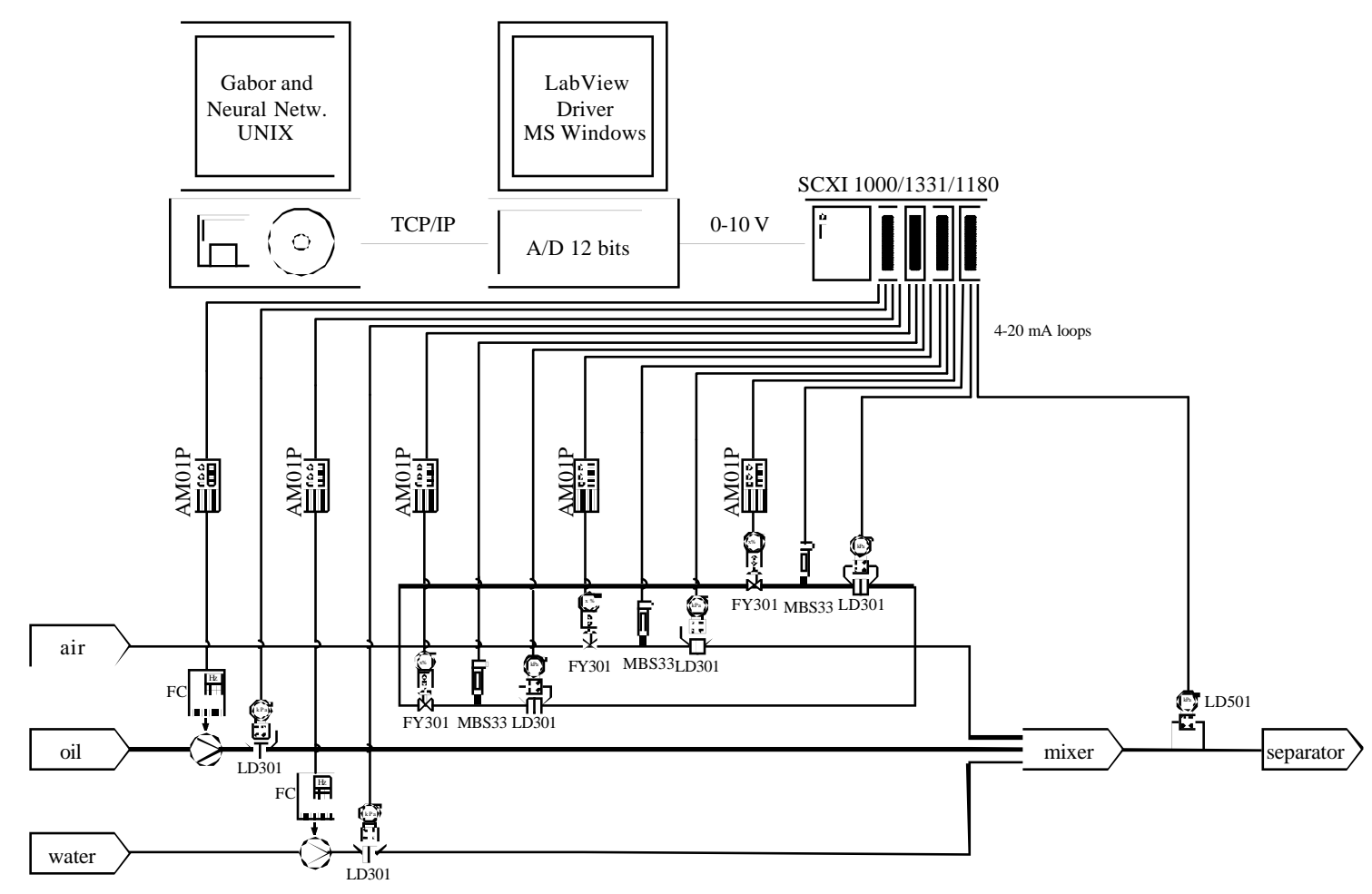

Figura 18: Arquitetura geral do sistema

Se já temos o módulo de aquisição e condicionamento de sinais definido, o escopo do projeto agora é a construção de um programa para rodar em tempo real que, a cada ciclo, adquira os dados de pressão flutuante $x[n]$, amostrados 
e condicionados pelo Labview, calcule os coeficientes da distribuição tempofreqüência através da transformada de Gabor, execute o módulo simulador da rede neural artificial e apresente graficamente as variáveis processadas e os resultados obtidos. As figuras 19 e 20 descrevem um diagrama de fluxo dos dados e um diagrama hierárquico de funções respectivamente. Estes diagramas dão uma idéia geral de como o software foi estruturado e construído.

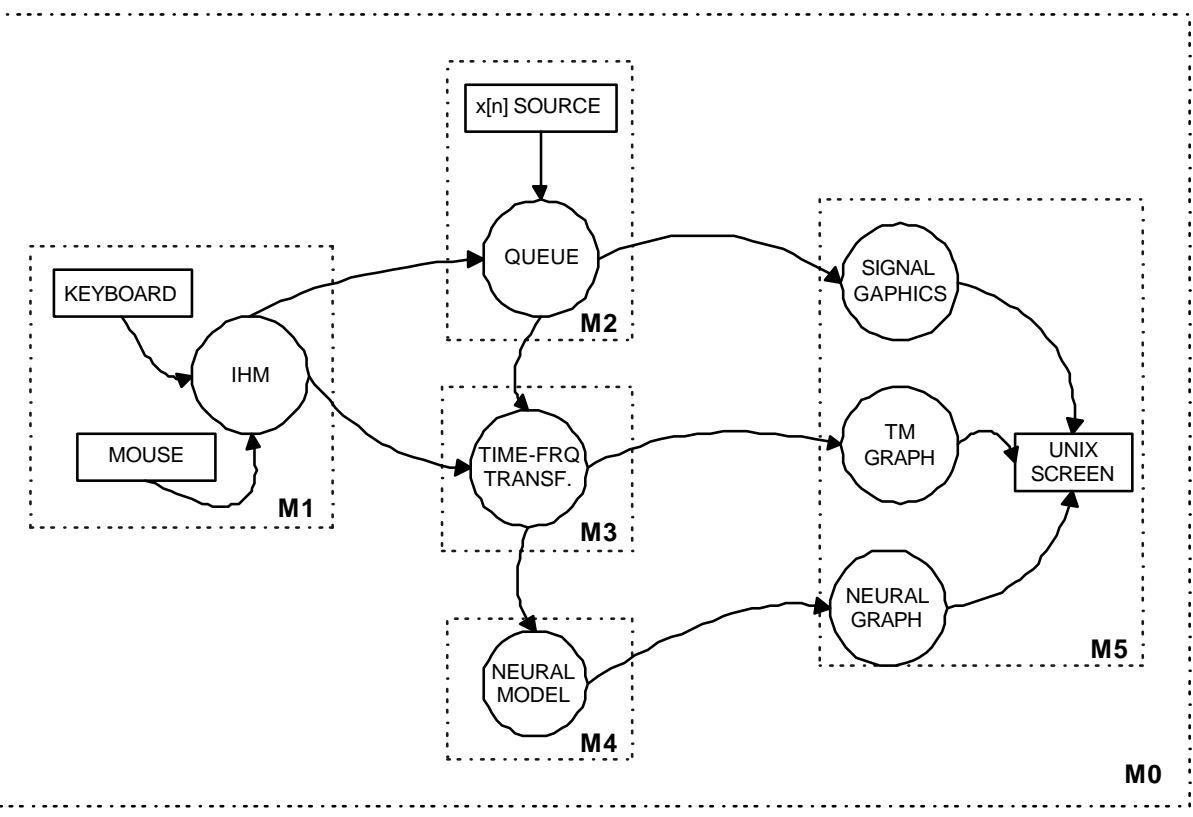

Figura 19: Diagrama de Fluxo de Dados do Sistema

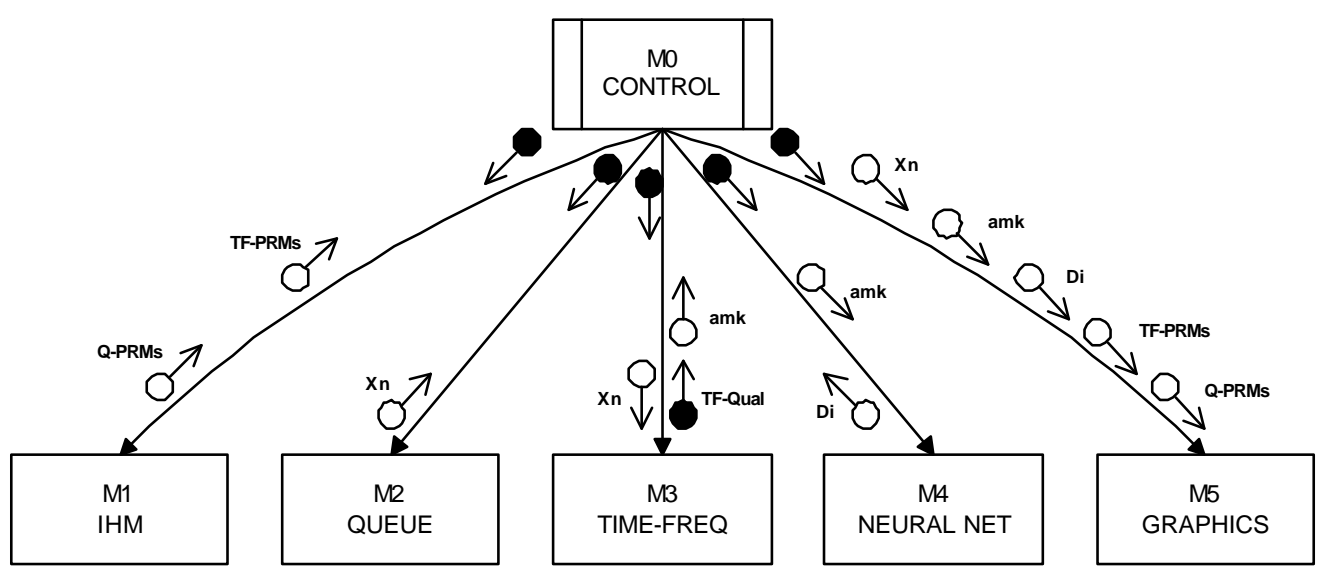

Figura 20: Diagrama Hierárquico de Funções do Sistema 


\subsubsection{Desenvolvimento do módulo de cálculo dos coeficientes tempo- freqüência - Transformada de Gabor}

Aqui descrevemos a implementação de um módulo de programa escrito em ANSI C, para execução em linha e em tempo real, que recebe como entrada um vetor de valores discretos dos gradientes de pressão x[n]. Estes valores são adquiridos e condicionados pelo módulo Labview a uma determinada e configurável freqüência de aquisição f. A aplicação da transformada de Gabor aos vetores $x[n]$ é o objetivo deste módulo. $O$ resultado da execução deste trecho de código é a geração da matriz $a_{m, k}$ de coeficientes tempo-freqüência de Gabor. A Equação (42), na seção 2.2 estabelece esta transformada.

A execução computacional deste equacionamento demanda processamento intensivo de integrações numéricas, somatórias e operações baseadas em números complexos, tornando necessária a implementação de uma biblioteca básica de operações numéricas. Escrevemos essa biblioteca à partir dos conceitos e exemplos apresentados por Press (1999) em "Numerical Recipes in C". Outro trecho de código importante foi desenvolvido para o gerenciamento das filas de entrada (LANGSAM et al., 1999) dos dados $x[n]$. É neste último trecho de código que fazemos gerenciamento das funcionalidades de tempo real da transformada.

Após os dados de entrada $x[n]$ serem recebidos da fila de entrada é então disparada a execução do código que calcula os coeficientes tempo-freqüência $a_{m, k}$ da transformada de Gabor. Este código é apresentado no seguinte trecho:

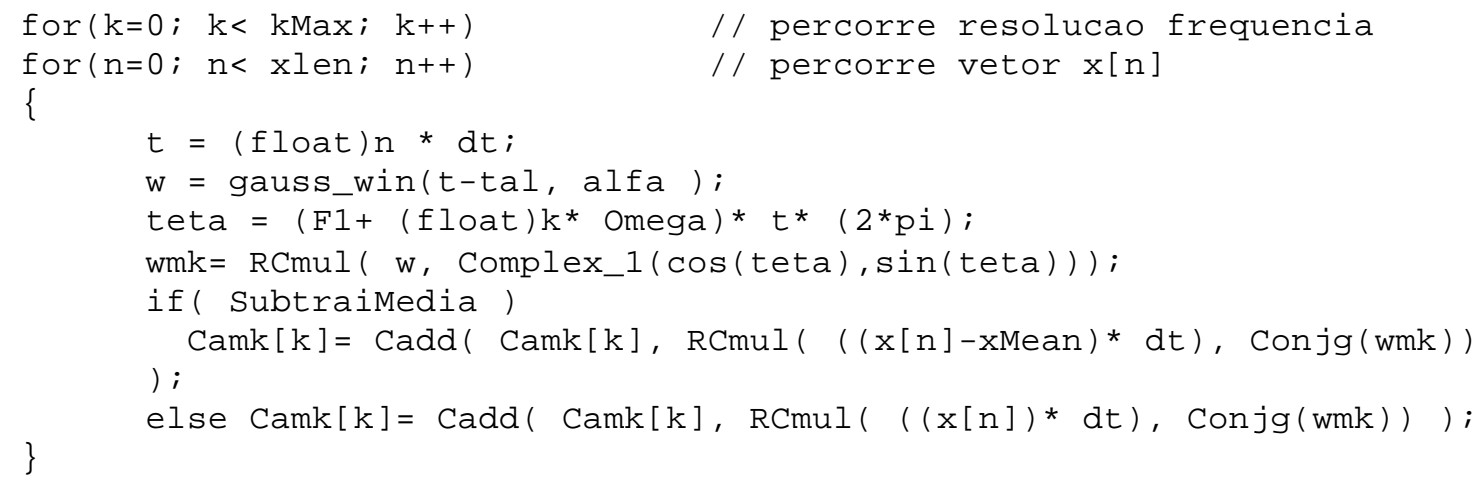


Os trechos de programa para controle da execução foram então escritos, de maneira que os parâmetros $f$ (freqüência de aquisição), $\alpha$ (velocidade de decaimento da janela Gaussiana), $T$ (Resolução no tempo), $\Omega$ (resolução em freqüência) e o range (intervalo de freqüências a ser computado) possam ser ajustados através de janela gráfica e em tempo de execução do programa.

A Figura 21 apresenta esta janela e os seus parâmetros de controle. Nesta janela podemos também observar uma caixa de ajuste para a freqüência de testes, que é apresentada no gráfico imediatamente abaixo, seguida de sua modulação pela janela gaussiana deslizante - estas simulações orientam o usuário na determinação de valores coerentes para os parâmetros da transformada de Gabor. Um segundo gráfico, abaixo, apresenta a resolução do plano tempo-freqüência no espaço de transformação delimitado pela gaussiana. Ambos os gráficos são redesenhados automaticamente quando da mudança de algum dos parâmetros e, centrados em torno do tempo $t=0$, representam graficamente o espaço matemático sobre o qual a transformada será aplicada.

Botões na base da janela controlam a execução do programa em termos globais. Os botões $N N$ e TF ativam a execução da rede neural e da transformada de Gabor, respectivamente. Run ativa ou desativa a execução do programa como um todo. Os demais são utilizados para posicionamento de dados na fila de entrada, envio e atualização de parâmetros de operação e finalização do programa. 


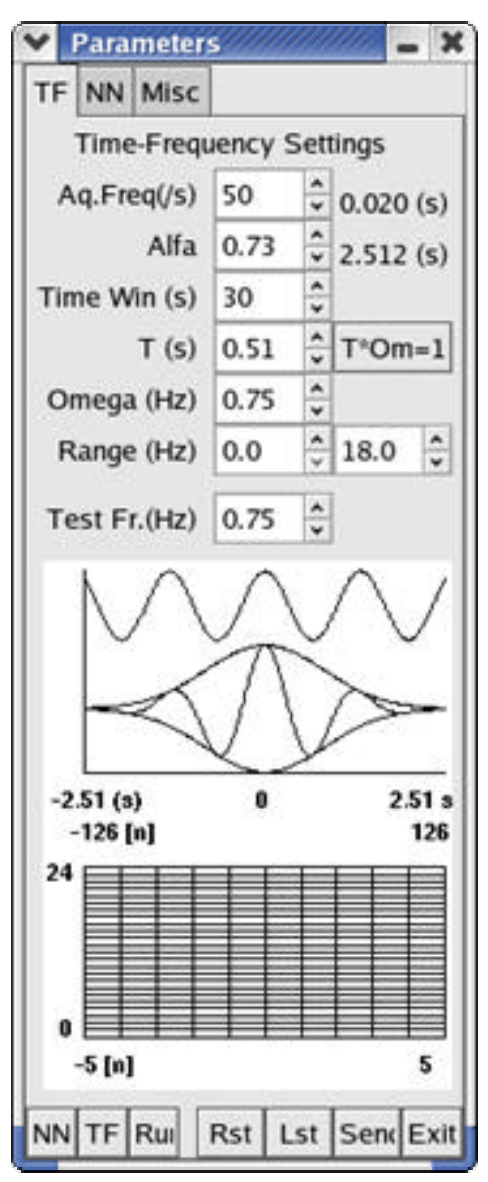

Figura 21: Janela de parâmetros do módulo de execução e controle da transformada de Gabor. Pode-se arbitrar os parâmetros de aquisição e processamento da transformada. Áreas gráficas permitem visualização interativa da modulação entre a janela analisadora gaussiana e a freqüência de teste arbitrada.

Uma importante funcionalidade disponível nesta janela de controle que podemos destacar é a área que apresenta o resultado gráfico da modulação entre a janela analisadora gaussiana adotada e uma dada freqüência de teste. Para que a janela analisadora seja efetiva em todo o espectro analisado, o parâmetro $\alpha$ (que determina o tempo de decaimento da gaussiana) deve ser tal que a envoltória produzida seja suficiente para acomodar alguns ciclos da menor freqüência analisada, ou seja, o limite inferior do range. Ainda na figura 21, na parte inferior, podemos ver o quadriculado que simula as resoluções no tempo e na freqüência, nos eixos $x$ e y respectivamente. Estas duas áreas gráficas são atualizadas interativamente, após cada comando de configuração entrado pelo usuário, e permitem prever e sintonizar o comportamento do módulo da transformada de Gabor. 
Para a visualização dos resultados da transformada foi implementada uma outra janela gráfica, que é atualizada a cada ciclo de execução do software. Esta janela é apresentada na figura 22. Em sua região superior, temos 0 gráfico de histórico do sinal de pressão $\mathrm{dP} / \mathrm{dx}$ no tempo t nos eixos y e $\mathrm{x}$ respectivamente. $\mathrm{O}$ tempo $\mathrm{t}=0$ corresponde à extremidade direita do eixo horizontal $e$, neste exemplo de configuração, $t=30$ segundos (passados) corresponde à extremidade esquerda e $\mathrm{n}$, que é o número de amostras adquiridas durante este período, é igual a 1500. A escala de pressão, no eixo vertical, é proporcional a à faixa de calibração do LD400, que neste caso é de 0 a $200 \mathrm{mmH}_{2} \mathrm{O}$. Noutro gráfico, na região inferior da janela, são apresentados os resultados da transformada de Gabor deste sinal. Neste gráfico, que é uma representação dos coeficientes da distribuição tempo-freqüência, temos o índice $m$ relacionado à escala de tempo e representado na escala horizontal do gráfico. Da mesma forma que no gráfico de pressão, $t=0$ corresponde ao momento atual e está posicionado na extremidade direita do gráfico. Neste exemplo, $\mathrm{m}=60$ equivale ao período de 30 segundos, com resolução $\mathrm{T}=0.5 \mathrm{~s}$, e está posicionado na extremidade esquerda do gráfico. No eixo vertical temos a representação da escala de freqüências presentes no sinal. Neste exemplo, a transformada de Gabor tem seus parâmetros tais que geram uma escala de análise de 0 a $18 \mathrm{~Hz}$, com resolução $\mathrm{O}=0.5 \mathrm{~Hz}$. Tem-se então uma matriz de pontos $\mathrm{a}[\mathrm{m}, \mathrm{k}]$, onde, para cada $\mathrm{m}$, que representa um intervalo de tempo (0.5 segundos neste caso), tem-se um vetor de espectro de densidade de energia presente no sinal naquele dado intervalo de tempo. No gráfico inferior à esquerda temos a representação deste espectro para $t=0$, ou seja, calculado pela mais recente execução da transformada sobre os valores de pressão adquiridos do processo. $O$ gráfico localizado na área superior esquerda da janela representa a curva de Gauss do sinal de pressão de entrada, representando a sua média e desvio padrão, calculados à partir $x[n]$ no intervalo de tempo sobre o qual é aplicada a transformada durante último ciclo de execução. 


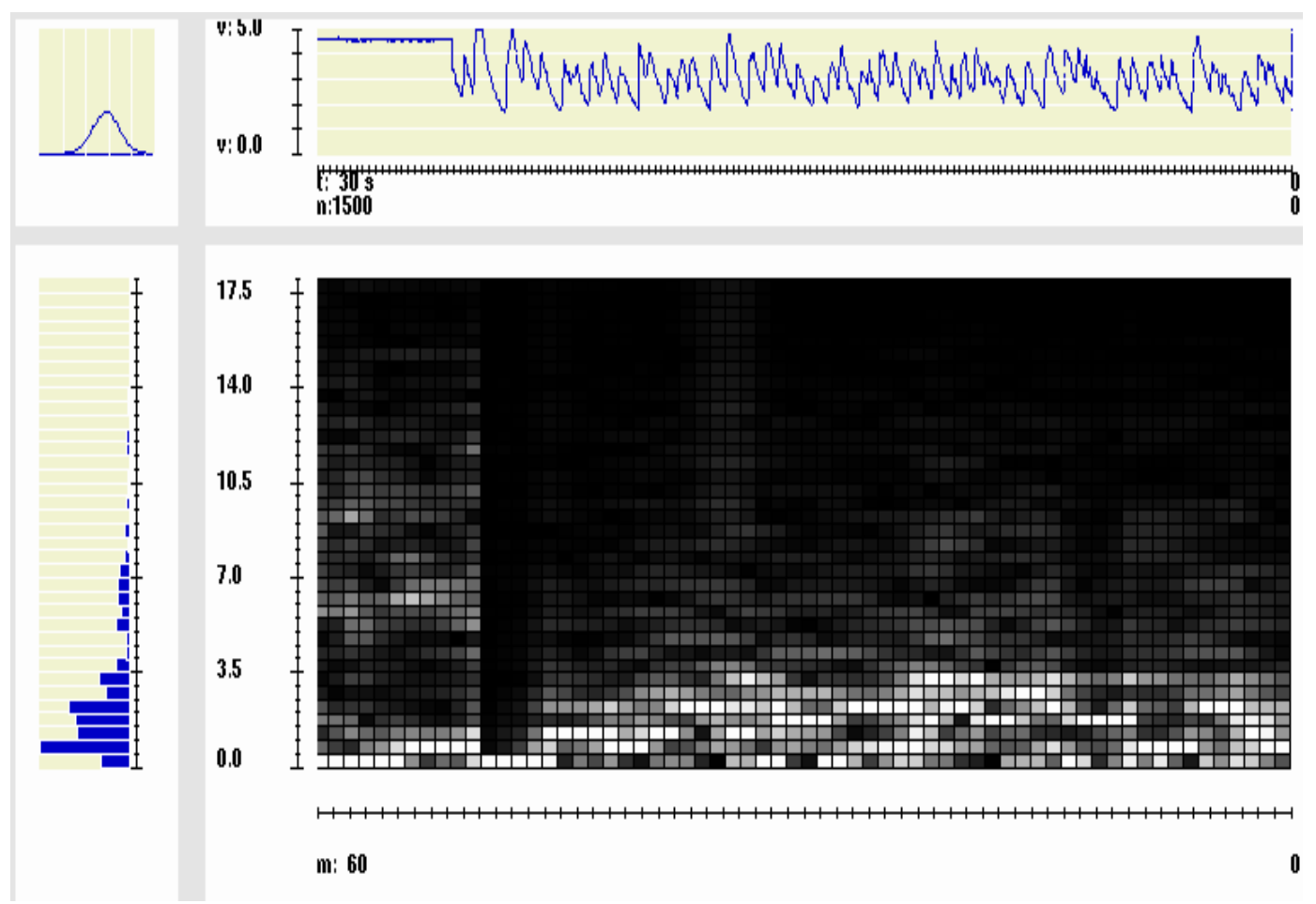

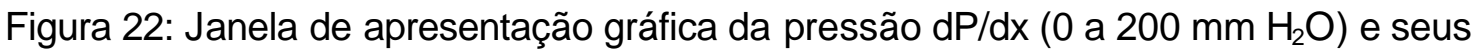
respectivos coeficientes tempo-freqüência, para uma janela de tempo de 30 segundos, $\mathrm{T}=0.5 \mathrm{~s}$,range de $0 \mathrm{a} 18 \mathrm{~Hz}$ e $\Omega=0.5 \mathrm{~Hz}$.

Estes gráficos são animados através de uma função de scroll, que produz o deslizamento horizontal concomitante do gráfico dos sinais de pressão e do gráfico da respectiva distribuição tempo-freqüência, da direita para a esquerda, e tornam a interface bastante intuitiva e didática, conforme ilustrado na figura 22. Ela funciona como uma janela de histórico do sinal e de seus espectros de densidade de energia registrados ao longo do tempo. É através desta janela que o usuário pode avaliar os sinais e os resultados obtidos após seus processamentos. Desta forma pode-se ajustar os parâmetros do sistema interativamente até que se obtenha os melhores resultados. Isto facilita a análise qualitativa da matriz $\mathrm{a}[m, k]$, previamente ao processo de alimentação e treinamento do módulo de das redes neurais. 


\subsubsection{Desenvolvimento do módulo de simulação de redes neurais}

Neste módulo, a variável de entrada é uma matriz $\mathrm{a}[\mathrm{m}, \mathrm{k}]$, onde $\mathrm{m}$ é o número de espectros com resolução $\mathrm{T}$ consecutivos no tempo, $\mathrm{k}$ é o número de intervalos com resolução $\Omega$ no espectro de freqüências. $\mathrm{k} / \Omega$ é portanto 0 intervalo de freqüências analisadas pela transformada de Gabor. A cada ciclo de execução do código essa matriz é atualizada em esquema FIFO - "first in, first out". Uma nova coluna - o útimo espectro momentâneo calculado - é adicionada e a m-ésima é descartada da matriz de entrada. Durante fase de treinamento da rede neural, a matriz $a[m, k]$ é associada a um padrão de escoamento especifico e bem conhecido. Estas informações constituem os pares de padrões de entrada e saída da rede e são utilizados no seu treinamento. Após convenientemente treinada, em tempo de execução a rede neural produz o diagnóstico do padrão de escoamento à partir da matriz a[m,k]. Esta arquitetura é descrita pela figura 23 a seguir.
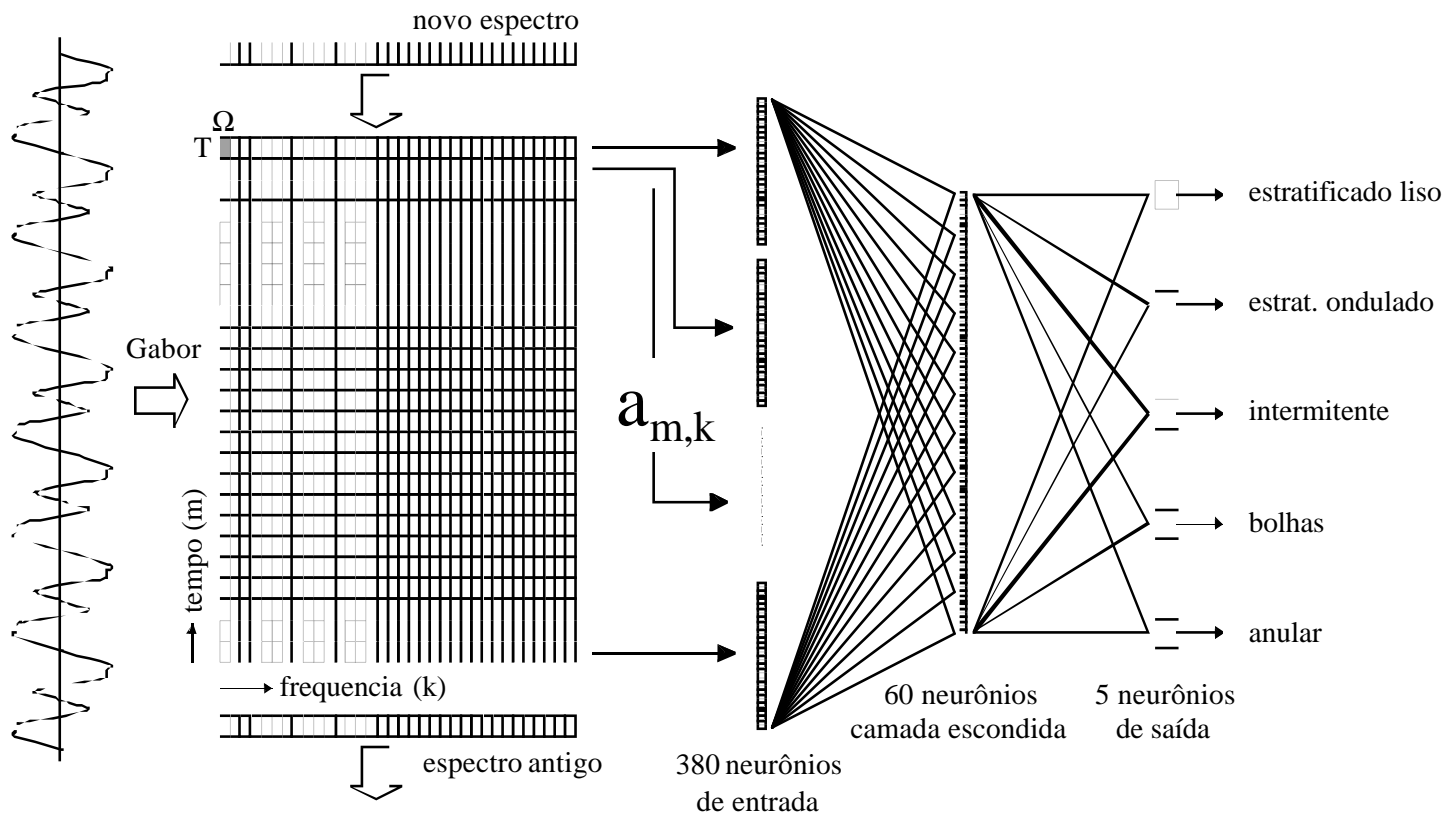

Figura 23: Arquitetura de alimentação da rede neural artificial 
O processo de treinamento da rede consiste basicamente na construção dos pares de entrada / saída $\left(a_{m, k_{i}}^{P}, \sigma_{i}^{P}\right)$, onde para cada entrada, que aqui pode ser visualizada como uma porção - a mais recente - do plano tempo-freqüência é atribuída um vetor equivalente de saída desejada, correspondente ao padrão de escoamento observado. Para controlar tal processo implementamos uma janela gráfica à partir da qual o usuário "informa" ao sistema qual é o padrão de escoamento fisicamente presente na tubulação (Figura 24).

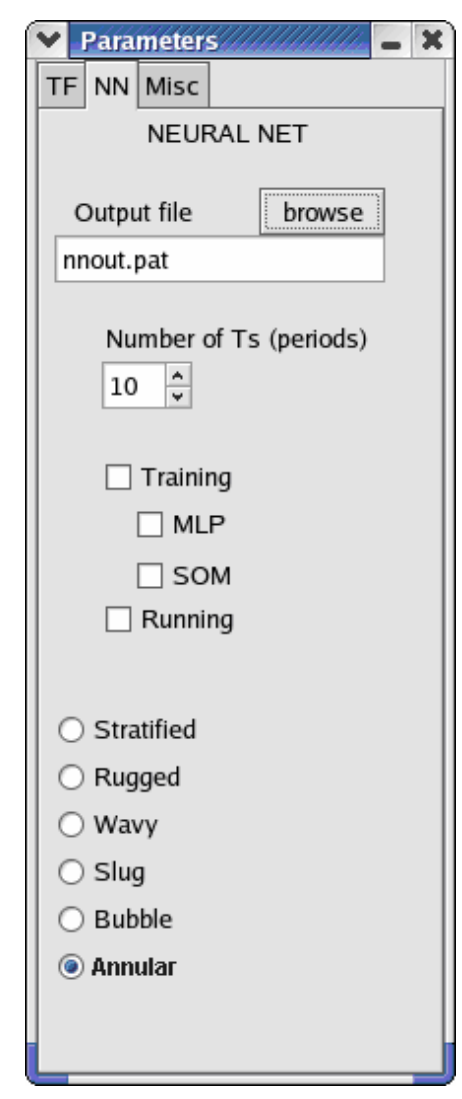

Figura 24: Janela de ajuste dos parâmetros da rede neural

Após a construção os conjuntos de pares para treinamento, segue-se o projeto e implementação da arquitetura da rede neural, onde especificamos suas características como o número de neurônios nas camadas de entrada, número de camadas intermediárias, dimensionalidade, número de neurônios em cada camada intermediária e o número de neurônios da camada de saída. Esta fase e o treinamento subseqüente são ambos efetuados através do simulador de redes neurais SNNS - "Stutgart Neural Network Simulatior" (http://wwwra.informatik.uni-tuebingen.de/SNNS), em sua versão 4.3 para sistema 
operacional Unix e ambiente gráfico de janelas "X Window". Após efetuado o treinamento - que pode ser iterativo através das janelas gráficas do sistema (Figura 25) ou em processo de batelada executadas em background - a rede e os respectivos vetores de "bias" e pesos, $b_{i, j}$ e $w_{i, k}$, são então ligados aos demais módulos para compor o aplicativo de diagnóstico em tempo real. À partir desta configuração, com a arquitetura da rede neural definida, torna-se possível o re-treinamento "on-line" da rede. Para isto seria necessária a implementação de alguns programas batch e lógicas adicionais, cuja demanda de esforços seria perfeitamente viável em uma eventual industrialização do projeto.

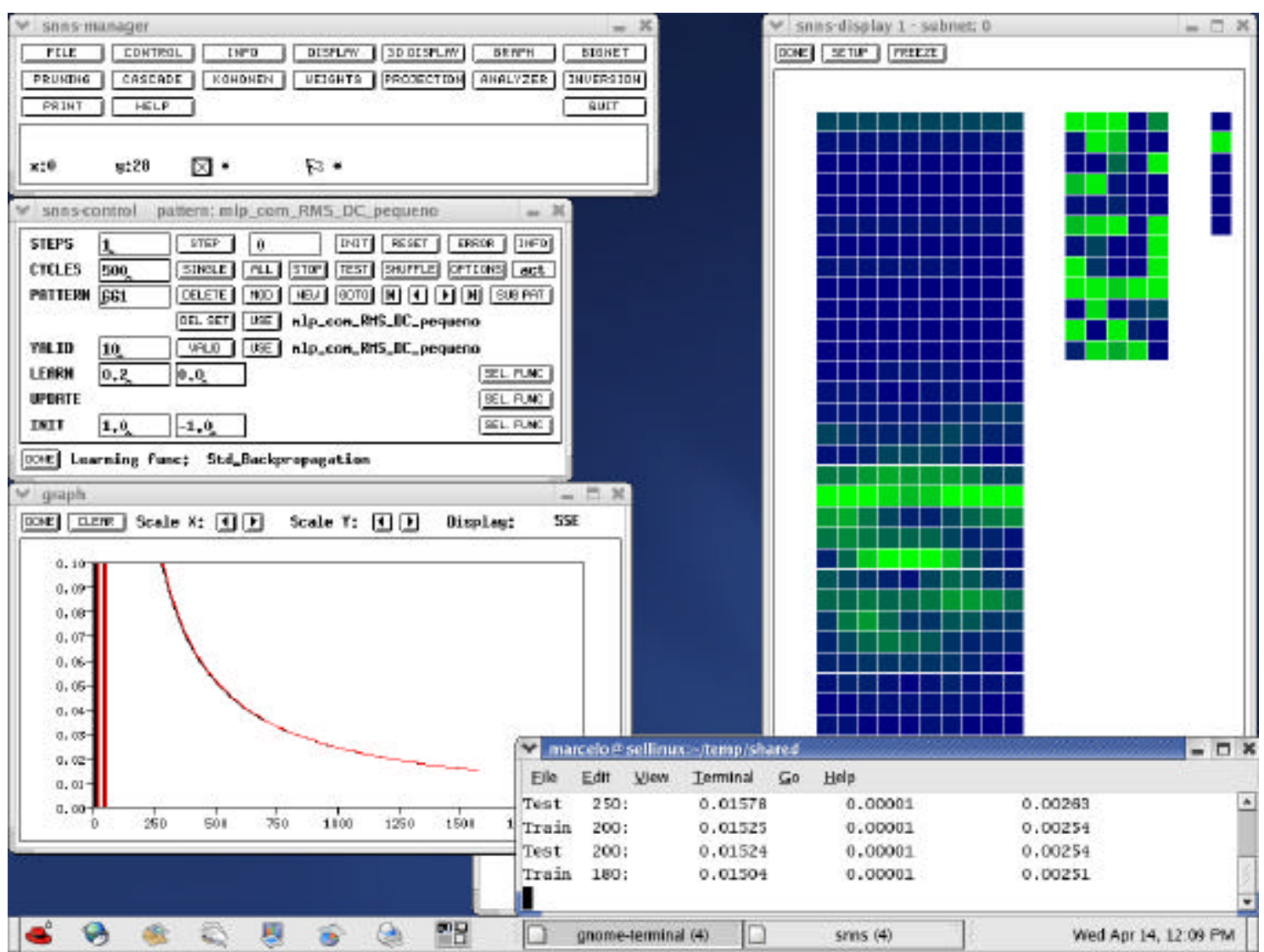

Figura 25: Ambiente operacional do SNNS, com as janelas de controle, treinamento, gráfico de convergência, arquitetura e níveis de disparo de cada neurônio. 


\subsubsection{A solução integrada}

Realizadas as fases anteriormente descritas, esta seção descreve a integração de todos os módulos escritos em uma única aplicação, capaz de atender ao objetivo do trabalho, que é o de identificar "on-line" o padrão de escoamento bifásico horizontal à partir dos sinais de pressão $\mathrm{dP} / \mathrm{dx}$ adquiridos diretamente do escoamento. $O$ encadeamento dos módulos de aquisição e condicionamento de sinais, da transformada de Gabor e da rede neural artificial treinada produziu como resultado a solução capaz de executar esse diagnóstico. Para os testes, pudemos produzir estes padrões fisicamente e de maneira inequívoca na seção de testes do laboratório.

Para a visualização em tempo de execução destes resultados, foi adicionado à parte inferior da janela de interface descrita na seção 4.1.1 (Figura 22) um gráfico para a apresentação dos valores dos vetores de saída da rede neural $\eta_{i}$ para um dado ciclo de cálculo m. Esta janela (Figura 26) passou a integrar então a visualização dos gráficos de tendência dos sinais de gradientes de pressão, seus respectivos coeficientes tempo-freqüência e as saídas do simulador de redes neurais, i.e., a identificação do padrão de escoamento. Neste último, as linhas em verde correspondem aos padrões de escoamento desativados pela rede neural, que são os que a rede inferiu não estarem presentes no momento de sua análise. Os valores em vermelho por sua vez representam os estados que a rede inferiu estarem presentes naqueles momentos. Da mesma forma que os demais gráficos de tendência, este armazena também um histórico animado em tempo real onde é possível inclusive observar as transições entre um padrão de escoamento e outro. É importante destacar que a expressão "tempo real" é usada no sentido de que o diagnóstico é feito continuamente, porém, há um atraso entre o fenômeno físico e o seu diagnóstico. Este atraso é inerente à análise de tempo freqüência e é proporcional à extensão da janela de análise (definida pelo parâmetro $\alpha$ ) na equação (42). Tipicamente em torno de 2 ou 3 segundos, este atraso no diagnóstico é aceitável se considerarmos a dinâmica destes escoamentos. A figura 26 apresenta como exemplo os resultados obtidos pelo sistema no 
período em que houve uma transição entre o padrão de escoamento estratificado liso e estratificado ondulado. O respectivo tempo de atraso entre as mudanças no sinal e a mudança no diagnóstico pode ser notado.

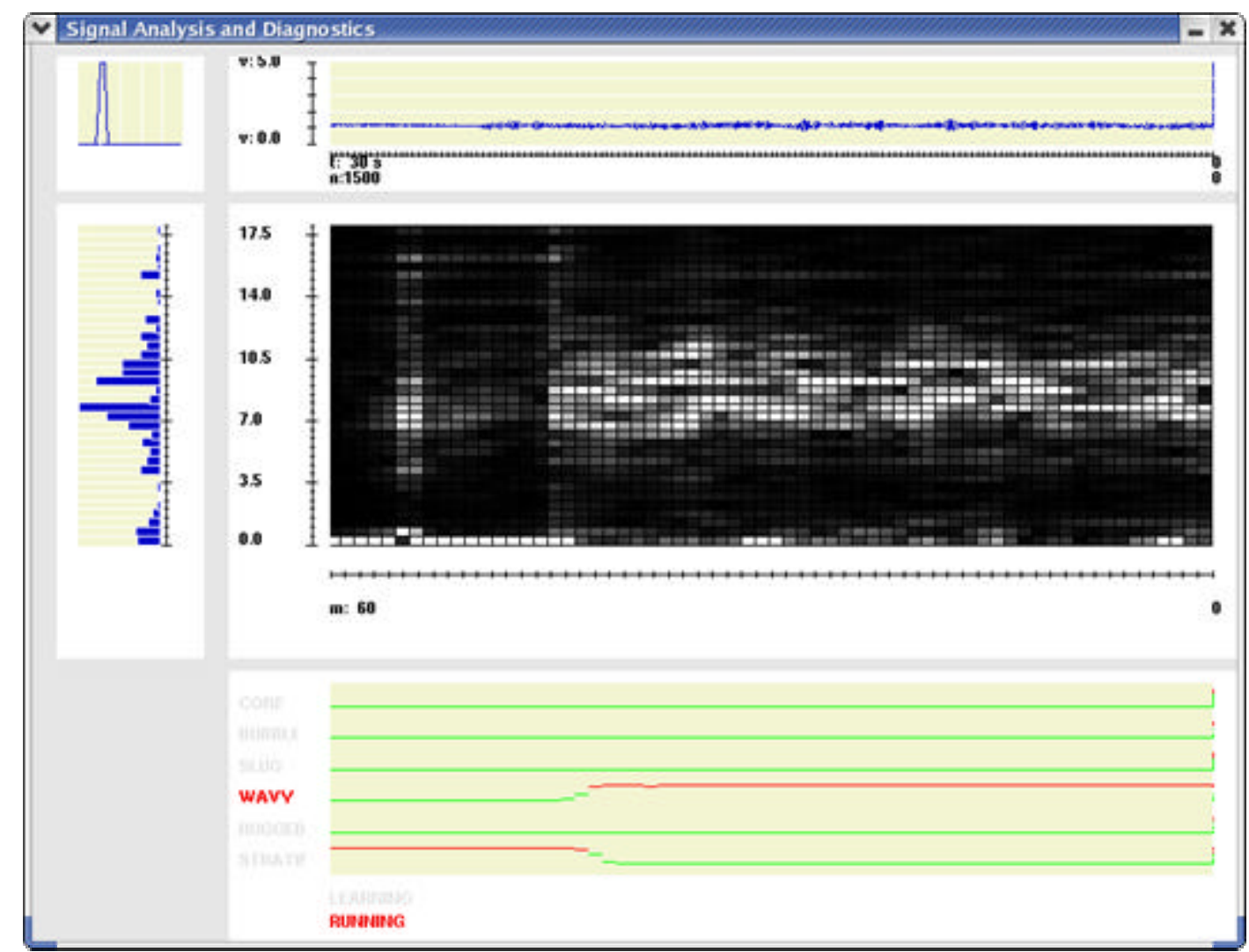

Figura 26: Janela de identificação do padrão de escoamento. De cima para baixo: pressão $\mathrm{dP} / \mathrm{dx}$, coeficientes tempo-freqüência e as saídas da rede neural (em verde, e em zero quando inativas e em vermelho, e em 1, quando ativadas).

Além da visualização "on-line" o sistema gera alguns arquivos com os históricos dos resultados obtidos no tempo. Estes arquivos serão então utilizados para uma análise mais minuciosa dos resultados obtidos nas próximas seções. 


\section{TESTES EXPERIMENTAIS}

Os conjuntos de entradas e saídas da rede neural foram gerados à partir de vários sinais de pressão flutuante adquiridos na seção de testes do NETeF. Para a constituição de conjuntos representativos de cada um dos padrões de escoamento, estabelecidos visualmente, foram geradas várias combinações de velocidades superficiais de ar e água, os pares $\left(U_{G S}, U_{L S}\right)$, de forma a abranger as possíveis existências de sub-padrões desconhecidos. Ocorrências deste tipo são comuns no padrão de escoamento intermitente, conforme descrito por Klein et al. (2004).

A aquisição foi feita a $50 \mathrm{~Hz}$, durante um período mínimo de 20.48 segundos, que correspondem a um mínimo de 1024 amostras. Alguns escoamentos bifásicos são caracterizados por freqüências muito baixas, por exemplo os intermitentes de baixa velocidade, nos quais a freqüência de intermitência pode ser tão baixa quanto $0.25 \mathrm{~Hz}$, em linhas de 50 milímetros de diâmetro. Estas freqüências demandaram períodos de aquisição maiores, de até 16384 amostras, ou 327.7 segundos. Trechos destes sinais foram utilizados para o treinamento da rede. Posteriormente a rede foi testada "on-line" no circuito experimental do NETeF para a verificação qualitativa do seu desempenho, que, conforme se pode inferir das figuras 29,30 e 31 , é bastante satisfatório. A avaliação quantitativa do desempenho da rede foi feita com uma nova base de sinais, amostrados de forma a representar todos os padrões de escoamento, e é discutida no próximo capítulo.

A figura 27 mostra a região do mapa de Taitel \& Dukler à partir da qual os sinais foram adquiridos, delimitada pelas vazões máximas alcançadas pela bomba e pelo compressor. Os limites inferiores - indicados pelas linhas tracejadas - estão associados à estabilidade de operação da planta em regime permanente e estabelecem as mínimas vazões possíveis para a manutenção deste critério. Esta estabilidade está relacionada com a resolução dos medidores de vazão e dos algoritmos PID implementados nas malhas de controle. 


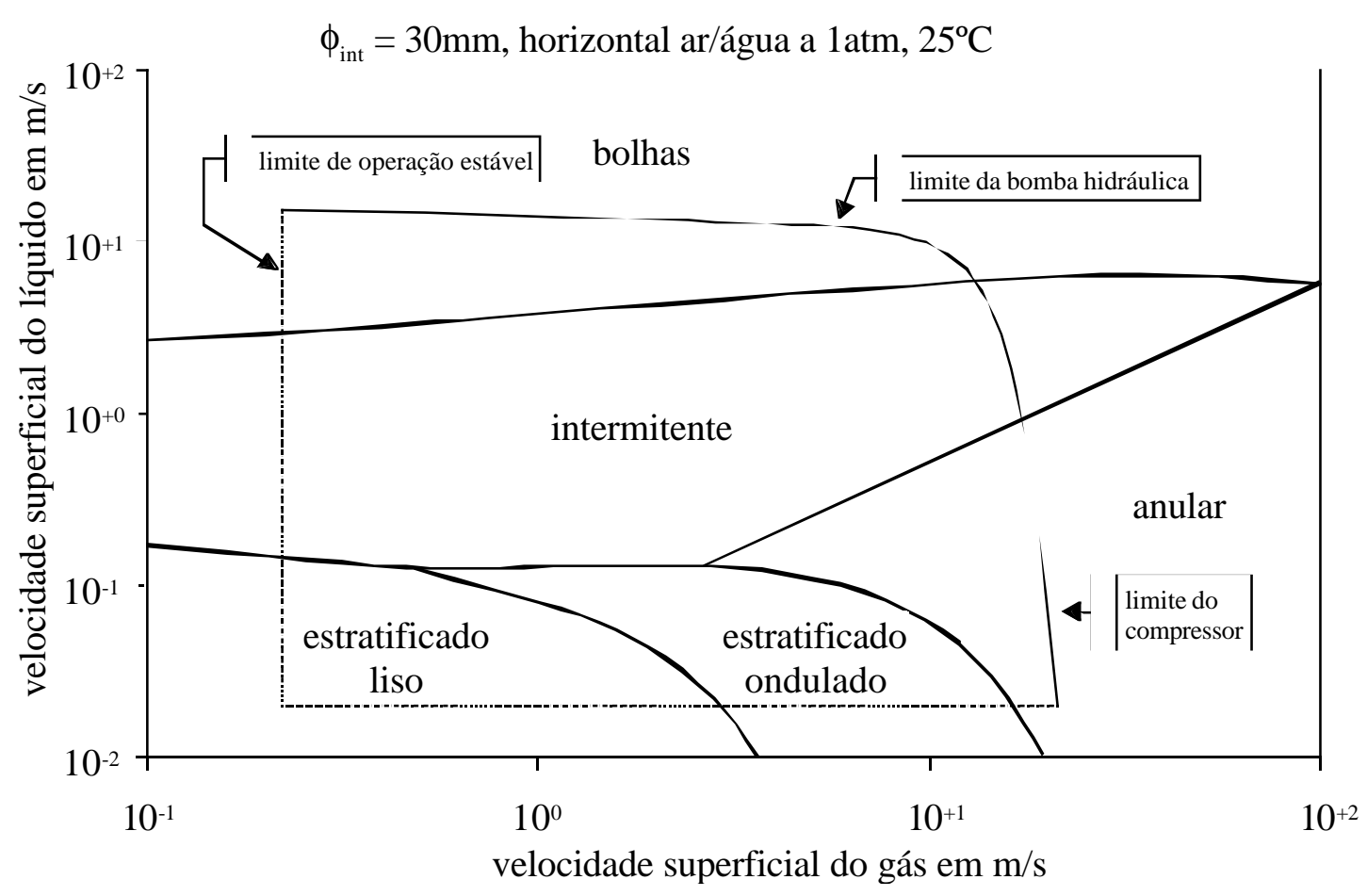

Figura 27 : Mapa de Taitel \& Dukler calculado para a seção de testes do NETeF. A região tracejada delimita o espaço de amostragem e operação efetiva da planta, com seus limites definidos pela potência do compressor e pela região de operação estável das bombas.

Os parâmetros intrínsecos da transformada de Gabor dos sinais de pressão foram determinados após varias análises exploratórias, durante as quais otimizamos a performance do sistema, considerando a eficiência computacional e o percentual de identificação correta dos padrões de escoamento. Mais especificamente, uma partição redundante do plano tempofreqüência foi escolhida, com $\beta=8, T=0.5 \mathrm{~s}$ e $\Omega=1.57 \mathrm{rad} / \mathrm{s}$ (=0.5 Hertz). A velocidade de decaimento da janela Gaussiana foi ajustada para $\alpha=0.73 \mathrm{~s}^{-1}$, o que resultou em coeficientes $10\left(\mathrm{~N}_{1}\right)$ e $36\left(\mathrm{~N}_{2}\right)$ nas direções do tempo e freqüência, respectivamente. O número total de coeficientes tempo-freqüência dado pela Equação (41) equivale ao número de neurônios na camada de entrada da rede neural, e resultou em 360, ou seja, 10 espectros instantâneos com 36 amplitudes de freqüência cada. 
Os pares de entrada-saída $\left(a_{m, k_{i}}^{P}, \delta_{i}{ }^{P}\right)$ da rede neural foram gerados de forma interativa e on-line na seção de testes. Assim foi possível a formação de um conjunto para treinamento generalizador, com aproximadamente 20 minutos de sinais para cada um dos padrões de escoamento. Várias combinações de vazões $U_{G S}$ e $U_{L S}$, representativos de um mesmo padrão, foram gerados para garantir esta generalização. O treinamento da rede neural artificial foi feito então, de forma supervisionada, através do aplicativo SNNS em aproximadamente 2000 épocas, necessárias para se atingir um erro igual a 0.01, conforme o estabelecido pela Equação (45), em versão normalizada. A figura 28 apresenta o gráfico de convergência do erro.

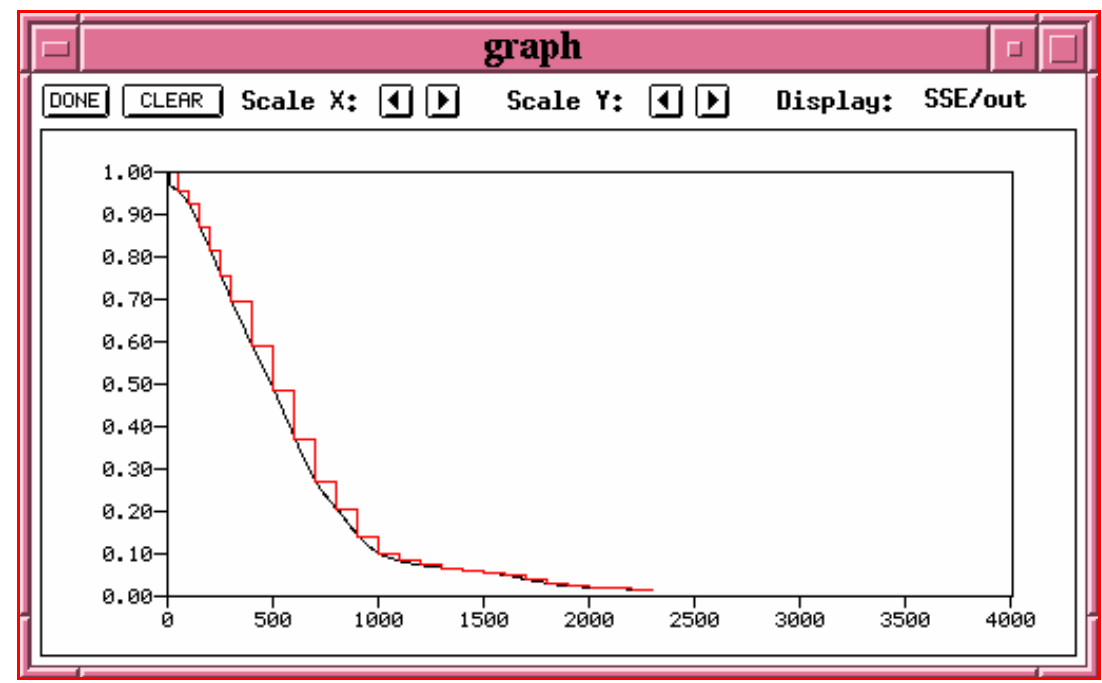

Figura 28 : Gráfico SNNS de convergência de erro no treinamento da rede neural. O eixo x mostra o número de épocas do algoritmo de treinamento e o y mostra o erro relativo.

Após a rede ter sido treinada, seus coeficientes e arquitetura são exportados e integrados à aplicação final. Vários padrões de escoamento foram então produzidos na seção de testes e expostos ao sistema para diagnóstico. Alguns exemplos de sinais de gradientes de pressão, com seus respectivos coeficientes tempo-freqüência e algumas janelas com resultados da identificação de padrão de escoamento bifásico produzidos pela aplicação são apresentados nas Figuras 29, 30 e 31 . 


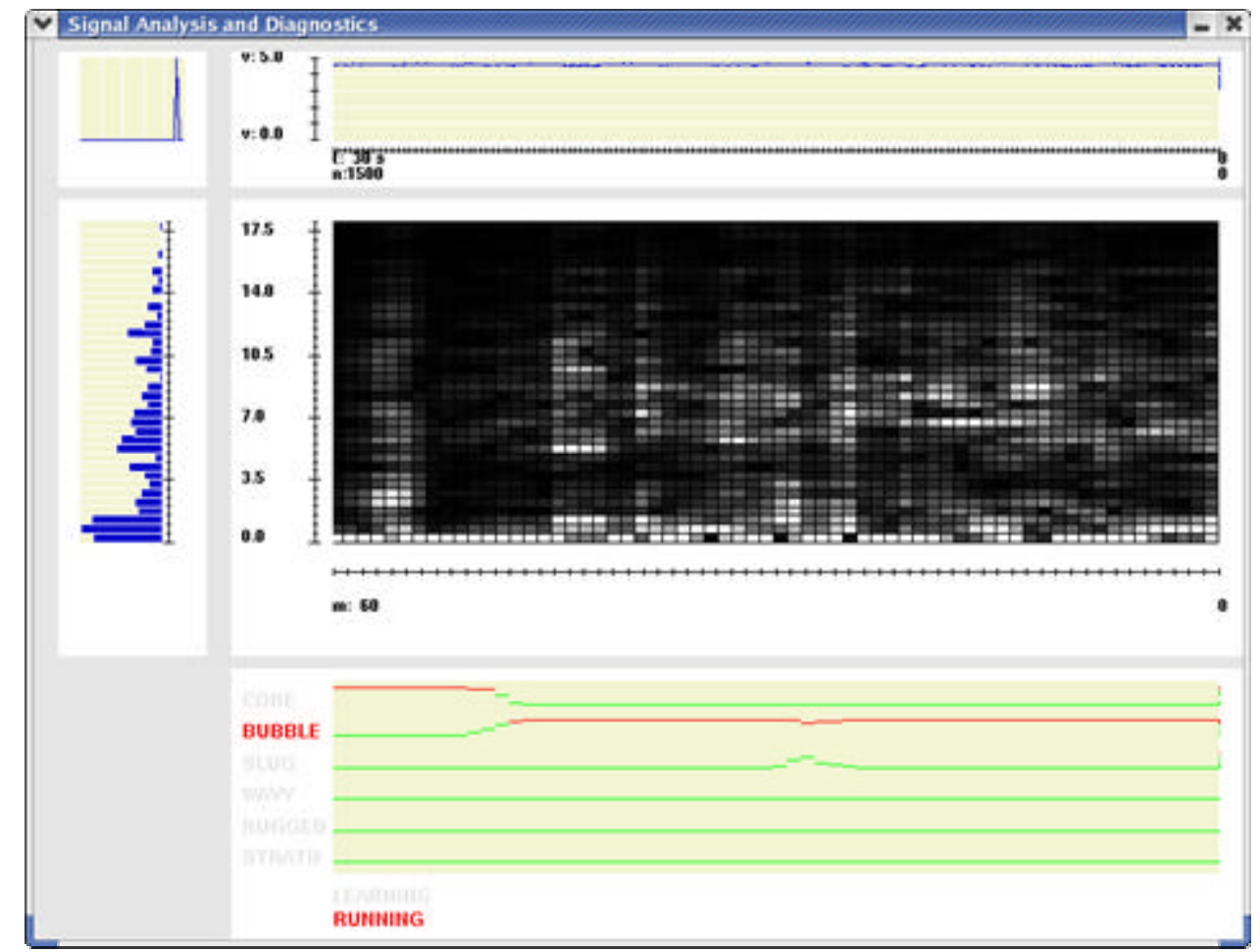

Figura 29: Sinais de pressão, seus respectivos coeficientes tempo-freqüência e as saídas da rede neural durante transição entre os padrões anular e a bolhas. A janela total de tempo apresentada é de 30 segundos.

A Figura 29 apresenta a resposta do sistema a uma transição entre os regimes anular e a bolhas. Durante esta transição podemos notar que as demais saídas permanecem inalteradas, em zero. Apenas as duas saídas correspondentes aos escoamentos em transição se alternam, de forma que se pode ver claramente o momento em que a saída da rede neural correspondente ao escoamento anular, ativada anteriormente, começa sua excursão até zero, ao mesmo tempo em que a saída equivalente ao escoamento a bolhas sai de zero até chegar a 1. O tempo desta transição pode ser observado entre 2 e 3 segundos. À direita, pode-se observar uma instabilidade entre as saídas da rede correspondentes aos regimes a bolhas e intermitente, refletindo uma instabilidade física no escoamento devido à proximidade dos pares ( $\left.U_{G S}, U_{L S}\right)$ da região de fronteira de transição entre estes padrões. 


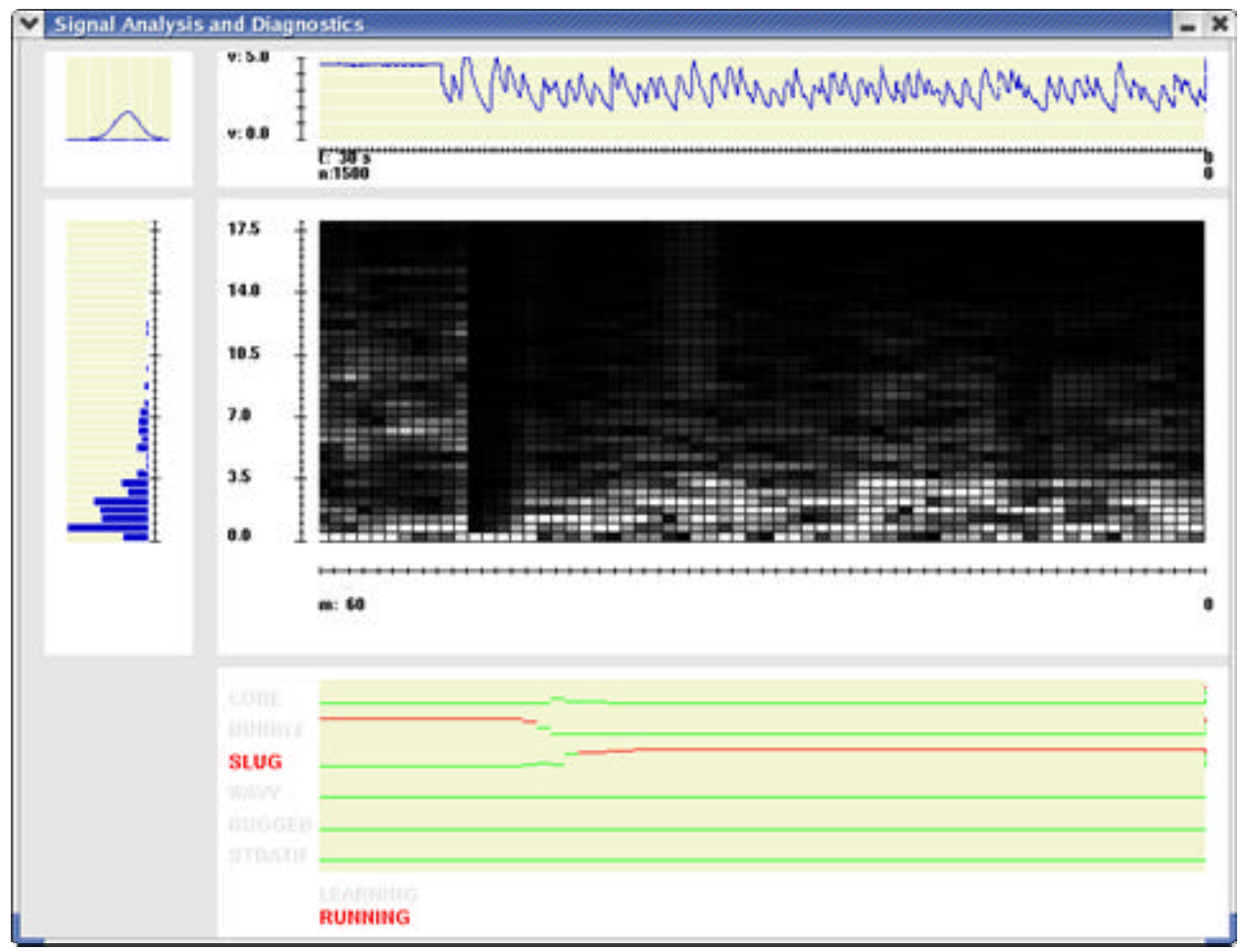

Figura 30: Sinais de pressão, seus respectivos coeficientes tempo-freqüência e as saídas da rede neural durante transição entre os padrões a bolhas e intermitente. $A$ janela total de tempo apresentada é de 30 segundos.

Da mesma forma, a Figura 30 apresenta a resposta do sistema a uma transição entre os regimes a bolhas e intermitente. Durante esta transição podemos notar que todas as saídas permanecem inalteradas, em zero, com exceção das saídas correspondentes aos escoamentos a bolhas, intermitente e anular. Este último, apesar de não diagnosticado na transição, sofre uma leve alteração de seu estado de inatividade, em função novamente do fato do escoamento, composto pelos pares $\left(U_{G S}, U_{L S}\right)$, estar próximo à região de tríplice fronteira entre estes escoamentos (a bolhas, intermitente e anular). Esta região de fronteira tripla pode ser observada no mapa de escoamentos de Taitel \& Dukler da figura 7. A transição entre o regime a bolhas e intermitente ocorre de forma semelhante à observada na figura anterior, com as saídas correspondentes aos dois escoamentos se alternando em aproximadamente 2 ou 3 segundos. A figura 31 apresenta os sinais s, seus coeficientes tempofreqüência e saídas da rede neural durante operação em escoamento anular, em regime permanente. 


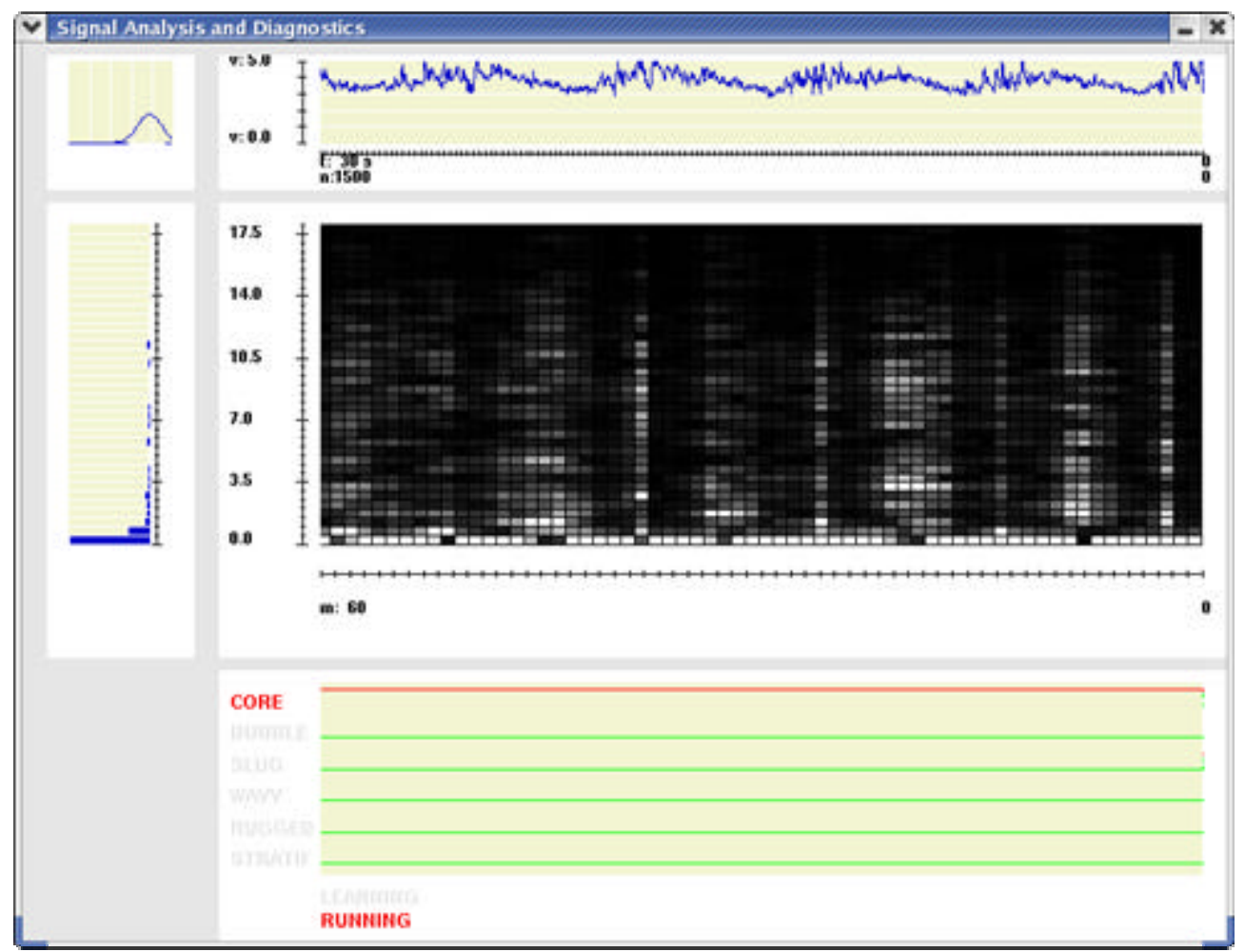

Figura 31: Sinais de pressão, seus respectivos coeficientes tempo-freqüência e as saídas da rede neural em diagnóstico de padrão anular. A janela total de tempo apresentada é de 30 segundos.

A próxima seção discute e analisa com mais profundidade os resultados obtidos nestes testes. 


\section{RESULTADOS}

O desempenho da metodologia proposta para a identificação do padrão de escoamento pode ser aferida de várias maneiras. Lembramos que os valores alvos da identificação são exclusivamente 1 ou 0 - o que estabelece se determinado padrão está ou não presente -, e que os valores obtidos nas saídas da rede variam continuamente entre estes limites. A metodologia de aferição proposta, os resultados obtidos na prática experimental e suas aferições serão apresentados nesta seção.

Em termos de seus diagnósticos, cada padrão de escoamento é representado por um ponto $\vec{\eta} \in \mathfrak{R}^{5}$, onde seus componentes $\eta_{1}, \eta_{2}, \eta_{3}, \eta_{4}, \eta_{5}$ correspondem a cada uma das saídas treinadas da rede neural. Para cada padrão i, a saída equivalente ideal da rede deve ser tal que $\eta_{i}=1$ e as demais saídas nulas.

Conforme abordagem feita por Seleghim (2002), este tipo de rede neural pode ser interpretada formalmente como uma aplicação não linear, ordenada e suavizada que relaciona dados com alta dimensionalidade aos elementos de um espaço vetorial ordenado de dimensão pequena. Neste caso específico, temos uma aplicação em que o mapeamento dos possíveis conjuntos de coeficientes tempo-freqüência $[a] \in \mathfrak{R}^{\mathrm{MxK}}$ - calculados à partir do sinal de pressão flutuante adquirido do escoamento - leva a um conjunto $\vec{\eta} \in \mathfrak{R}^{5}$ geometricamente representativo da informação contida nos dados primários. $\mathrm{Na}$ medida em que a análise direta destes resultados se torna impraticável devido à complexidade e dimensão dos dados, justifica-se o emprego de métodos matemático-numéricos como os de agrupamento ("clusterização") de dados. Desta forma, uma realização do escoamento é representada por um ponto no espaço de caracterização e, por sua vez, um padrão de escoamento é caracterizado por um aglomerado ("cluster") característico de pontos.

Para a avaliação da dispersão destes aglomerados de pontos $\vec{\eta}$ no espaço $\mathfrak{R}^{5}$ ao redor dos pontos de diagnósticos ideais $(1,0,0,0,0),(0,1,0,0,0,) \ldots(0,0,0,0,1)$ torna-se conveniente a definição uma função de erro como segue: 


$$
\begin{aligned}
& e_{\text {estratif }}=\sqrt{\left(1-\eta_{1}\right)^{2}+\left(0-\eta_{2}\right)^{2}+\left(0-\eta_{3}\right)^{2}+\left(0-\eta_{4}\right)^{2}+\left(0-\eta_{5}\right)^{2}} \\
& \text { endulado }=\sqrt{\left(0-\eta_{1}\right)^{2}+\left(1-\eta_{2}\right)^{2}+\left(0-\eta_{3}\right)^{2}+\left(0-\eta_{4}\right)^{2}+\left(0-\eta_{5}\right)^{2}} \\
& \left.e_{\text {interm }}=\sqrt{\left(0-\eta_{1}\right)^{2}+\left(0-\eta_{2}\right)^{2}+\left(1-\eta_{3}\right)^{2}+\left(0-\eta_{4}\right)^{2}+\left(0-\eta_{5}\right)^{2}}\right\} \stackrel{?}{\leq} e_{\text {limit }} \\
& \text { ebolhas }=\sqrt{\left(0-\eta_{1}\right)^{2}+\left(0-\eta_{2}\right)^{2}+\left(0-\eta_{3}\right)^{2}+\left(1-\eta_{4}\right)^{2}+\left(0-\eta_{5}\right)^{2}} \\
& e_{\text {anular }}=\sqrt{\left(0-\eta_{1}\right)^{2}+\left(0-\eta_{2}\right)^{2}+\left(0-\eta_{3}\right)^{2}+\left(0-\eta_{4}\right)^{2}+\left(1-\eta_{5}\right)^{2}}
\end{aligned}
$$

Estes limites de erro podem ser visualizados para cada um dos padrões de escoamento como regiões do espaço $\mathfrak{R}^{5}$ dentro das quais o sistema deve operar. A titulo de exemplo, para entendermos o significado destas definições, se fizermos uma simplificação da Equação (47) para $\mathfrak{R}^{3}$ - supondo uma rede treinada para decidir entre apenas 3 diagnósticos - torna-se possível a visualização gráfica destas regiões conforme apresentado na figura 32. Neste caso, as regiões de diagnóstico correto são descritas como esferas centradas em $(1,0,0)(0,1,0)$ e $(0,0,1)$ e com raios iguais aos erros erro $\eta_{1}$, erro $\eta_{2}$ e erro ${ }_{\eta 3}$, respectivamente. De acordo com esta metodologia de aferição serão consideradas corretas as ocorrências $\left(\eta_{1}, \eta_{2}, \eta_{3}\right)$, contidas dentro destas regiões. 


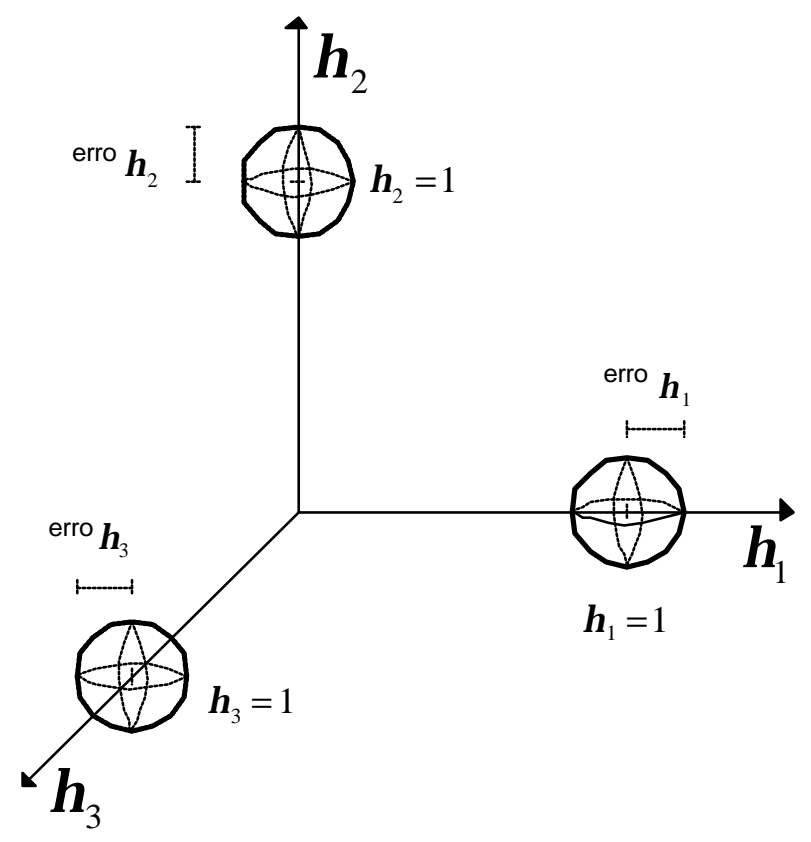

Figura 32: Visualização gráfica da função de erro simplificada para $\mathfrak{R}^{3}$.

É importante ressaltar que estes erros podem ser calculados em linha e em tempo real para cada passo de diagnóstico e assim monitorados com relação

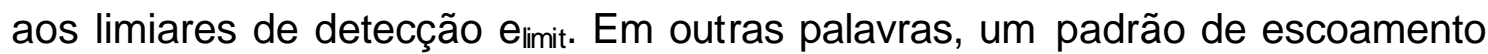
específico é identificado se o seu sinal de erro correspondente for menor que um valor de elimit predefinido convenientemente. A certeza deste procedimento de identificação de um determinado padrão pode ser definida como o número de diagnósticos corretos dividido pelo número total de sinais amostrados do mesmo padrão, identificados visualmente (a carta de Taitel \& Dukler é utilizada como referência qualitativa). Obviamente, quanto maior for o limite de identificação, maior é a certeza e vice-versa, tendendo a zero com $\mathrm{e}_{\text {limit }}=0$. Os resultados obtidos neste trabalho são apresentados na Tabela (1), onde podemos ver que $100 \%$ de certeza é atingida para $e_{\text {limit }}=0.09$, o que corresponde a uma performance extremamente boa. É também possível notar que os padrões de escoamento intermitente foram identificados com grande certeza para outros elimit. Isto pode ser atribuído à assinatura no diagrama tempo-freqüência muito característica deste tipo de escoamento, dominada pela freqüência de intermitência. Este é igualmente o caso dos escoamentos 
estratificados ondulados, que também têm uma assinatura no diagrama tempofreqüência fortemente marcada pela freqüência de oscilação da interface de estratificação, resultando na segunda melhor certeza de identificação. As menores certezas foram obtidas para os escoamentos anulares, o que pode ser provavelmente explicado pelo fato de que estes escoamentos foram amostrados muito próximos das regiões das transições com os padrões intermitente e estratificado, devido às limitações na vazão máxima de ar fornecida pelo compressor. 
Tabela 1: Níveis de certeza na identificação do padrão de escoamento em relação aos diferentes níveis de identificação da Equação (47)

\begin{tabular}{|c|c|c|c|c|c|c|}
\hline \multirow{2}{*}{$\begin{array}{l}\text { Limites de } \\
\text { identificação }\end{array}$} & $\begin{array}{c}\text { Padrões de } \\
\text { Escoamento } \\
?\end{array}$ & $\begin{array}{l}\text { Estratificado } \\
\quad \text { liso }\end{array}$ & $\begin{array}{c}\text { Estratificado } \\
\text { ondulado }\end{array}$ & intermitente & A bolhas & anular \\
\hline & $\begin{array}{c}\text { Número } \\
\text { amostras? }\end{array}$ & 320 & 875 & 2098 & 313 & 348 \\
\hline \multirow{3}{*}{0.09} & Acertos & 320 & 875 & 2098 & 313 & 348 \\
\hline & Erros & 0 & 0 & 0 & 0 & 0 \\
\hline & Certeza & $100 \%$ & $100 \%$ & $100 \%$ & $100 \%$ & $100 \%$ \\
\hline \multirow{3}{*}{0.08} & Acertos & 320 & 874 & 2098 & 313 & 348 \\
\hline & Erros & 0 & 1 & 0 & 0 & 0 \\
\hline & Certeza & $100 \%$ & $99.89 \%$ & $100 \%$ & $100 \%$ & $100 \%$ \\
\hline \multirow{3}{*}{0.07} & Acertos & 317 & 871 & 2094 & 313 & 348 \\
\hline & Erros & 3 & 4 & 4 & 0 & 0 \\
\hline & Certeza & $99.06 \%$ & $99.54 \%$ & $99.81 \%$ & $100 \%$ & $100 \%$ \\
\hline \multirow{3}{*}{0.06} & Acertos & 308 & 853 & 2060 & 307 & 335 \\
\hline & Erros & 13 & 6 & 38 & 6 & 13 \\
\hline & Certeza & $96.25 \%$ & $97.49 \%$ & $98.19 \%$ & $98.08 \%$ & $96.26 \%$ \\
\hline \multirow{3}{*}{0.05} & Acertos & 297 & 831 & 2008 & 298 & 295 \\
\hline & Erros & 23 & 44 & 90 & 15 & 53 \\
\hline & Certeza & $92.81 \%$ & $94.97 \%$ & $95.71 \%$ & $95.20 \%$ & $84.77 \%$ \\
\hline \multirow{3}{*}{0.04} & Acertos & 281 & 788 & 1931 & 268 & 261 \\
\hline & Erros & 39 & 87 & 167 & 45 & 87 \\
\hline & Certeza & $87.81 \%$ & $90.06 \%$ & $92.04 \%$ & $85.62 \%$ & $75 \%$ \\
\hline \multirow{3}{*}{0.03} & Acertos & 264 & 746 & 1858 & 239 & 216 \\
\hline & Erros & 56 & 129 & 240 & 74 & 132 \\
\hline & Certeza & $82.5 \%$ & $85.26 \%$ & $88.56 \%$ & $76.36 \%$ & $62.07 \%$ \\
\hline \multirow{3}{*}{0.02} & Acertos & 248 & 689 & 1764 & 199 & 173 \\
\hline & Erros & 72 & 186 & 334 & 114 & 175 \\
\hline & Certeza & $77.5 \%$ & $78.74 \%$ & $84.08 \%$ & $63.58 \%$ & $49.71 \%$ \\
\hline \multirow{3}{*}{0.01} & Acertos & 200 & 541 & 1541 & 139 & 95 \\
\hline & Erros & 120 & 334 & 557 & 174 & 253 \\
\hline & Certeza & $62.5 \%$ & $61.83 \%$ & $73.45 \%$ & $44.40 \%$ & $27.30 \%$ \\
\hline \multirow{3}{*}{0.005} & Acertos & 128 & 395 & 1176 & 60 & 40 \\
\hline & Erros & 192 & 480 & 922 & 253 & 308 \\
\hline & Certeza & $40 \%$ & $45.14 \%$ & $56.05 \%$ & $19.17 \%$ & $11.49 \%$ \\
\hline \multirow{3}{*}{0.001} & Acertos & 5 & 26 & 143 & 0 & 0 \\
\hline & Erros & 315 & 849 & 1955 & 313 & 348 \\
\hline & Certeza & $1.56 \%$ & $2.97 \%$ & $6.82 \%$ & $0 \%$ & $0 \%$ \\
\hline
\end{tabular}


Para efeito de visualização gráfica destes resultados, novamente é conveniente fazermos uma simplificação do espaço $\mathfrak{R}^{5}$ do espectro de diagnósticos possíveis para $\mathfrak{R}^{3}$, desta forma, visualizável em gráficos de 3 dimensões. Apesar da perda de informação inerente a esta simplificação, a melhor visualização destes clusters de informação é a representação gráfica combinada em três eixos - cada eixo equivale a uma saída da rede neural dos resultados obtidos. Disto resultaram portanto duas figuras. Na primeira delas, a Figura 33, são apresentadas as saídas da rede neural correspondentes aos padrões estratificado, ondulado e intermitente. Da mesma forma, na Figura 34 são apresentados os valores das saídas correspondentes aos diagnósticos dos padrões de escoamento a bolhas, anular e, novamente, o intermitente. Arbitramos a presença do escoamento intermitente nas duas figuras devido ao fato deste estar fisicamente próximos dos padrões estratificado e ondulado, cujos clusters são descritos na figura 33 e com os escoamentos a bolhas e a nular, nos clusters descritos na figura 34 . 
ESTRATIFICADO

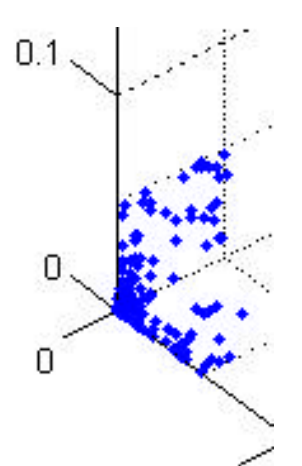

INTERMITENTE

ONDULADO

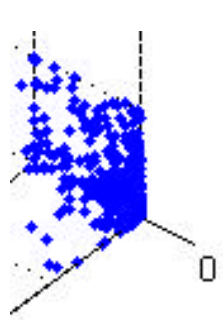

0.1

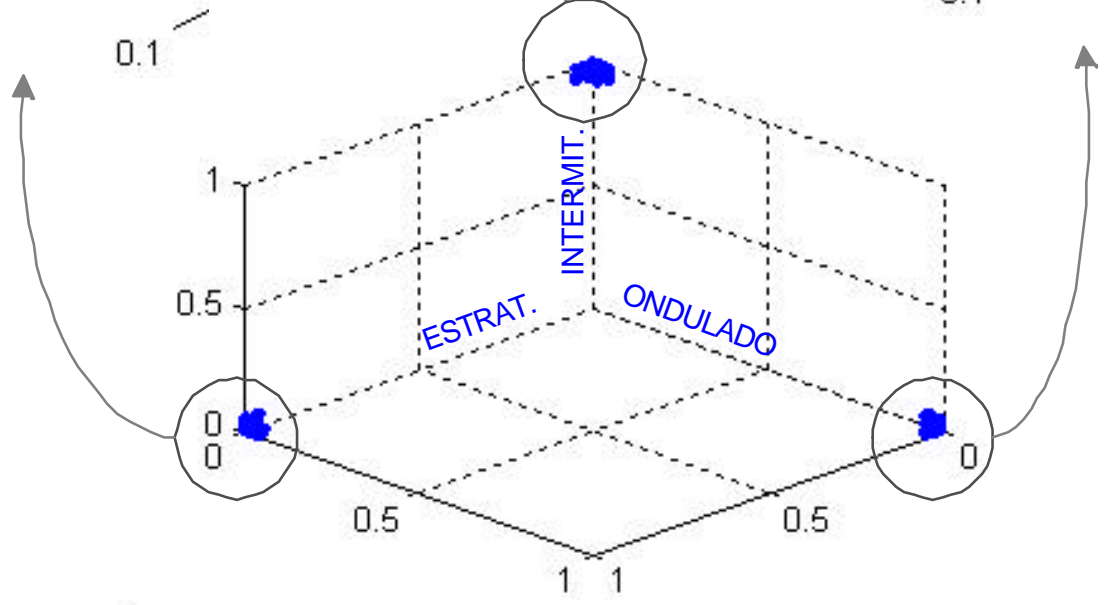

Figura 33: Visualização gráfica da distribuição das saídas da rede neural combinadas para os diagnósticos de padrão estratificado, estratificado ondulado e intermitente. 
BOLHAS

INTERMITENTE

ANULAR
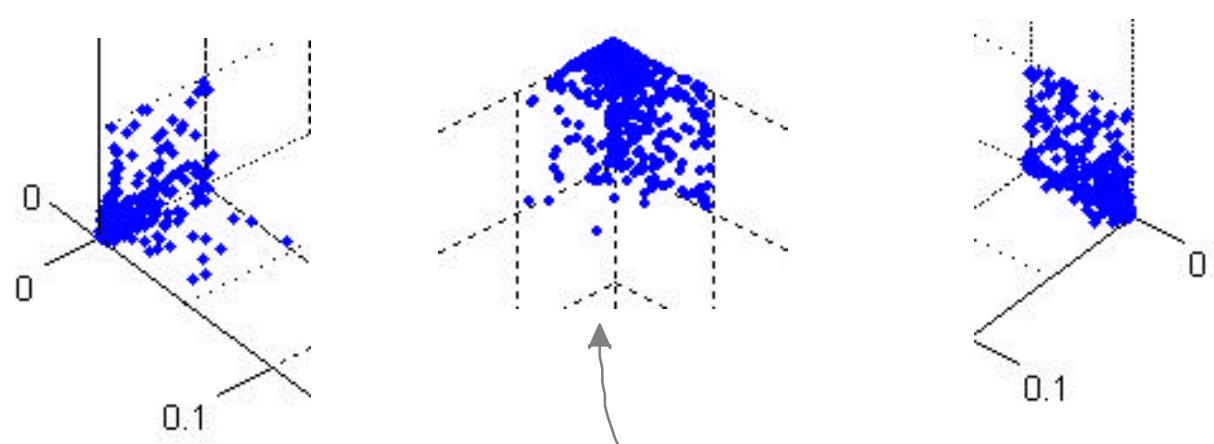

0.1

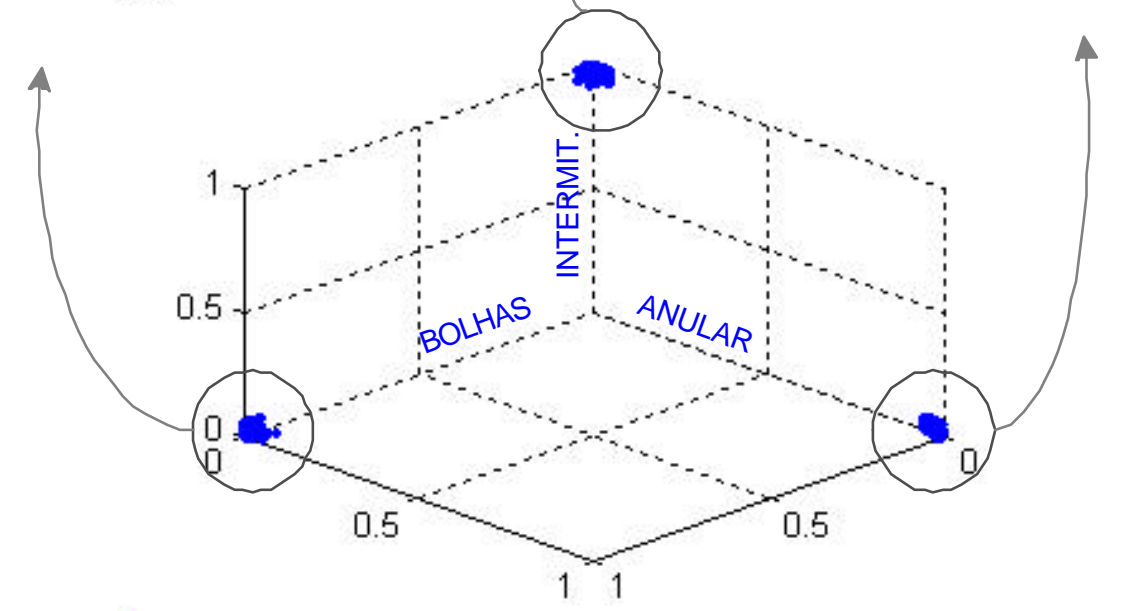

Figura 34: Visualização gráfica da distribuição das saídas da rede neural combinadas para os diagnósticos de padrão a bolhas, anular e intermitente.

Pode-se observar pela análise da dispersão destes clusters que existe um valor de erro limite dentro do qual o percentual de acerto da aplicação é de 100\%. Desta observação decorre outra, a de que em nenhum caso de diagnóstico i houve uma saída $\eta_{i}<\eta_{j, j \neq i}$, ou seja, em nenhum dos casos testados a rede apontou para um padrão de escoamento (ou cluster relacionado a este padrão) diferente daquele observado fisicamente. Outra característica interessante dos resultados obtidos é a inexistência de pontos dispersos entre os clusters de classificação. Estes clusters, por sua vez, estão inequivocamente confinados na vizinhança de seus centros ideais. Esta característica se torna de grande relevância em termos qualitativos e quantitativos tendo em mente 0 atendimento ao objetivo de se construir uma ferramenta de detecção em linha e em tempo real. A absoluta concentração dos resultados em clusters distintos e 
distantes uns dos outros no espaço de diagnóstico simplifica a decisão sobre qual o padrão a ser anunciado. Desta forma, torna-se desnecessária a implementação de trechos de código subseqüentes para analise dos resultados nos casos em que ocorram a sobreposição ou proximidade de clusters e / ou dispersão dos resultados. Estes códigos poderiam ser complexos e, na mesma medida, os seus erros inerentes poderiam diminuir a confiabilidade do diagnóstico.

Outra característica interessante pode ser constatada através da observação das regiões ampliadas dos clusters de pontos nas figuras 33 e 34 . Em todas as regiões de concentração pode ser visto que todas as saídas $\eta_{i}$ "perdedoras" da rede neural tiveram seus menores valores atribuídos a zero ou ligeiramente maiores que zero. Da mesma maneira, todas as saídas $\eta_{i}$ "vencedoras" tiveram seus valores atribuídos a 1,0 ou ligeiramente menores. Em nenhum caso a rede neural produziu saídas fora do intervalo $[0,1]$. Esta característica pode ser atribuída como decorrente da função de ativação de saída dos neurônios utilizada nesta configuração de rede neural. A função que utilizamos é predefinida no SNNS como "logistic activation function", e é estabelecida à partir da conhecida função sigmóide, que e é definida como

$$
y=\frac{1}{1+e^{-x}}
$$

onde:

$x$ é o valor de entrada da função $e$

y é o seu valor de saída

A função de ativação logística, por sua vez definida no SNNS como

$$
a_{j}(t+1)=\frac{1}{1+e^{-\left(\sum_{i} w_{j i} o_{i}(t)-\theta_{j}\right)}}
$$

onde:

$a_{j}(t)$ é a função de ativação do neurônio j no tempo t; 
$W_{i j} \quad$ é o peso da conexão entre os neurônios i e j;

$\mathrm{O}_{i}(\mathrm{t})$ é o valor da saída do neurônio i no tempo t;

$\theta_{\mathrm{j}} \quad$ é o "bias" do neurônio j

é utilizada neste trabalho como o mecanismo de ativação em todos os neurônios da rede, inclusive na camada de saída, o que explica portanto os padrões de dispersão observados nos resultados apresentados. Da função logística são esperados valores de saída dos neurônios que tendem a 0 quando $\left(\sum_{i} w_{i j} o_{i}(t)-\theta_{j}\right) \rightarrow-\infty$ e tendem a 1 quando $\left(\sum_{i} w_{i j} o_{i}(t)-\theta_{j}\right) \rightarrow+\infty$. Ver figura 35 abaixo

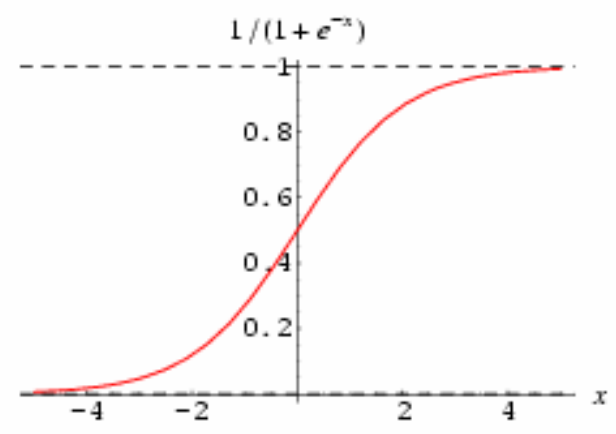

Figura 35: Função sigmóide de ativação neural. Utilizada uniformemente em todos os neurônios da rede.

Vale observar que se pode configurar grupos, camadas ou neurônios independentemente, com diferentes funções de ativação, estabelecidas previamente no SNNS ou definidas pelo usuário em linguagem padrão ANSI C. Variações neste sentido podem ser consideradas em eventuais explorações futuras para efeito de otimi zação ou industrialização do projeto. 


\section{CONCLUSÕES E PERSPECTIVAS}

Foi desenvolvido neste trabalho um procedimento para identificação em linha e em tempo real de padrões de escoamentos gás-líquido. $O$ procedimento foi baseado na aquisição de sinais de gradientes de pressão - pressão flutuante e nas suas subseqüentes decomposições em coeficientes tempo-freqüência associados à transformada de Gabor, seguido pelas suas análises através de uma rede neural previamente treinada. Testes experimentais foram feitos para validar e aferir a performance do procedimento proposto de identificação.

Netes testes foram gerados diferentes padrões de escoamento ar-água no circuito experimental do laboratório do Núcleo de Engenharia Térmica e Fluidos da Universidade de São Paulo em São Carlos. A seção de testes utilizada possui 12 metros de comprimento e $30 \mathrm{~mm}$ de diâmetro interno. $\mathrm{O}$ procedimento de treinamento da rede neural se constituiu da aquisição dos sinais de pressão à partir de padrões de escoamento conhecidos e em se igualando as saídas desejadas da rede à zero, exceto para o neurônio correspondente ao padrão selecionado, o qual é igualado a um. Foram coletadas um total de 3954 amostras, à partir de todos os diferentes padrões para a composição do conjunto de treinamento.

Este conjunto de amostras permitiu também a avaliação da performance do procedimento proposto, particularmente no que se refere à certeza associada com a identificação de cada padrão de escoamento. Uma certeza total de $100 \%$ é atingida quando o nível de identificação é atribuído a 0.09 na Equação (47). Os padrões intermitente e estratificado ondulado foram identificados com maior certeza, o que pode ser atribuído às suas assinaturas características no tempo-freqüência, associadas com a freqüência de intermitência e oscilação de interface, respectivamente. Os menores índices de certeza foram obtidos para o escoamento anular, provavelmente porque este padrão foi sub-explorado devido às limitações na vazão máxima de ar fornecida pelo compressor. 
Estes resultados se mostraram extremamente promissores, e representam uma importante contribuição para a área - fortemente marcada pela multidisciplinaridade - de aplicaões em monitoração de escoamentos multifásicos industriais. É importante também ressaltar que as baixas incertezas aferidas são bastante encorajadoras no que se refere às possibilidades de uso industrial deste método.

Trabalhos futuros podem incluir novos experimentos com diferentes inclinações da seção de testes e também a detecção de anomalias, como uma ruptura na tubulação, por exemplo. Seria igualmente interessante o estudo da influência da densidade da partição do plano tempo-freqüência, dado pelo $\beta$ na Equação (40), do número de neurônios das camadas escondidas do modelo neural e variações de funções de ativação dos neurônios na performance global do procedimento de identificação. 


\section{REFERÊNCIAS}

ASME MFC-3M (1989). Measurement of fluid flow in pipes using orifice, nozzle, and venturi. $68 p$.

AGRAWALL, S. S.; GREGORY, G. A.; GOVIER, G. W. (1973). An analysis of horizontal stratified two-phase flow in pipes. Canadian Journal of Chemical Engineering, v.51, p.280.

ANGELI, P.; HEWITT, G. F. (1998). Pressure gradient in horizontal liquid-liquid flows. International Journal of Multiphase Flow, 24, pp. 1183-1203.

AMERICAN PETROLEUM INSTITUTE (1995). Computational Pipeline Monitoring. API Publication 1130.

API - AMERICAN PETROLEUM INSTITUTE (1995). Evaluation Methodology for Software Based Leak Detection Systems. API Publication 1155.

BANNWART, A. C. (2001). Modeling aspects of oil-water core-annular flows. Journal of Petroleum Science And Engineering , 32 (2-4): pp.127-143.

BANNWART, A. C.; RODRIGUEZ, O. M. H.; DE CARVALHO, C. H. M.; WANG, I. S.; OBREGON VARA, R. M. (2004). Flow Patterns in Heavy Crude Oilwater Flow. Journal of Energy Resources Technology-Transactions of the ASME, 126, pp. 184-189.

BENJAMIN, T. B. (1959). Shearing flow over a wavy boundary. Journal of Fluid Mechanics, v.6, p.161.

BROCK, R. R. (1970). Periodic permanent roll waves, Proccedings of American Society of Civil Engineers, v.96, HYD -12, p.2565. 
CHU, K. T. (1973). Statistical characteristics and modeling of wavy liquid film in vertical two-phase flow, Ph.D. Thesis, University of Houston, Texas - USA.

COHEN L. (1995). Time frequency analysis. Prentice-Hall, Englewood Cliffs.

CRIVELARO, K. C. O. (1999). Identificação de regimes de escoamento bifáisco horizontal com auxílio de redes neurais. Dissertação de Mestrado em Engenharia Mecância, Escola de Engenharia de São Carlos - Universidade de São Paulo.

CRIVELARO, K. C. O.; HERVIEU, E.; SELEGHIM JR., P. (2002). Identification of horizontal two-phase flow regimes through a neural network models. Journal of the Brazilian Society of Mechanical Sciences. , v.14, n.1, p.1-16.

DAUBECHIES, I. (1992). Ten lectures on wavelets. SIAM, Philadelphia, 348p.

DRAHOS, J.; CERMÁK, J. (1989). Diagnostics of gas-liquid flow patterns in chemical engineering systems. Chemical Engineering Processes, Vol. 26, pp. 147-164.

FRANCA, F.; ACIKGOZ, M.; LAHEY JR., R.T.; CLAUSSE, A. (1991). The use of fractal techniques for flow regime identification. International Journal on Multiphase Flow, Vol. 17, №4, pp. 545-552.

GABOR, D. (1946). Theory of Communication. J. IEE, Part III, London, p. 429457.

HAGAN, M.T.; DEMUTH, H.B.; BEALE, M. (1996). Neural Network Design. Boston PWS.

HAYKIN, S. (1994). Neural network a comprehensive foundation. Macmillan College :New York. 
HERVIEU, E.; LEDUCQ, D. (1991). The wavelet transform as a diagnostic tool in two-phase flows: characterisation of multiphase flows from wall measurements. European Two-Phase Flow Group Meeting: Rome.

HERVIEU, E.; SELEGHIM, P. (1998). An objective indicator for two-phase flow pattern transition. Nuclear Enineering. Design, Vol. 184: (2-3), pp. 421-435.

HUBBARD, M. G.; DUKLER, A. E. (1966). The characterization of flow regimes for horizontal two-phase flow. Proc. Heat Transfer and Fluid Mech. Institute. Stanford University Press - M.A. Saad \& J.A. Moller eds.

JEFFREYS, J. (1925). On the formation of water waves by wind. Proc. Royal Soc. A107, p.198.

JEFFREYS, J. (1926). On the formation of water waves by wind. Proc. Royal Soc., A110, p.241.

KANDEL, A.; LANGHOLZ, G. (1992). Hybrid architectures for intelligent systems. CRC Press, $420 \mathrm{p}$.

KLEIN, F. L.; SELEGHIM JR., P.; HERVIEU, E. (2004). Time-Frequency Analysis of Intermittent Two-Phase Flows in Horizontal Piping. Journal of the Brazilian Society of Mechanical Sciences and Engineering, accepted for publication.

LAMB, H. (1932). Hydrodynamics. Ed. 6, Dover Publications, New York, 738 p.

LANGSAM, Y.; AUGESTEIN, M. J.; TENENBAUM, A. M. (1999). Data structures using $\mathrm{C}$ and $\mathrm{C}++$ second edition, Prentice Hall, 672p.

LEVICH, V. G. (1962). Physicochemical Hydrodynamics. Prentice-Hall, Englewood Cliffs, N.J. 
LEWIN, D. R.; FAIGON, M.; FUCHS, A.; SEMIAT R. (1992). Modelling and control of two-phase systems. Compututational Chemical Engineering, Vol. 16, Nº, pp. 5149-5146.

LOCKHART, R. W.; MARTINELLI, R. C. (1949). Proposed correlation of data for isothermal two-phase, two-component flow in pipes. Chem Eng. Progress, v.45, p.39.

MATSUI, G. (1984). Identification of flow regimes in vertical gas-liquid twophase flow using differential pressure fluctuations. International Journal on Multiphase Flow, Vol. 10, №6, p. 711-720.

MEYER, Y. (1993). Wavelets: algorithms and applications, SIAM, Philadelphia, $133 p$.

MI, Y.; ISHII, M.; TSOUKALAS, L. H. (1998). Vertical two-phase flow identification using advanced instrumentation and neural networks. Nuclear Engineering and Design, v. 184, p. 409-420.

MILNE-THOMPSON, L.M. (1960). Theoretical Hydrodynamics. The MacMillan Co., New York.

MISHIMA, K.; ISHII, M. (1984). Flow regime transition criteria for upward twophase flow in vertical tubes. Int. Journal on Heat and Mass Transfer, v. 27, N5, pp. 723-737.

MOURA, C. H. W.; SAMPAIO, D. S.; LACERDA, I. M.; SELLI, M. F. (2004). Monitoring Leakages on oile production offloading at open seas using statistics associated with mass balance methods. Procedings of International Pipeline Conference 2004, Calgary, Alberta, Canada, Nro IPC04-0763, 5p.

PRESS, W. H.; FLANNERY, B. P.; TEUKOLSKY, S.A.; VETTERLING, W. T. (1992). Numerical Recipes in C. Cambridge University Press, 966p. 
ROSENBLAT, F. (1958). The preceptron: a probabilistic model for information storage and organization in the brain. Psycological Review v.65, p.386-408.

SAETHER, G.; BENDIKSEN, K.; MULLER, J.; FROLAND, E. (1990). The Fractal Statistics of Liquid Slug Lengths. International Journal on Multiphase Flow, Vol. 16, №6, pp. 1117-1126.

SEKOGUCHI, K.; INOUE, K.; IMASAKA, T. (1987). Void signal analysis and gas-liquid two-phase flow regime determination by a statistical pattern recognition method. JSME International Journal, Vol. 30, №266, pp. 12661273.

SELEGHIM JR., P.; HERVIEU, E. (1994). Caractérisation des changements de configuration des écoulements diphasiques gaz-liquide par analyse de la fréquence instantanée. C.R. Acad. Sci. Paris, t. 319, Série II, p. 611-616.

SELEGHIM JR., P. (1996). Caractérisation des changements de configuration d'un écoulement diphasique horizontal par l'application de méthodes d'analyse temps-fréquence. PhD. Thesis, Institut National Polytechnique de Grenoble, Spécialité : Mécanique.

SELEGHIM JR., P.; HERVIEU, E.; SANTOS, A. M. (1998). Time-Frequency Characterisation of Two-Phase Horizontal Air-Water Flow Regimes. Journal of the Brazilian Society of Mechanical Sciences. Brasil: v.20, n.3, p.1-14.

SELEGHIM JR. (2002). Criação de uma linha de pesquisa em instrumentação e controle de escoamentos multifásicos industriais. Livre Docência em Engenharia Mecânica, Escola de Engenharia de São Carlos - Universidade de São Paulo, 133p.

SILVA, H. V.; MOROOKA, C. K.; GUILHERME, I. R.; MENDES, J. R. P.; FONSECA, T. C. (2003). Leak detection using a fyzzy system. Proccedings of COBEM 2003, COBEM2003 - 0889, November 10-14, São Paulo. 
SILVA, R. A.; BUIATTI, C. M.; CRUZ, S. L.; PEREIRA, J. A. F. R. (1996). Pressure wave behaviour and leak detection in pipelines. Computer chem. Engng., v.20, pp. 491-496.

STEWART, R. W. (1967). Mechanics of the air-sea interface, boundary layers and turbulence. Phys. Fluids, v.10, p.547.

TAITEL, Y.; DUKLER, A. E. (1976). A model for predicting flow regime transitions in horizontal and near horizontal gas-liquid flow. AIChE Journal, Vol. 22, №1, pp. 47-55.

TINDELL, B.; ZHANG, X. J. (2004). Liquid Pipeline Leak Detection: The Esso Experience. Pipeline \& Gas Journal, February.

TUTU, N. K. (1984). Pressure drop fluctuations and bubble-slug transition in a vertical two-phase air-water flow. International Journal on Multiphase Flow Vol. 10, N², pp. 211-216.

VINCE, M.A.; LAHEY, R.T. JR. (1982). On the development of an objective flow regime indicator. International Journal on Multiphase Flow, Vol. 8, №2, pp. 93-124.

WEISMAN, J.; DUNCAN, D.; GIBSON, J.; CRAWFORD, T. (1979). Effects of fluid properties and pipe diameter on two-phase flow patterns in horizontal lines. International Journal on Multiphase Flow, Vol. 5, pp. 437-462.

WU, H.; ZHOU, F.; WU, Y. (2001). Intelligent identification system of flow regime of oil-gas-water multiphase flow. International Journal on Multiphase Flow, Vol. 27, pp. 459-475.

XIE, T; GHIAASIAAN, SM; KARRILA, S. (2004). Artificial neural network approach for flow regime classification in gas-liquid-fiber flows based on frequency domain analysis of pressure signals. CHEMICAL ENGINEERING SCIENCE 59 (11): 2241-2251 JUN. 
YAN, H.; LIU, Y. H.; LIU, C. T. (2004). Identification of flow regimes using back-propagation networks trained on simulated data based on a capacitance tomography sensor. Measurement Science and Technolgy. Vol.15, pp. 432-436.

ZHANG, X. J. (1993). Statistical Leak Detection in Gas and Liquid Pipelines. Pipes \& Pipelines International, July-August: 26-29 pp.

ZHANG, X. J. (1997). Designing a Cost-effective and Reliable Pipeline Leak Detection Syste $m$. Pipes \& Pipelines International, January-February, pp 2026.

ZHANG X. J. (1999). Real Time Pipeline Leak Detection on Shell's North Western Ethylene Pipeline. IMechE, pp. 69-77. 


\section{APÊNDICE A - Programas C para cálculos das transições Taitel \& Dukler : métodos e variáveis definidos na seção 2.1.2}

\section{A.1 Transição entre padrão estratificado liso e intermitente}

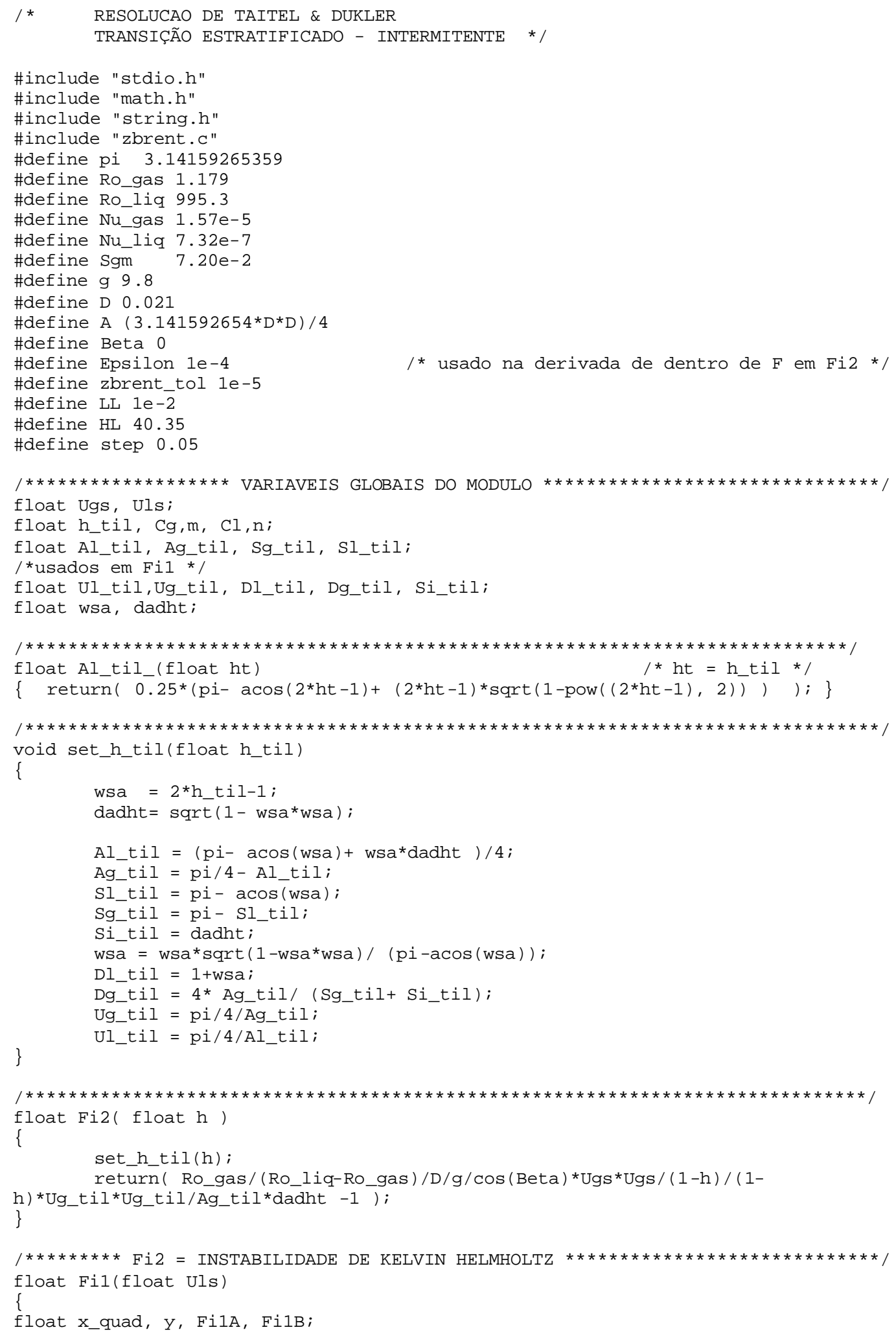




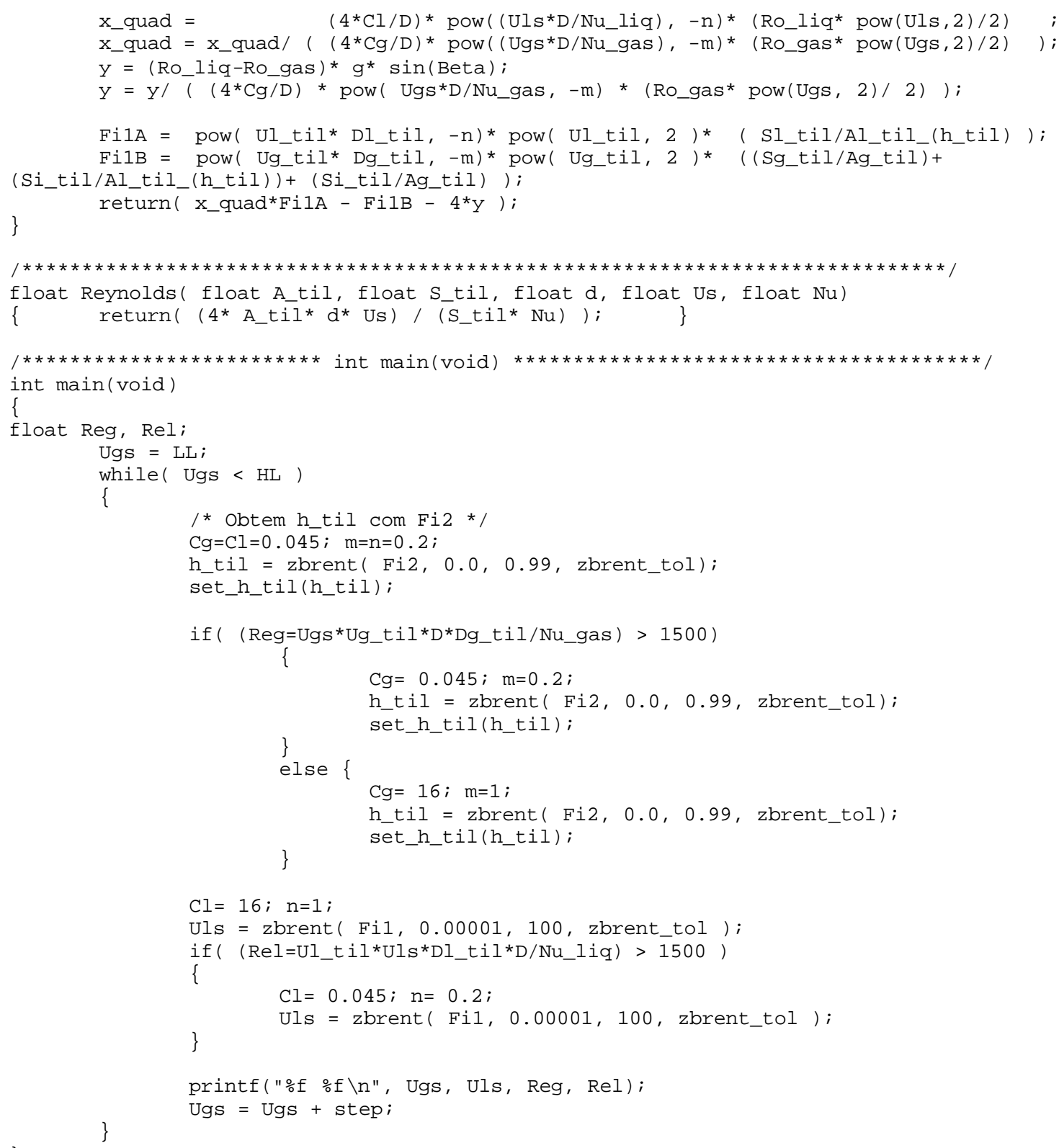




\section{A.2 Transição entre padrão estratificado liso e anular}

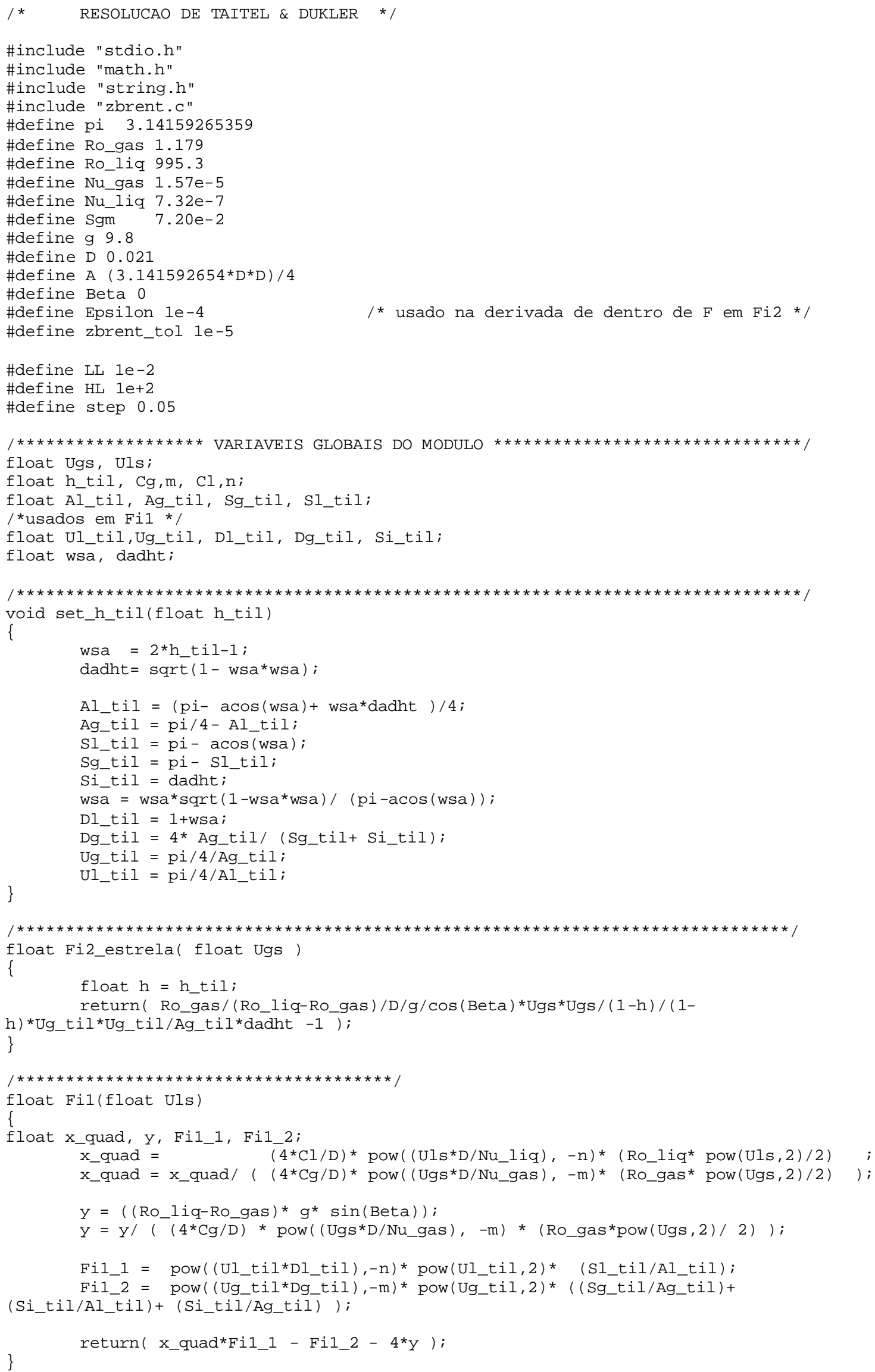




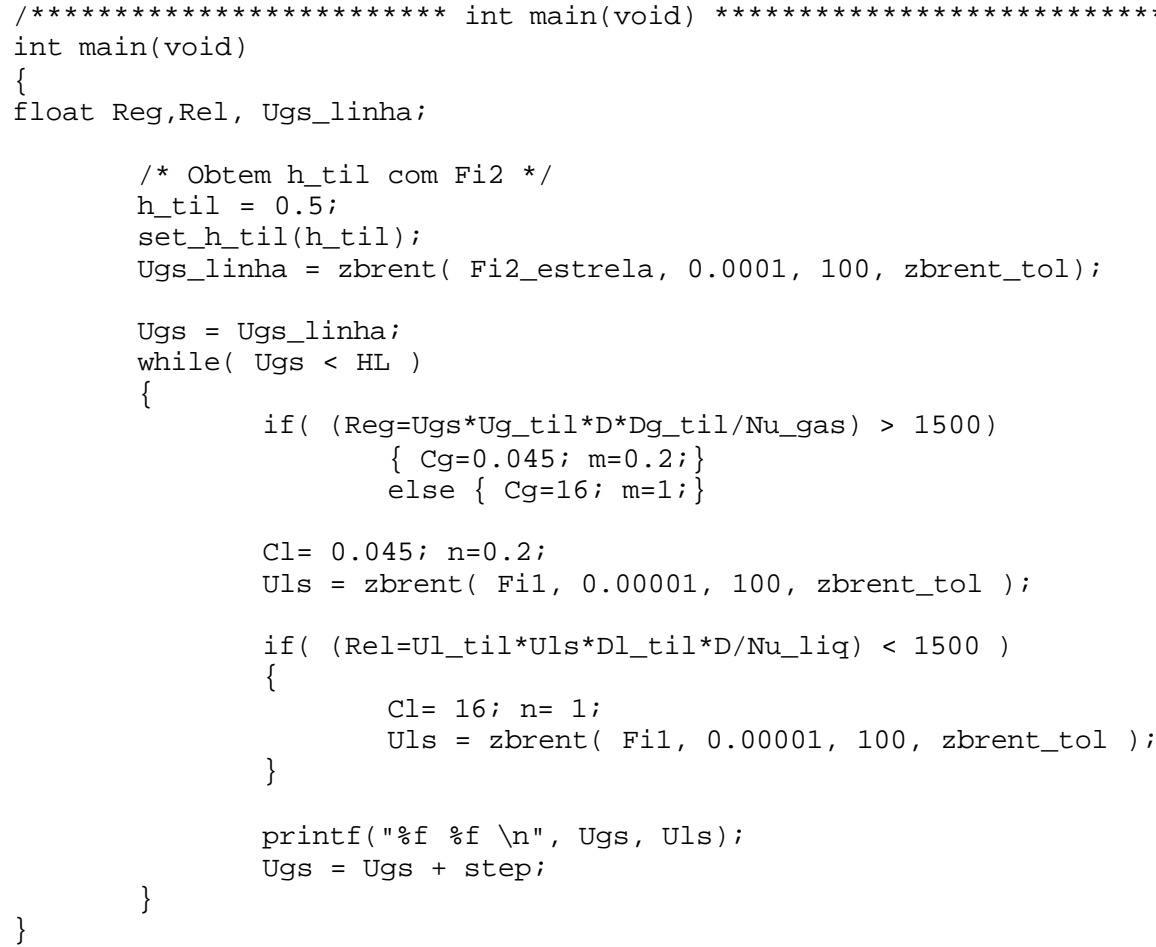




\section{A.3 Transição entre padrão estratificado liso e ondulado}

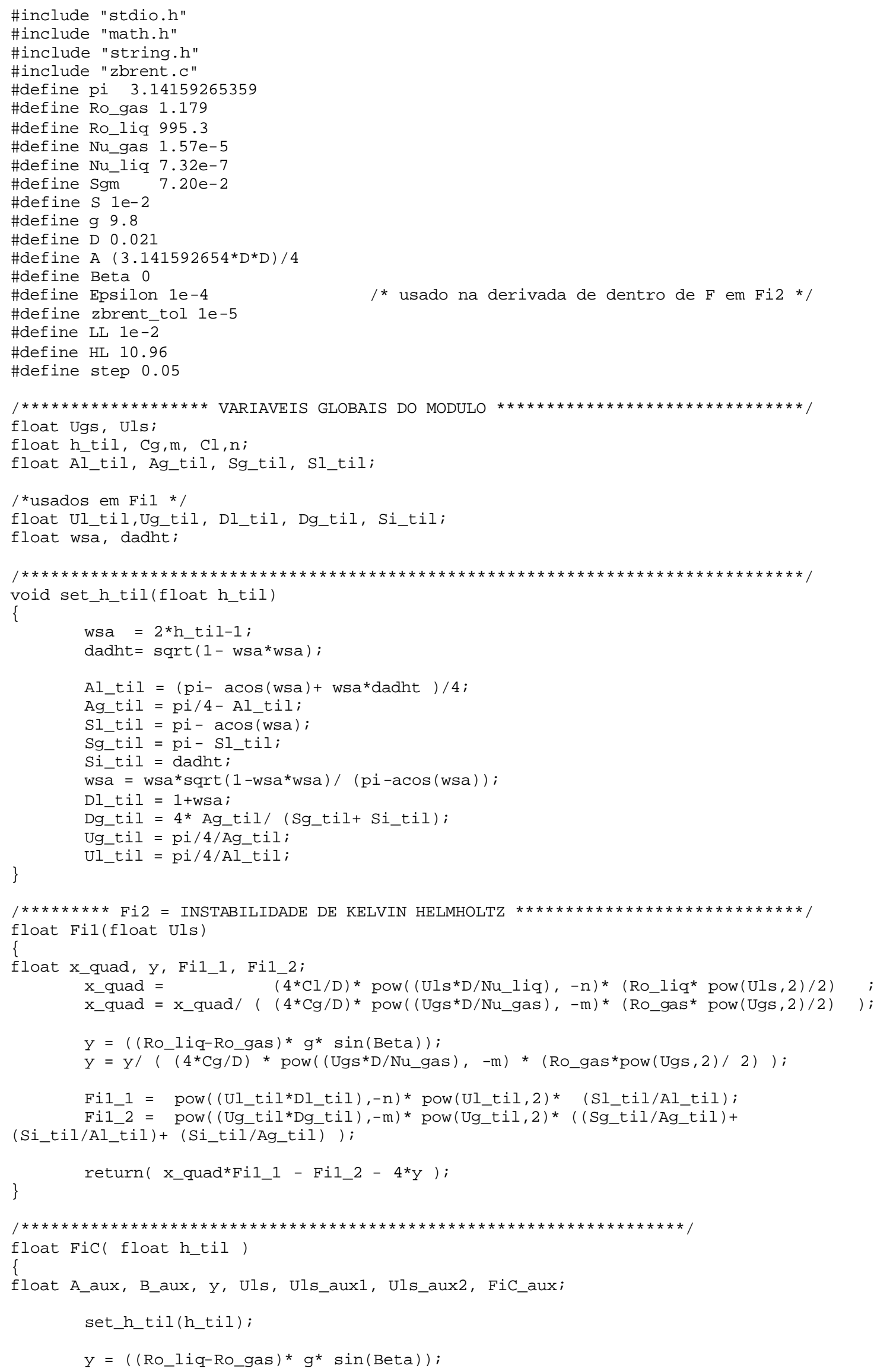


$\mathrm{y}=\mathrm{y} /\left(\left(4{ }^{*} \mathrm{Cg} / \mathrm{D}\right) * \operatorname{pow}\left(\left(\mathrm{Ugs}{ }^{*} \mathrm{D} / \mathrm{Nu}\right.\right.\right.$ _gas $\left.),-\mathrm{m}\right) *($ Ro_gas*pow $\left.(\mathrm{Ugs}, 2) / 2)\right)$;

A_aux $=\operatorname{pow}\left(\left(U 1 \_t i l * D l \_t i l\right),-n\right) * \operatorname{pow}\left(U 1 \_t i l, 2\right) *$ (Sl_til/Al_til);

B_aux $=$ pow $(($ Ug_til $*$ Dg_til $),-m) *$ pow $($ Ug_til, 2$) *(($ Sg_til/Ag_til $)+$ (Si_til/Al_til) $+($ Si_til/Ag_til) ) ;

Uls_aux1 $=\mathrm{Cg} *$ pow $($ Ugs $* \mathrm{D} / \mathrm{Nu}$ gas, $-\mathrm{m}) *$ Ro_gas $*$ pow $($ Ugs, 2$)$;

Uls_aux2 $=\mathrm{Cl} *$ pow $\left(\mathrm{D} / \mathrm{Nu} \_l i q,-\mathrm{n}\right) *$ Ro_liq;

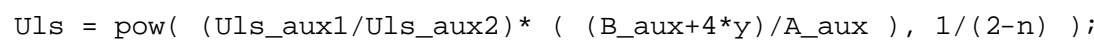

FiC_aux $=($ (Ro_gas*pow $(U g s, 2)) *$ Uls $) /\left(\right.$ (Ro_liq-Ro_gas) $* g^{*} \cos ($ Beta $) *$ Nu_liq ) - pow ( $2 /$ (Ug_til*sqrt (UI_til*S)), 2) ;

return( FiC_aux );

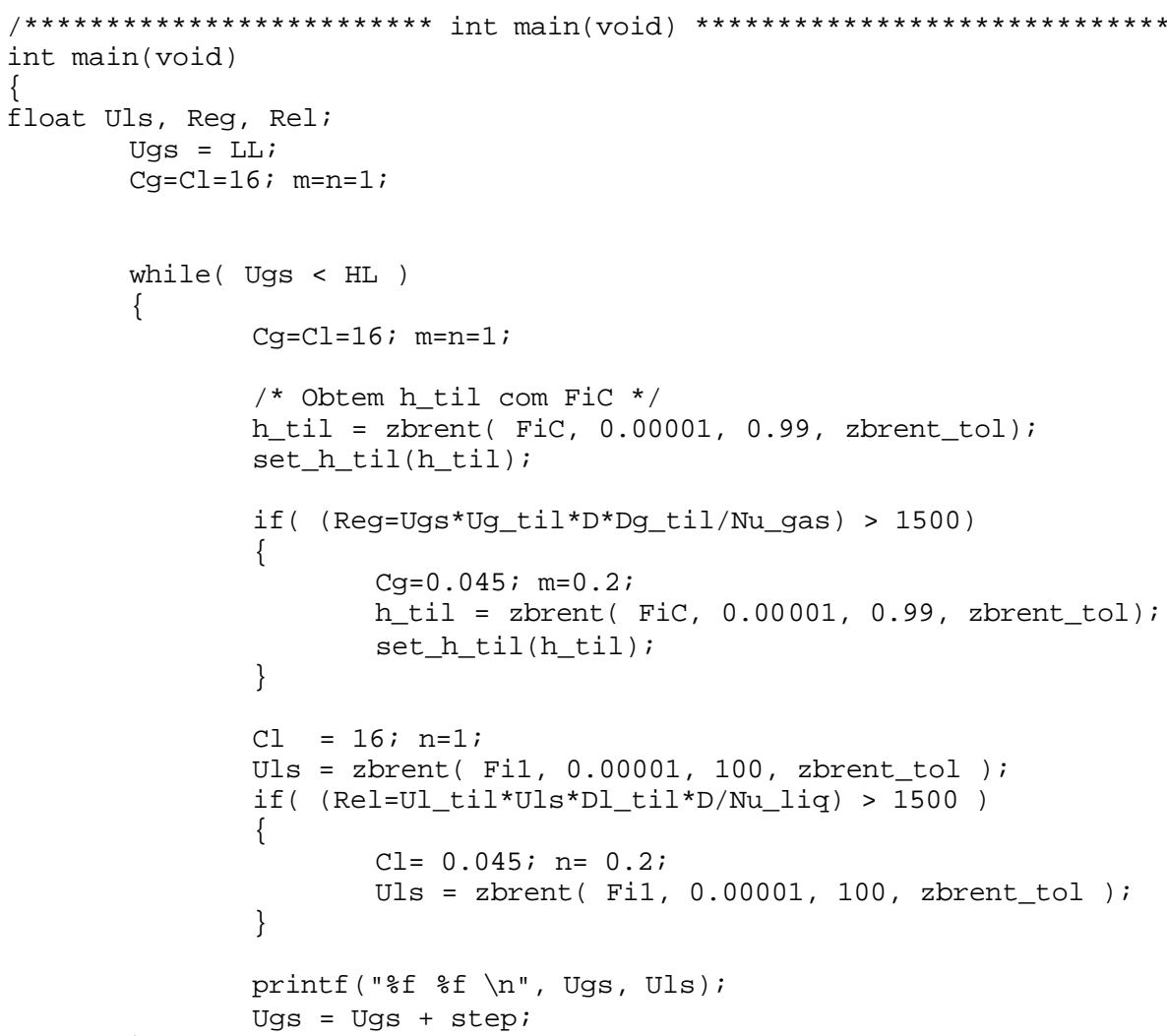




\section{A.4 Transição entre padrão intermitente e a bolhas}

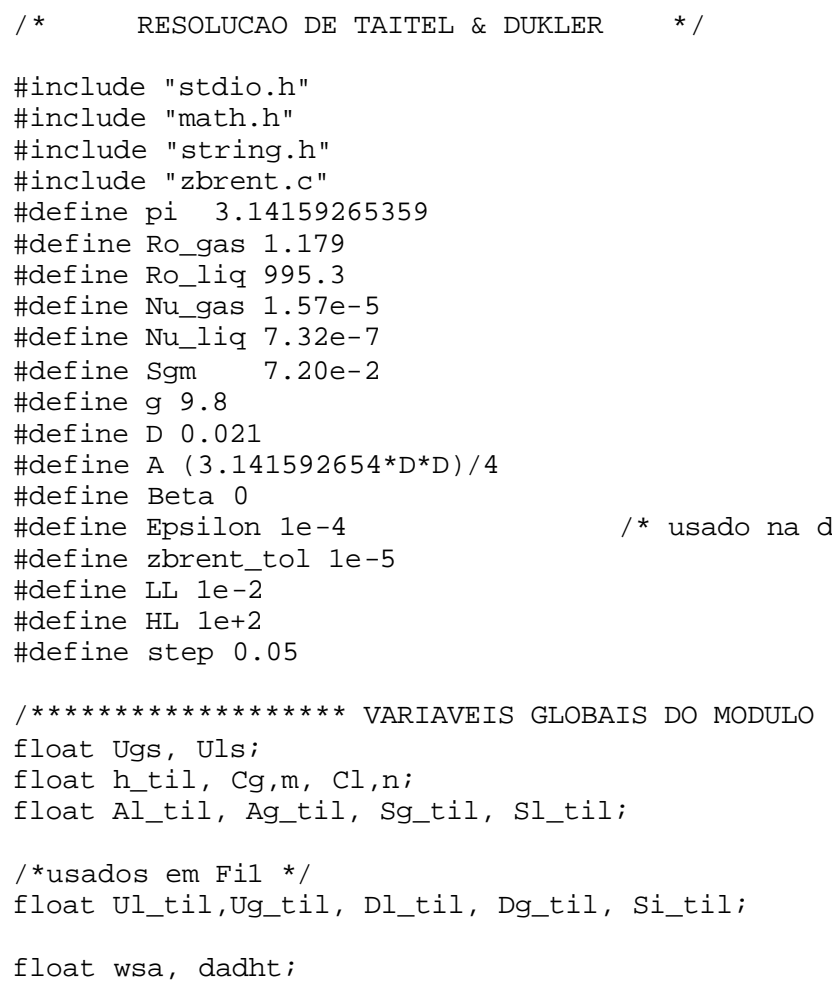




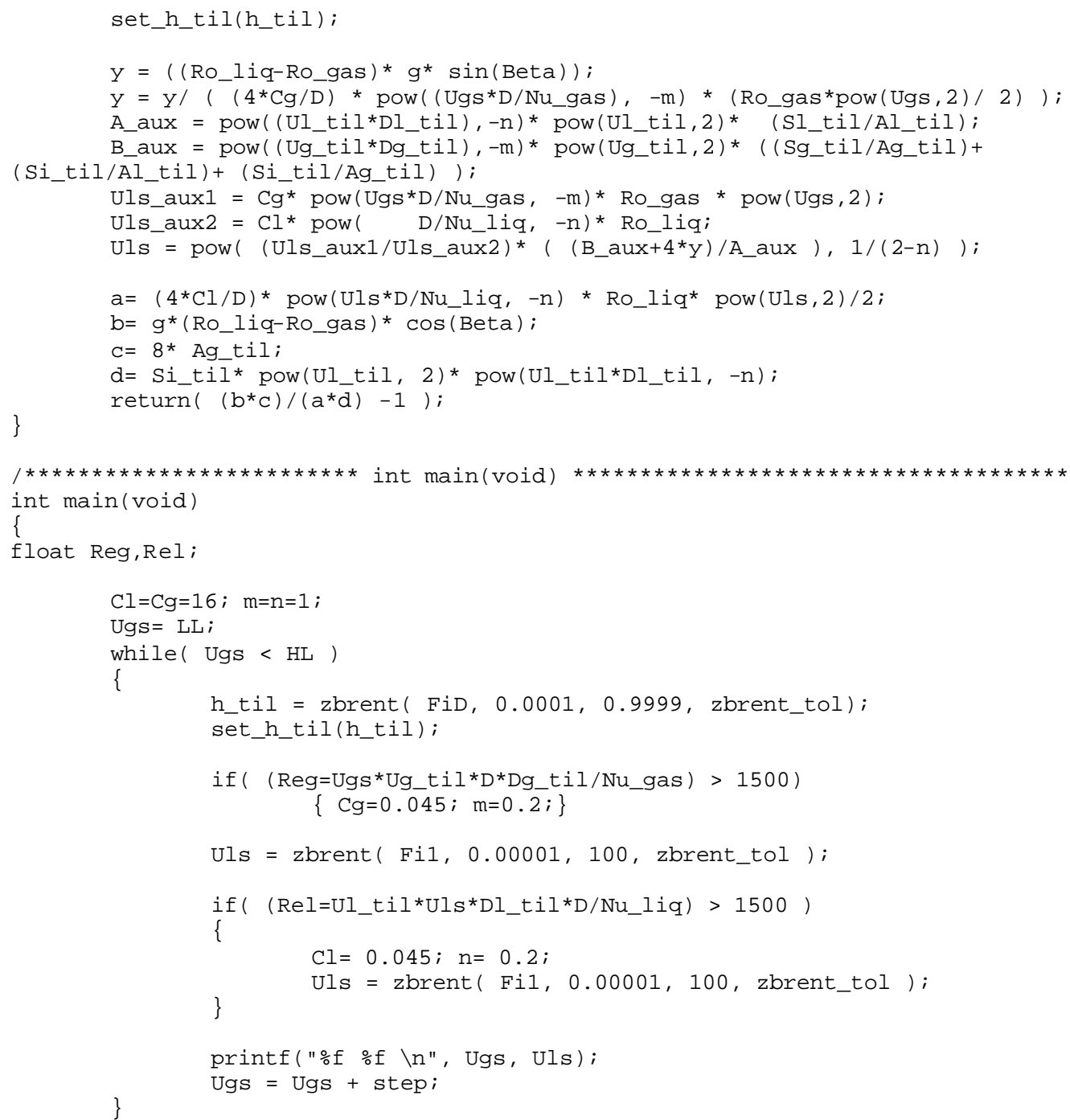




\section{APÊNDICE B - Transições entre padrões de escoamento por}

\section{Taitel \& Dukler}

\section{B.1 Transição entre padrão estratificado e intermitente- Pares de \\ velocidades superficiais do escoamento gás-líquido ( $\left.U_{\mathrm{GS}}, \mathrm{U}_{\mathrm{LS}}\right) \mathrm{em} \mathrm{m} / \mathrm{s}$, na tubulação de $30 \mathrm{~mm}$ de diâmetro interno do NETeF:}

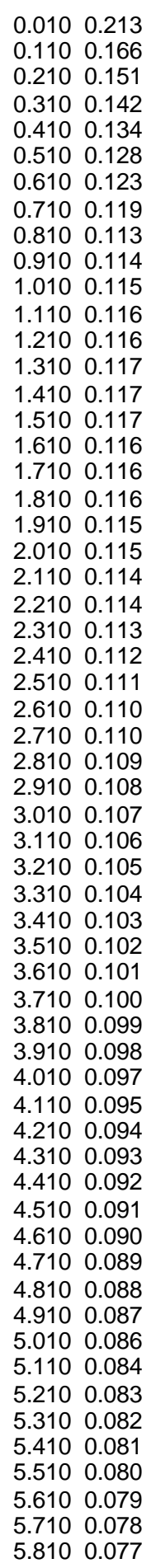

5.9100 .076

6.0100 .075

6.1100 .073

6.2100 .072

6.3100 .071

6.4100 .070

6.5100 .069

6.6100 .068

$\begin{array}{lll}6.710 & 0.067\end{array}$

6.8100 .066

6.9100 .065

7.0100 .064

7.1100 .063

$\begin{array}{lll}7.210 & 0.062\end{array}$

$\begin{array}{ll}7.310 & 0.061\end{array}$

7.4100 .060

$\begin{array}{lll}7.510 & 0.059\end{array}$

7.6100 .058

$\begin{array}{lll}7.710 & 0.057\end{array}$

$\begin{array}{lll}7.810 & 0.056\end{array}$

7.9100 .055

8.0100 .054

8.1100 .053

8.2100 .052

8.3100 .051

8.4100 .051

8.5100 .050

8.6100 .049

8.7100 .048

8.8100 .047

8.9100 .046

9.0100 .045

9.1100 .044

9.2100 .044

9.3100 .043

9.4100 .042

9.5100 .041

9.6100 .040

9.7100 .040

9.8100 .039

9.9100 .038

$10.010 \quad 0.037$

$\begin{array}{lll}10.110 & 0.037\end{array}$

$10.210 \quad 0.036$

$10.310 \quad 0.035$

$10.410 \quad 0.034$

$10.510 \quad 0.034$

$\begin{array}{lll}10.610 & 0.033\end{array}$

$\begin{array}{lll}10.710 & 0.032\end{array}$

$10.810 \quad 0.032$

$10.910 \quad 0.031$

$11.010 \quad 0.030$

11.1100 .030

$\begin{array}{lll}11.210 & 0.029\end{array}$

$\begin{array}{lll}11.310 & 0.029\end{array}$

$11.410 \quad 0.028$

$\begin{array}{lll}11.510 & 0.027\end{array}$

$\begin{array}{lll}11.610 & 0.027\end{array}$

$11.710 \quad 0.026$
$11.810 \quad 0.026$

$11.910 \quad 0.025$

$12.010 \quad 0.024$

$12.110 \quad 0.024$

$12.210 \quad 0.023$

$12.310 \quad 0.023$

12.4100 .022

$\begin{array}{lll}12.510 & 0.022\end{array}$

$\begin{array}{lll}12.610 & 0.021\end{array}$

$\begin{array}{lll}12.710 & 0.021\end{array}$

12.8100 .020

12.9100 .020

13.0100 .019

$13.110 \quad 0.019$

13.2100 .019

13.3100 .018

13.4100 .018

$\begin{array}{lll}13.510 & 0.017\end{array}$

$\begin{array}{lll}13.610 & 0.017\end{array}$

$\begin{array}{lll}13.710 & 0.017\end{array}$

13.8100 .016

$13.910 \quad 0.016$

$14.010 \quad 0.015$

$14.110 \quad 0.015$

$14.210 \quad 0.015$

$14.310 \quad 0.014$

$14.410 \quad 0.014$

$14.510 \quad 0.014$

$14.610 \quad 0.013$

$14.710 \quad 0.013$

$14.810 \quad 0.013$

$14.910 \quad 0.012$

$15.010 \quad 0.012$

$15.110 \quad 0.012$

$\begin{array}{lll}15.210 & 0.011\end{array}$

$15.310 \quad 0.011$

$\begin{array}{lll}15.410 & 0.011\end{array}$

$\begin{array}{lll}15.510 & 0.011\end{array}$

$15.610 \quad 0.010$

15.7100 .010

$15.810 \quad 0.010$

15.9100 .010

$\begin{array}{lll}16.010 & 0.009\end{array}$

$16.110 \quad 0.009$

16.2100 .009

16.3100 .009

$\begin{array}{lll}16.410 & 0.009\end{array}$

16.5100 .008

16.6100 .008

$16.710 \quad 0.008$

16.8100 .008

16.9100 .008

$17.010 \quad 0.007$

$\begin{array}{lll}17.110 & 0.007\end{array}$

$\begin{array}{lll}17.210 & 0.007\end{array}$

$\begin{array}{lll}17.310 & 0.007\end{array}$

$17.410 \quad 0.006$

$17.510 \quad 0.006$

17.6100 .006
$17.710 \quad 0.006$

17.8100 .006

$\begin{array}{lll}17.910 & 0.005\end{array}$

$18.010 \quad 0.005$

$18.110 \quad 0.005$

$\begin{array}{lll}18.210 & 0.005\end{array}$

18.3100 .005

$18.410 \quad 0.004$

$\begin{array}{lll}18.510 & 0.004\end{array}$

18.6100 .004

18.7100 .004

18.8100 .004

18.9100 .004

$19.010 \quad 0.004$

19.1100 .003

19.2100 .003

19.3100 .003

$19.410 \quad 0.003$

19.5100 .003

$19.610 \quad 0.003$

19.7100 .003

19.8100 .003

$19.910 \quad 0.003$

20.0100 .002

$20.110 \quad 0.002$

$20.210 \quad 0.002$

20.3100 .002

$20.410 \quad 0.002$

20.5100 .002

20.6100 .002

$20.710 \quad 0.002$

20.8100 .002

20.9100 .002

21.0100 .002

21.1100 .002

21.2100 .002

21.3100 .002

21.4100 .002

21.5100 .001

21.6100 .001

21.7100 .001

21.8100 .001

21.9100 .001

22.0100 .001

22.1100 .001

22.2100 .001

22.3100 .001

22.4100 .001

22.5100 .001

22.6100 .001

22.7100 .001

22.8100 .001

22.9100 .001

23.0100 .001

23.1100 .001

23.2100 .001

23.3100 .001

23.4100 .001

23.5100 .001 
$23.610 \quad 0.001$

23.7100 .001

23.8100 .001

23.9100 .001

24.0100 .001

24.1100 .001

$24.210 \quad 0.001$

24.3100 .001

$24.410 \quad 0.001$

$24.510 \quad 0.001$

24.6100 .001

24.7100 .001

24.8100 .000

$24.910 \quad 0.000$

25.0100 .000

25.1100 .000

25.2100 .000

25.3100 .000

$25.410 \quad 0.000$

25.5100 .000

25.6100 .000

25.7100 .000

25.8100 .000

$25.910 \quad 0.000$

26.0100 .000

26.1100 .000

26.2100 .000

$26.310 \quad 0.000$

26.4100 .000

26.5100 .000

26.6100 .000

26.7100 .000

26.8100 .000

26.9100 .000

27.0100 .000

$27.110 \quad 0.000$

$27.210 \quad 0.000$

27.3100 .000

$27.410 \quad 0.000$

27.5100 .000

27.6100 .000

$27.710 \quad 0.000$
$27.810 \quad 0.000$

$27.910 \quad 0.000$

28.0100 .000

28.1100 .000

28.2100 .000

28.3100 .000

28.4100 .000

28.5100 .000

28.6100 .000

28.7100 .000

28.8100 .000

28.9100 .000

29.0100 .000

29.1100 .000

29.2100 .000

29.3100 .000

29.4100 .000

29.5100 .000

29.6100 .000

29.7100 .000

29.8100 .000

29.9100 .000

30.0100 .000

$30.110 \quad 0.000$

$30.210 \quad 0.000$

30.3100 .000

$30.410 \quad 0.000$

$30.510 \quad 0.000$

$30.610 \quad 0.000$

$30.710 \quad 0.000$

30.8100 .000

$30.910 \quad 0.000$

31.0100 .000

31.1100 .000

31.2100 .000

31.3100 .000

31.4100 .000

31.5100 .000

31.6100 .000

31.7100 .000

31.8100 .000

31.9100 .000
$32.010 \quad 0.000$

$32.110 \quad 0.000$

$32.210 \quad 0.000$

32.3100 .000

32.4100 .000

32.5100 .000

32.6100 .000

32.7100 .000

32.8100 .000

32.9100 .000

33.0100 .000

33.1100 .000

33.2100 .000

33.3100 .000

33.4100 .000

33.5100 .000

33.6100 .000

$33.710 \quad 0.000$

33.8100 .000

33.9100 .000

34.0100 .000

$34.110 \quad 0.000$

34.2100 .000

$34.310 \quad 0.000$

$34.410 \quad 0.000$

$34.510 \quad 0.000$

34.6100 .000

34.7100 .000

34.8100 .000

$34.910 \quad 0.000$

35.0100 .000

$35.110 \quad 0.000$

35.2100 .000

35.3100 .000

$35.410 \quad 0.000$

$35.510 \quad 0.000$

35.6100 .000

35.7100 .000

35.8100 .000

$35.910 \quad 0.000$

36.0100 .000

$36.110 \quad 0.000$
$36.210 \quad 0.000$

36.3100 .000

36.4100 .000

36.5100 .000

36.6100 .000

36.7100 .000

36.8100 .000

36.9100 .000

37.0100 .000

$37.110 \quad 0.000$

$37.210 \quad 0.000$

$37.310 \quad 0.000$

$37.410 \quad 0.000$

$37.510 \quad 0.000$

37.6100 .000

37.7100 .000

37.8100 .000

37.9100 .000

38.0100 .000

38.1100 .000

$38.210 \quad 0.000$

38.3100 .000

$38.410 \quad 0.000$

38.5100 .000

38.6100 .000

38.7100 .000

38.8100 .000

38.9100 .000

39.0100 .000

39.1100 .000

39.2100 .000

39.3100 .000

$39.410 \quad 0.000$

39.5100 .000

39.6100 .000

39.7100 .000

39.8100 .000

39.9100 .000

$40.010 \quad 0.000$

$40.110 \quad 0.000$

$40.210 \quad 0.000$

$40.310 \quad 0.000$ 


\section{B.2 Transição entre padrão intermitente e anular - Pares de velocidades} superficiais do escoamento gás-líquido ( $\left.U_{\mathrm{GS}}, \mathrm{U}_{\mathrm{LS}}\right) \mathrm{em} \mathrm{m} / \mathrm{s}$, na tubulação de $30 \mathrm{~mm}$ de diâmetro interno do NETeF:

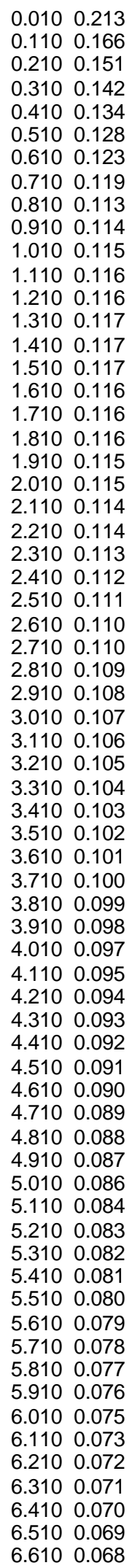

$\begin{array}{lll}6.710 & 0.067\end{array}$

6.8100 .066

6.9100 .065

7.0100 .064

$\begin{array}{lll}7.110 & 0.063\end{array}$

$\begin{array}{lll}7.210 & 0.062\end{array}$

$\begin{array}{lll}7.310 & 0.061\end{array}$

$\begin{array}{lll}7.410 & 0.060\end{array}$

$\begin{array}{lll}7.510 & 0.059\end{array}$

$\begin{array}{lll}7.610 & 0.058\end{array}$

$\begin{array}{lll}7.710 & 0.057\end{array}$

7.8100 .056

7.9100 .055

8.0100 .054

8.1100 .053

8.2100 .052

8.3100 .051

8.4100 .051

8.5100 .050

8.6100 .049

8.7100 .048

8.8100 .047

8.9100 .046

9.0100 .045

$9.110 \quad 0.044$

9.2100 .044

9.3100 .043

9.4100 .042

9.5100 .041

9.6100 .040

9.7100 .040

9.8100 .039

9.9100 .038

$\begin{array}{lll}10.010 & 0.037\end{array}$

$\begin{array}{lll}10.110 & 0.037\end{array}$

$10.210 \quad 0.036$

$\begin{array}{lll}10.310 & 0.035\end{array}$

$10.410 \quad 0.034$

$10.510 \quad 0.034$

$10.610 \quad 0.033$

$\begin{array}{lll}10.710 & 0.032\end{array}$

$\begin{array}{lll}10.810 & 0.032\end{array}$

$\begin{array}{lll}10.910 & 0.031\end{array}$

11.0100 .030

$11.110 \quad 0.030$

$\begin{array}{lll}11.210 & 0.029\end{array}$

$\begin{array}{lll}11.310 & 0.029\end{array}$

$\begin{array}{lll}11.410 & 0.028\end{array}$

$\begin{array}{lll}11.510 & 0.027\end{array}$

$\begin{array}{lll}11.610 & 0.027\end{array}$

$\begin{array}{lll}11.710 & 0.026\end{array}$

$\begin{array}{lll}11.810 & 0.026\end{array}$

$11.910 \quad 0.025$ $12.010 \quad 0.024$

$12.110 \quad 0.024$

$12.210 \quad 0.023$

$\begin{array}{lll}12.310 & 0.023\end{array}$

$\begin{array}{lll}12.410 & 0.022\end{array}$

$12.510 \quad 0.022$

$\begin{array}{lll}12.610 & 0.021\end{array}$

$\begin{array}{lll}12.710 & 0.021\end{array}$

12.8100 .020

$12.910 \quad 0.020$

13.0100 .019

$13.110 \quad 0.019$

13.2100 .019

13.3100 .018
$13.410 \quad 0.018$

$\begin{array}{lll}13.510 & 0.017\end{array}$

$\begin{array}{lll}13.610 & 0.017\end{array}$

$\begin{array}{lll}13.710 & 0.017\end{array}$

13.8100 .016

13.9100 .016

$14.010 \quad 0.015$

$\begin{array}{lll}14.110 & 0.015\end{array}$

$14.210 \quad 0.015$

$14.310 \quad 0.014$

$14.410 \quad 0.014$

$14.510 \quad 0.014$

$\begin{array}{lll}14.610 & 0.013\end{array}$

$14.710 \quad 0.013$

$14.810 \quad 0.013$

$14.910 \quad 0.012$

$15.010 \quad 0.012$

$15.110 \quad 0.012$

$15.210 \quad 0.011$

$\begin{array}{lll}15.310 & 0.011\end{array}$

$\begin{array}{lll}15.410 & 0.011\end{array}$

$\begin{array}{lll}15.510 & 0.011\end{array}$

$15.610 \quad 0.010$

$15.710 \quad 0.010$

$15.810 \quad 0.010$

$15.910 \quad 0.010$

$16.010 \quad 0.009$

16.1100 .009

$\begin{array}{lll}16.210 & 0.009\end{array}$

16.3100 .009

16.4100 .009

16.5100 .008

16.6100 .008

$16.710 \quad 0.008$

16.8100 .008

$16.910 \quad 0.008$

$17.010 \quad 0.007$

$\begin{array}{lll}17.110 & 0.007\end{array}$

$\begin{array}{lll}17.210 & 0.007\end{array}$

$\begin{array}{lll}17.310 & 0.007\end{array}$

17.4100 .006

$17.510 \quad 0.006$

$17.610 \quad 0.006$

$\begin{array}{lll}17.710 & 0.006\end{array}$

17.8100 .006

$17.910 \quad 0.005$

$18.010 \quad 0.005$

$18.110 \quad 0.005$

$\begin{array}{lll}18.210 & 0.005\end{array}$

18.3100 .005

$18.410 \quad 0.004$

$18.510 \quad 0.004$

$18.610 \quad 0.004$

$18.710 \quad 0.004$

18.8100 .004

$18.910 \quad 0.004$

$19.010 \quad 0.004$

$19.110 \quad 0.003$

$19.210 \quad 0.003$

$19.310 \quad 0.003$

$19.410 \quad 0.003$

$19.510 \quad 0.003$

19.6100 .003

19.7100 .003

19.8100 .003

$19.910 \quad 0.003$

20.0100 .002
$20.110 \quad 0.002$ 20.2100 .002 $20.310 \quad 0.002$ 20.4100 .002 20.5100 .002 20.6100 .002 20.7100 .002 20.8100 .002 20.9100 .002 21.0100 .002 21.1100 .002 $21.210 \quad 0.002$ $21.310 \quad 0.002$ 21.4100 .002 21.5100 .001 21.6100 .001 21.7100 .001 21.8100 .001 21.9100 .001 22.0100 .001 22.1100 .001 22.2100 .001 22.3100 .001 $22.410 \quad 0.001$ $22.510 \quad 0.001$ 22.6100 .001 22.7100 .001 22.8100 .001 22.9100 .001 23.0100 .001 23.1100 .001 23.2100 .001 23.3100 .001 23.4100 .001 23.5100 .001 23.6100 .001 23.7100 .001 23.8100 .001 23.9100 .001 24.0100 .001 24.1100 .001 24.2100 .001 24.3100 .001 24.4100 .001 24.5100 .001 24.6100 .001 24.7100 .001 24.8100 .000 24.9100 .000 25.0100 .000 25.1100 .000 $25.210 \quad 0.000$ 25.3100 .000 25.4100 .000 25.5100 .000 25.6100 .000 25.7100 .000 25.8100 .000 25.9100 .000 26.0100 .000 26.1100 .000 26.2100 .000 26.3100 .000 26.4100 .000 26.5100 .000 26.6100 .000 26.7100 .000 
$26.810 \quad 0.000$

26.9100 .000

$27.010 \quad 0.000$

27.1100 .000

27.2100 .000

$27.310 \quad 0.000$

27.4100 .000

27.5100 .000

27.6100 .000

27.7100 .000

27.8100 .000

27.9100 .000

28.0100 .000

28.1100 .000

28.2100 .000

28.3100 .000

28.4100 .000

28.5100 .000

28.6100 .000

28.7100 .000

28.8100 .000

28.9100 .000

29.0100 .000

$29.110 \quad 0.000$

29.2100 .000

29.3100 .000

$29.410 \quad 0.000$

29.5100 .000

29.6100 .000

29.7100 .000

29.8100 .000

29.9100 .000

$30.010 \quad 0.000$

$30.110 \quad 0.000$
$30.210 \quad 0.000$

$30.310 \quad 0.000$

$30.410 \quad 0.000$

30.5100 .000

30.6100 .000

$30.710 \quad 0.000$

30.8100 .000

30.9100 .000

31.0100 .000

31.1100 .000

31.2100 .000

31.3100 .000

31.4100 .000

31.5100 .000

31.6100 .000

31.7100 .000

31.8100 .000

31.9100 .000

32.0100 .000

$32.110 \quad 0.000$

32.2100 .000

32.3100 .000

$32.410 \quad 0.000$

32.5100 .000

32.6100 .000

32.7100 .000

32.8100 .000

32.9100 .000

33.0100 .000

33.1100 .000

33.2100 .000

33.3100 .000

33.4100 .000

33.5100 .000
$33.610 \quad 0.000$

33.7100 .000

33.8100 .000

33.9100 .000

34.0100 .000

$34.110 \quad 0.000$

$34.210 \quad 0.000$

34.3100 .000

34.4100 .000

$34.510 \quad 0.000$

34.6100 .000

34.7100 .000

34.8100 .000

34.9100 .000

35.0100 .000

$35.110 \quad 0.000$

$35.210 \quad 0.000$

35.3100 .000

35.4100 .000

$35.510 \quad 0.000$

$35.610 \quad 0.000$

$35.710 \quad 0.000$

35.8100 .000

35.9100 .000

$36.010 \quad 0.000$

$36.110 \quad 0.000$

36.2100 .000

$36.310 \quad 0.000$

$36.410 \quad 0.000$

$36.510 \quad 0.000$

36.6100 .000

$36.710 \quad 0.000$

$36.810 \quad 0.000$

36.9100 .000
37.0100 .000

$37.110 \quad 0.000$

37.2100 .000

37.3100 .000

37.4100 .000

$37.510 \quad 0.000$

37.6100 .000

37.7100 .000

37.8100 .000

37.9100 .000

38.0100 .000

38.1100 .000

38.2100 .000

38.3100 .000

38.4100 .000

38.5100 .000

38.6100 .000

38.7100 .000

38.8100 .000

$38.910 \quad 0.000$

39.0100 .000

39.1100 .000

39.2100 .000

39.3100 .000

39.4100 .000

$39.510 \quad 0.000$

39.6100 .000

39.7100 .000

39.8100 .000

$39.910 \quad 0.000$

$40.010 \quad 0.000$

$40.110 \quad 0.000$

$40.210 \quad 0.000$

$40.310 \quad 0.000$ 


\section{B.3 Transição entre padrão estratificado liso e ondulado- Pares de} velocidades superficiais do escoamento gás-líquido ( $\left.U_{\mathrm{GS}}, \mathrm{U}_{\mathrm{LS}}\right) \mathrm{em} \mathrm{m} / \mathrm{s}$, na tubulação de $30 \mathrm{~mm}$ de diâmetro interno do NETeF:
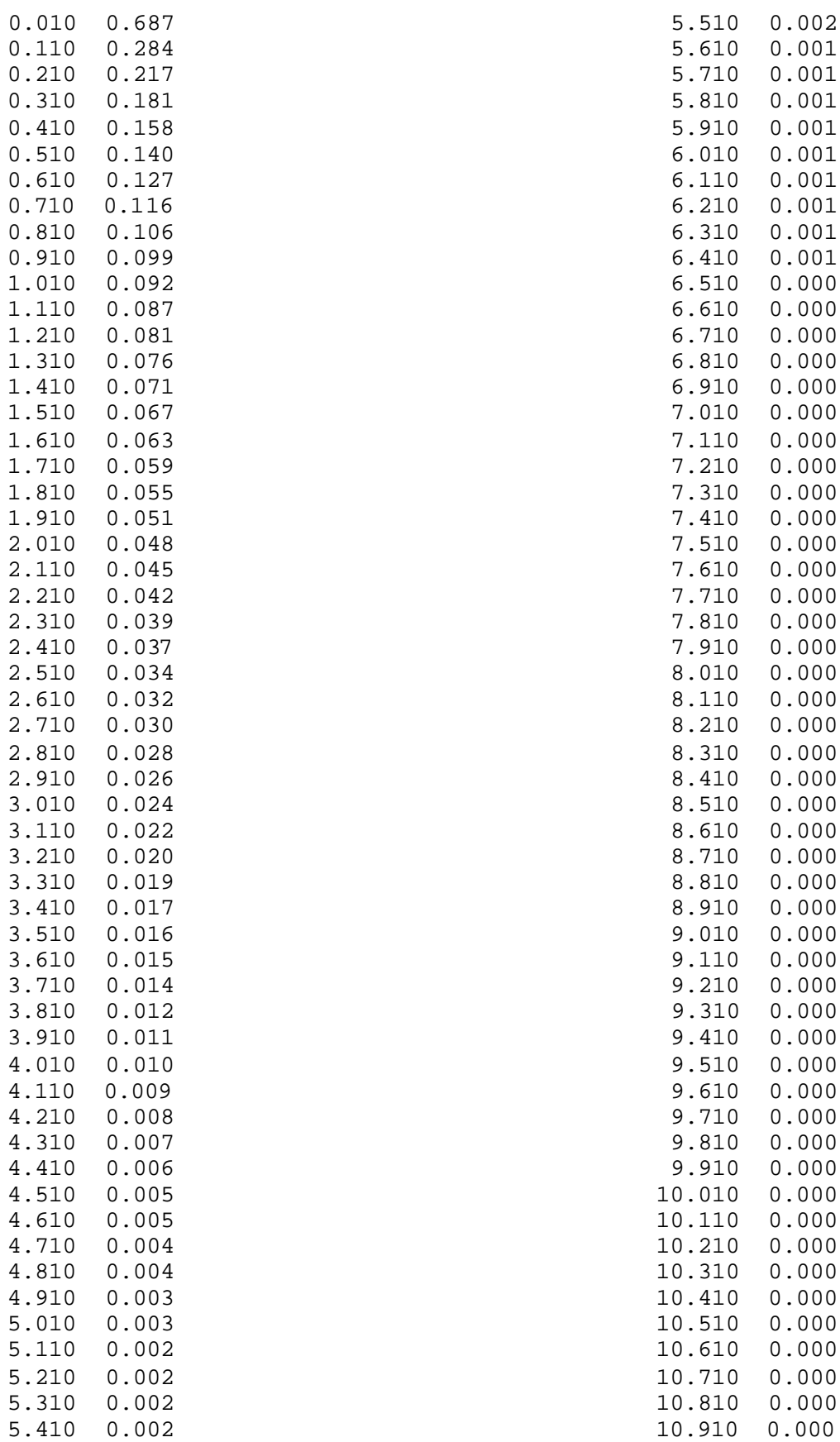


\section{B.4 Transição entre padrão intermitente e a bolhas - Pares de velocidades superficiais do escoamento gás-líquido ( $\left.U_{\mathrm{GS}}, \mathrm{U}_{\mathrm{LS}}\right) \mathrm{em} \mathrm{m} / \mathrm{s}$, na tubulação de}

\section{$30 \mathrm{~mm}$ de diâmetro interno do NETeF:}

$\begin{array}{ll}0.010 & 1.719 \\ 0.110 & 2.313 \\ 0.210 & 2.504 \\ 0.310 & 2.625 \\ 0.410 & 2.850 \\ 0.510 & 2.862 \\ 0.610 & 2.964 \\ 0.710 & 3.053 \\ 0.810 & 3.132 \\ 0.910 & 3.203 \\ 1.010 & 3.267 \\ 1.110 & 3.326 \\ 1.210 & 3.381 \\ 1.310 & 3.431 \\ 1.410 & 3.479 \\ 1.510 & 3.523 \\ 1.610 & 3.565 \\ 1.710 & 3.604 \\ 1.810 & 3.641 \\ 1.910 & 3.677 \\ 2.010 & 3.711 \\ 2.110 & 3.743 \\ 2.210 & 3.774 \\ 2.310 & 3.804 \\ 2.410 & 3.832 \\ 2.510 & 3.859 \\ 2.610 & 3.886 \\ 2.710 & 3.911 \\ 2.810 & 3.936 \\ 2.910 & 3.959 \\ 3.010 & 3.982 \\ 3.110 & 4.004 \\ 3.210 & 4.026 \\ 3.310 & 4.046 \\ 3.410 & 4.066 \\ 3.510 & 4.086 \\ 3.610 & 4.105 \\ 3.710 & 4.123 \\ 3.810 & 4.141 \\ 3.910 & 4.159 \\ 4.010 & 4.176 \\ 4.110 & 4.192 \\ 4.210 & 4.209 \\ 4.310 & 4.224 \\ 4.410 & 4.240 \\ 4.510 & 4.255 \\ 4.610 & 4.270 \\ 4.710 & 4.284 \\ 4.810 & 4.298 \\ 4.910 & 4.312 \\ 5.010 & 4.325 \\ 5.110 & 4.338 \\ 5.210 & 4.351 \\ 5.310 & 4.363 \\ 5.410 & 4.376 \\ 5.510 & 4.388 \\ 5.610 & 4.400 \\ 5.710 & 4.411 \\ 5.810 & 4.423 \\ 5.910 & 4.434 \\ 6.010 & 4.445 \\ 6.110 & 4.455 \\ 6.210 & 4.466 \\ 6.310 & 4.476 \\ 6.410 & 4.486\end{array}$

6.5104 .496

6.6104 .506

6.7104 .516

6.8104 .525

6.9104 .534

7.0104 .543

7.1104 .552

7.2104 .561

7.3104 .570

7.4104 .578

7.5104 .587

$7.610 \quad 4.595$

7.7104 .603

7.8104 .611

7.9104 .619

8.0104 .626

8.1104 .634

8.2104 .642

8.3104 .649

8.4104 .656

8.5104 .663

8.6104 .670

8.7104 .677

8.8104 .684

8.9104 .691

9.0104 .697

9.1104 .704

9.2104 .710

9.3104 .717

9.4104 .723

9.5104 .729

9.6104 .735

9.7104 .741

9.8104 .747

9.9104 .753

10.0104 .759

10.1104 .764

10.2104 .770

10.3104 .775

10.4104 .781

10.5104 .786

10.6104 .791

10.7104 .797

10.8104 .802

$10.910 \quad 4.807$

11.0104 .812

11.1104 .817

11.2104 .822

11.3104 .826

11.4104 .831

11.5104 .836

11.6104 .841

11.7104 .845

11.8104 .850

11.9104 .854

12.0104 .858

12.1104 .863

12.2104 .867

12.3104 .871

$12.410 \quad 4.875$

12.5104 .879

12.6104 .884

12.7104 .888

12.8104 .891

12.9104 .895
13.0104 .899

13.1104 .903

13.2104 .907

13.3104 .911

13.4104 .914

13.5104 .918

13.6104 .921

13.7104 .925

13.8104 .928

13.9104 .932

14.0104 .935

14.1104 .939

14.2104 .942

$14.310 \quad 4.945$

14.4104 .948

14.5104 .952

14.6104 .955

14.7104 .958

14.8104 .961

14.9104 .964

15.0104 .967

15.1104 .970

15.2104 .973

15.3104 .976

15.4104 .979

15.5104 .982

15.6104 .984

15.7104 .987

15.8104 .990

15.9104 .992

16.0104 .995

16.1104 .998

16.2105 .000

16.3105 .003

16.4105 .006

16.5105 .008

16.6105 .010

16.7105 .013

16.8105 .015

16.9105 .018

17.0105 .020

17.1105 .022

17.2105 .025

17.3105 .027

17.4105 .029

17.5105 .031

17.6105 .034

17.7105 .036

17.8105 .038

17.9105 .040

18.0105 .042

18.1105 .044

18.2105 .046

18.3105 .048

18.4105 .050

18.5105 .052

18.6105 .054

18.7105 .056

18.8105 .058

18.9105 .060

19.0105 .062

19.1105 .063

19.2105 .065

19.3105 .067

19.4105 .069
19.5105 .070

19.6105 .072

19.7105 .074

19.8105 .075

19.9105 .077

20.0105 .079

20.1105 .080

20.2105 .082

20.3105 .083

20.4105 .085

20.5105 .086

20.6105 .088

20.7105 .089

20.8105 .091

20.9105 .092

21.0105 .094

21.1105 .095

21.2105 .096

21.3105 .098

21.4105 .099

21.5105 .100

21.6105 .102

21.7105 .103

21.8105 .104

21.9105 .105

22.0105 .107

22.1105 .108

22.2105 .109

22.3105 .110

22.4105 .111

22.5105 .113

22.6105 .114

22.7105 .115

22.8105 .116

22.9105 .117

23.0105 .118

23.1105 .119

23.2105 .120

23.3105 .121

23.4105 .122

23.5105 .123

23.6105 .124

23.7105 .125

23.8105 .126

23.9105 .127

24.0105 .128

24.1105 .129

24.2105 .130

24.3105 .131

24.4105 .131

24.5105 .132

24.6105 .133

24.7105 .134

24.8105 .135

24.9105 .135

25.0105 .136

25.1105 .137

25.2105 .138

25.3105 .138

25.4105 .139

25.5105 .140

25.6105 .141

25.7105 .141

25.8105 .142

25.9105 .143
$26.010 \quad 5.143$

26.1105 .144 $26.210 \quad 5.144$ 26.3105 .145 26.4105 .146 26.5105 .146 26.6105 .147 26.7105 .147 26.8105 .148 26.9105 .148 27.0105 .149 27.1105 .149 27.2105 .150 27.3105 .150 27.4105 .151 27.5105 .151 27.6105 .152 27.7105 .152 27.8105 .153 27.9105 .153 28.0105 .154 28.1105 .154 28.2105 .154 28.3105 .155 28.4105 .155 28.5105 .155 28.6105 .156 28.7105 .156 28.8105 .156 28.9105 .157 29.0105 .157 29.1105 .157 29.2105 .158 29.3105 .158 29.4105 .158 29.5105 .158 29.6105 .159 29.7105 .159 29.8105 .159 29.9105 .159 30.0105 .160 30.1105 .160 30.2105 .160 30.3105 .160 30.4105 .160 30.5105 .161 30.6105 .161 30.7105 .161 30.8105 .161 30.9105 .161 31.0105 .161 31.1105 .161 31.2105 .162 31.3105 .162 31.4105 .162 31.5105 .162 31.6105 .162 31.7105 .162 31.8105 .162 31.9105 .162 32.0105 .162 32.1105 .162 32.2105 .162 32.3105 .162 32.4105 .162 
32.5105 .162

32.6105 .162

32.7105 .162

32.8105 .162

32.9105 .162

33.0105 .162

33.1105 .162

33.2105 .162

33.3105 .162

33.4105 .162

33.5105 .162

33.6105 .162

33.7105 .162

33.8105 .161

33.9105 .161

34.0105 .161

34.1105 .161

34.2105 .161

34.3105 .161

34.4105 .161

34.5105 .161

34.6105 .160

34.7105 .160

34.8105 .160

34.9105 .160

35.0105 .160

35.1105 .160

$35.210 \quad 5.159$

35.3105 .159

35.4105 .159

35.5105 .159

35.6105 .159

35.7105 .158

35.8105 .158

35.9105 .158

36.0105 .158

36.1105 .157

36.2105 .157

36.3105 .157

$36.410 \quad 5.157$

36.5105 .156

36.6105 .156

36.7105 .156

36.8105 .155

36.9105 .155

37.0105 .155

$37.110 \quad 5.155$

37.2105 .154

37.3105 .154

37.4105 .154

37.5105 .153

37.6105 .153

37.7105 .153

37.8105 .152

$37.910 \quad 5.152$

38.0105 .151

$38.110 \quad 5.151$

38.2105 .151

38.3105 .150

38.4105 .150

38.5105 .150

38.6105 .149

38.7105 .149

38.8105 .148

38.9105 .148

39.0105 .148

$39.110 \quad 5.147$

$39.210 \quad 5.147$

39.3105 .146

39.4105 .146

39.5105 .145

39.6105 .145

$39.710 \quad 5.145$

39.8105 .144

39.9105 .144

40.0105 .143
$40.110 \quad 5.143$

40.2105 .142

40.3105 .142

40.4105 .141

40.5105 .141

40.6105 .140

40.7105 .140

40.8105 .139

40.9105 .139

41.0105 .138

41.1105 .138

41.2105 .137

$41.310 \quad 5.137$

41.4105 .136

41.5105 .136

41.6105 .135

41.7105 .134

41.8105 .134

41.9105 .133

42.0105 .133

42.1105 .132

42.2105 .132

42.3105 .131

42.4105 .131

$42.510 \quad 5.130$

42.6105 .129

42.7105 .129

42.8105 .128

42.9105 .128

43.0105 .127

43.1105 .126

$43.210 \quad 5.126$

43.3105 .125

43.4105 .125

43.5105 .124

43.6105 .123

43.7105 .123

43.8105 .122

43.9105 .121

44.0105 .121

44.1105 .120

44.2105 .119

44.3105 .119

44.4105 .118

44.5105 .117

44.6105 .117

44.7105 .116

44.8105 .115

44.9105 .115

45.0105 .114

45.1105 .113

45.2105 .113

45.3105 .112

45.4105 .111

45.5105 .111

45.6105 .110

45.7105 .109

45.8105 .109

45.9105 .108

46.0105 .107

$46.110 \quad 5.106$

46.2105 .106

46.3105 .105

46.4105 .104

46.5105 .103

46.6105 .103

46.7105 .102

46.8105 .101

46.9105 .100

47.0105 .100

47.1105 .099

47.2105 .098

47.3105 .097

47.4105 .097

47.5105 .096

47.6105 .095
$47.710 \quad 5.094$

47.8105 .093

47.9105 .093

48.0105 .092

48.1105 .091

48.2105 .090

48.3105 .089

48.4105 .089

48.5105 .088

48.6105 .087

48.7105 .086

48.8105 .085

48.9105 .085

49.0105 .084

49.1105 .083

49.2105 .082

49.3105 .081

49.4105 .081

49.5105 .080

49.6105 .079

49.7105 .078

49.8105 .077

49.9105 .076

50.0105 .075

50.1105 .075

50.2105 .074

50.3105 .073

50.4105 .072

50.5105 .071

50.6105 .070

50.7105 .069

50.8105 .069

50.9105 .068

51.0105 .067

51.1105 .066

51.2105 .065

51.3105 .064

51.4105 .063

51.5105 .062

51.6105 .061

51.7105 .061

51.8105 .060

51.9105 .059

52.0105 .058

52.1105 .057

52.2105 .056

52.3105 .055

52.4105 .054

52.5105 .053

52.6105 .052

52.7105 .051

52.8105 .051

52.9105 .050

53.0105 .049

53.1105 .048

53.2105 .047

53.3105 .046

53.4105 .045

53.5105 .044

53.6105 .043

53.7105 .042

53.8105 .041

53.9105 .040

54.0105 .039

54.1105 .038

54.2105 .037

54.3105 .036

54.4105 .035

54.5105 .034

54.6105 .033

54.7105 .032

54.8105 .031

54.9105 .030

55.0105 .030

55.1105 .029

55.2105 .028

55.3105 .027

55.4105 .026

55.5105 .025

55.6105 .024

55.7105 .023

55.8105 .022

55.9105 .021

56.0105 .020

56.1105 .019

56.2105 .018

56.3105 .017

56.4105 .016

56.5105 .015

56.6105 .013

56.7105 .012

56.8105 .011

56.9105 .010

57.0105 .009

57.1105 .008

57.2105 .007

57.3105 .006

57.4105 .005

57.5105 .004

57.6105 .003

57.7105 .002

57.8105 .001

57.9105 .000

58.0104 .999

58.1104 .998

58.2104 .997

58.3104 .996

58.4104 .995

58.5104 .994

58.6104 .993

58.7104 .992

58.8104 .991

58.9104 .990

59.0104 .989

59.1104 .987

59.2104 .986

59.3104 .985

59.4104 .984

59.5104 .983

59.6104 .982

59.7104 .981

$59.810 \quad 4.980$

59.9104 .979

60.0104 .978

$60.110 \quad 4.977$

60.2104 .976

$60.310 \quad 4.974$

60.4104 .973

60.5104 .972

$60.610 \quad 4.971$

60.7104 .970

60.8104 .969

60.9104 .968

61.0104 .967

61.1104 .966

61.2104 .965

61.3104 .963

61.4104 .962

61.5104 .961 
70.5094 .855

70.6094 .854

70.7094 .852

70.8094 .851

70.9094 .850

71.0094 .849

71.1094 .847

71.2094 .846

71.3094 .845

71.4094 .844

71.5094 .842

71.6094 .841

71.7094 .840

71.8094 .839

71.9094 .837

72.0094 .836

72.1094 .835

72.2094 .833

72.3094 .832

72.4094 .831

72.5094 .830

72.6094 .828

72.7094 .827

72.8094 .826

72.9094 .825

73.0094 .823

73.1094 .822

73.2094 .821

73.3094 .820

73.4094 .818

73.5094 .817

73.6094 .816

73.7094 .814

73.8094 .813

73.9094 .812

74.0094 .811

74.1094 .809

74.2094 .808

74.3094 .807

74.4094 .806

74.5094 .804

74.6094 .803

74.7094 .802

74.8094 .800

74.9094 .799

75.0094 .798

75.1094 .796

75.2094 .795

75.3094 .794

75.4094 .793

75.5094 .791

75.6094 .790

75.7094 .789

75.8094 .787

75.9094 .786

76.0094 .785

76.1094 .783

76.2094 .782

76.3094 .781
76.4094 .780

76.5094 .778

76.6094 .777

76.7094 .776

76.8094 .774

76.9094 .773

77.0094 .772

77.1094 .770

77.2094 .769

77.3094 .768

77.4094 .766

77.5094 .765

77.6094 .764

77.7094 .763

77.8094 .761

77.9094 .760

78.0094 .759

78.1094 .757

78.2094 .756

78.3094 .755

78.4094 .753

78.5094 .752

78.6094 .751

78.7094 .749

78.8094 .748

78.9094 .747

79.0094 .745

79.1094 .744

79.2094 .743

79.3094 .741

79.4094 .740

79.5094 .739

79.6094 .737

79.7094 .736

79.8094 .735

79.9094 .733

80.0094 .732

80.1094 .731

80.2094 .729

80.3094 .728

80.4094 .727

80.5094 .725

80.6094 .724

80.7094 .723

80.8094 .721

80.9094 .720

81.0094 .719

81.1094 .717

81.2094 .716

81.3094 .715

81.4094 .713

81.5094 .712

81.6094 .711

81.7094 .709

81.8094 .708

81.9094 .707

82.0094 .705

82.1094 .704

82.2094 .703
82.3094 .701

82.4094 .700

82.5094 .698

82.6094 .697

82.7094 .696

82.8094 .694

82.9094 .693

83.0094 .692

83.1094 .690

83.2094 .689

83.3094 .688

83.4094 .686

83.5094 .685

83.6094 .684

83.7094 .682

83.8094 .681

83.9094 .679

84.0094 .678

84.1094 .677

84.2094 .675

84.3094 .674

84.4094 .673

84.5094 .671

84.6094 .670

84.7094 .669

84.8094 .667

84.9094 .666

85.0094 .664

85.1094 .663

85.2094 .662

85.3094 .660

85.4094 .659

85.5094 .658

85.6094 .656

85.7094 .655

85.8094 .653

85.9094 .652

86.0094 .651

86.1094 .649

86.2094 .648

86.3094 .647

86.4094 .645

86.5094 .644

86.6094 .642

86.7094 .641

86.8094 .640

86.9094 .638

87.0094 .637

87.1094 .636

87.2094 .634

87.3094 .633

87.4094 .631

87.5094 .630

87.6094 .629

87.7094 .627

87.8094 .626

87.9094 .625

88.0094 .623

88.1094 .622
88.2094 .620

88.3094 .619

88.4094 .618

88.5094 .616

88.6094 .615

88.7094 .613

88.8094 .612

88.9094 .611

89.0094 .609

89.1094 .608

89.2094 .606

89.3094 .605

89.4094 .604

89.5094 .602

89.6094 .601

89.7094 .599

89.8094 .598

89.9094 .597

90.0094 .595

90.1094 .594

90.2094 .593

90.3094 .591

90.4094 .590

90.5094 .588

90.6094 .587

90.7094 .586

90.8094 .584

90.9094 .583

91.0094 .581

91.1094 .580

91.2094 .579

91.3094 .577

91.4094 .576

91.5094 .574

91.6094 .573

91.7094 .572

91.8094 .570

91.9094 .569

92.0094 .567

92.1094 .566

92.2094 .564

92.3094 .563

92.4094 .562

92.5094 .560

92.6094 .559

92.7094 .557

92.8094 .556

92.9094 .555

93.0094 .553

93.1094 .552

93.2094 .550

93.3094 .549

93.4094 .548

93.5094 .546

93.6094 .545

93.7094 .543

93.8094 .542

93.9094 .540

94.0094 .539

94.1094 .538

94.2094 .536

94.3094 .535

94.4094 .533

94.5094 .532

94.6094 .531

94.7094 .529

94.8094 .528

94.9094 .526

95.0094 .525

95.1094 .523

95.2094 .522

95.3094 .521

95.4094 .519

95.5094 .518

95.6094 .516

95.7094 .515

95.8094 .514

95.9094 .512

96.0094 .511

96.1094 .509

96.2094 .508

96.3094 .506

96.4094 .505

96.5094 .504

96.6094 .502

96.7094 .501

96.8094 .499

96.9094 .498

97.0094 .496

97.1094 .495

97.2094 .494

97.3094 .492

97.4094 .491

97.5094 .489

97.6094 .488

97.7094 .486

97.8094 .485

97.9094 .484

98.0094 .482

98.1094 .481

98.2094 .479

98.3094 .478

98.4094 .476

98.5094 .475

98.6094 .474

98.7094 .472

98.8094 .471

98.9094 .469

99.0094 .468

99.1094 .466

99.2094 .465

99.3094 .464 